University of Nebraska - Lincoln

DigitalCommons@University of Nebraska - Lincoln

USGS Staff -- Published Research

US Geological Survey

2013

\title{
Crimean-Congo hemorrhagic fever: History, epidemiology, pathogenesis, clinical syndrome and genetic diversity
}

Dennis A. Bente

University of Texas Medical Branch, dabente@utmb.edu

Naomi L. Forrester

University of Texas Medical Branch

Douglas M. Watts

University of Texas at El Paso

Alexander J. McAuley

University of Texas Medical Branch

Chris A. Whitehouse

US Geological Survey

See next page for additional authors

Follow this and additional works at: http://digitalcommons.unl.edu/usgsstaffpub

Bente, Dennis A.; Forrester, Naomi L.; Watts, Douglas M.; McAuley, Alexander J.; Whitehouse, Chris A.; and Bray, Mike, "CrimeanCongo hemorrhagic fever: History, epidemiology, pathogenesis, clinical syndrome and genetic diversity" (2013). USGS Staff-Published Research. 761.

http:// digitalcommons.unl.edu/usgsstaffpub/761

This Article is brought to you for free and open access by the US Geological Survey at DigitalCommons@University of Nebraska - Lincoln. It has been accepted for inclusion in USGS Staff -- Published Research by an authorized administrator of DigitalCommons@University of Nebraska - Lincoln. 
Authors

Dennis A. Bente, Naomi L. Forrester, Douglas M. Watts, Alexander J. McAuley, Chris A. Whitehouse, and Mike Bray 
Review

\title{
Crimean-Congo hemorrhagic fever: History, epidemiology, pathogenesis, clinical syndrome and genetic diversity
}

\author{
Dennis A. Bente ${ }^{\mathrm{a}, *}$, Naomi L. Forrester ${ }^{\mathrm{b}}$, Douglas M. Watts ${ }^{\mathrm{c}}$, Alexander J. McAuley ${ }^{\mathrm{a}}$, Chris A. Whitehouse ${ }^{\mathrm{d}}$, \\ Mike Bray ${ }^{\mathrm{e}}$ \\ a Department of Microbiology and Immunology, University of Texas Medical Branch, Galveston, TX 77555, United States \\ ${ }^{\mathrm{b}}$ Department of Pathology, University of Texas Medical Branch, Galveston, TX 77555-0610, United States \\ ${ }^{c}$ Department of Veterinary Services, University of Texas at El Paso, El Paso, TX 79968, United States \\ ${ }^{\mathrm{d}}$ National Wildlife Health Center, U.S. Geological Survey, Madison, WI 53711, United States

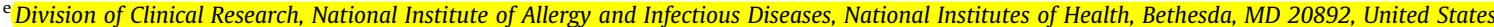

\section{A R T I C L E I N F O}

Article history:

Received 15 May 2013

Revised 5 July 2013

Accepted 9 July 2013

Available online 29 July 2013

\section{Keywords:}

Crimean-Congo hemorrhagic fever virus

Tick-borne virus

Arbovirus

Nairovirus

Bunyavirus

Viral hemorrhagic fever

\begin{abstract}
A B S T R A C T
Crimean-Congo hemorrhagic fever (CCHF) is the most important tick-borne viral disease of humans, causing sporadic cases or outbreaks of severe illness across a huge geographic area, from western China to the Middle East and southeastern Europe and throughout most of Africa. CCHFV is maintained in vertical and horizontal transmission cycles involving ixodid ticks and a variety of wild and domestic vertebrates, which do not show signs of illness. The virus circulates in a number of tick genera, but Hyalomma ticks are the principal source of human infection, probably because both immature and adult forms actively seek hosts for the blood meals required at each stage of maturation. CCHF occurs most frequently among agricultural workers following the bite of an infected tick, and to a lesser extent among slaughterhouse workers exposed to the blood and tissues of infected livestock and medical personnel through contact with the body fluids of infected patients. CCHFV is the most genetically diverse of the arboviruses, with nucleotide sequence differences among isolates ranging from $20 \%$ for the viral S segment to $31 \%$ for the $\mathrm{M}$ segment. Viruses with diverse sequences can be found within the same geographic area, while closely related viruses have been isolated in far distant regions, suggesting that widespread dispersion of CCHFV has occurred at times in the past, possibly by ticks carried on migratory birds or through the international livestock trade. Reassortment among genome segments during co-infection of ticks or vertebrates appears to have played an important role in generating diversity, and represents a potential future source of novel viruses. In this article, we first review current knowledge of CCHFV, summarizing its molecular biology, maintenance and transmission, epidemiology and geographic range. We also include an extensive discussion of CCHFV genetic diversity, including maps of the range of the virus with superimposed phylogenetic trees. We then review the features of CCHF, including the clinical syndrome, diagnosis, treatment, pathogenesis, vaccine development and laboratory animal models of CCHF. The paper ends with a discussion of the possible future geographic range of the virus. For the benefit of researchers, we include a Supplementary Table listing all published reports of CCHF cases and outbreaks in the English-language literature, plus some principal articles in other languages, with total case numbers, case fatality rates and all CCHFV strains on GenBank.
\end{abstract}

(c) 2013 Elsevier B.V. All rights reserved.

\section{Contents}

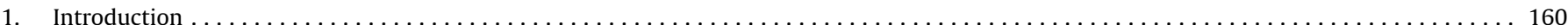

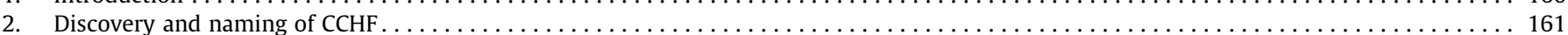

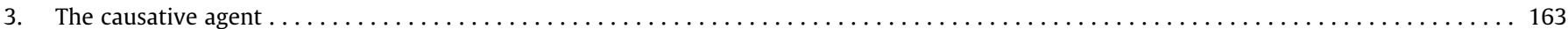

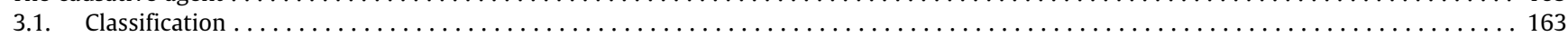

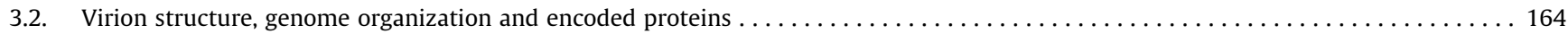

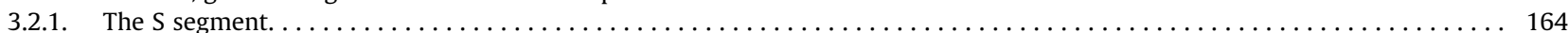

\footnotetext{
* Corresponding author. Tel.: +1 409266 6935; fax: +1 4092666810.

E-mail address: dabente@utmb.edu (D.A. Bente).
} 


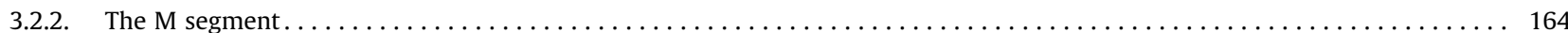

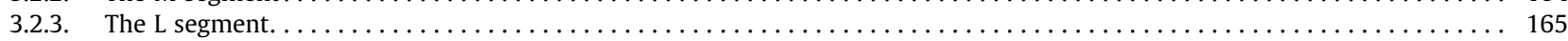

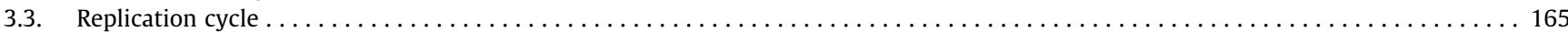

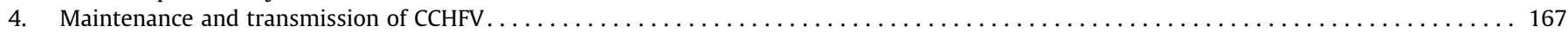

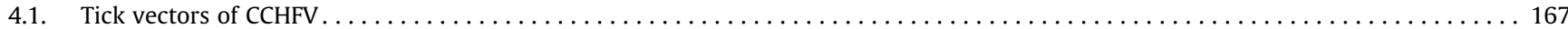

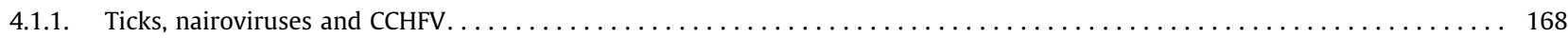

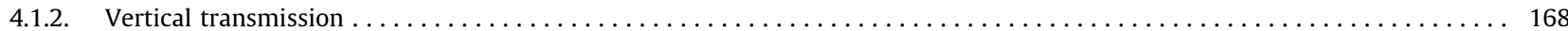

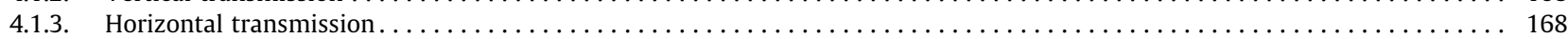

4.1.4. Competent tick vectors and their geographic distribution. $\ldots \ldots \ldots \ldots \ldots$

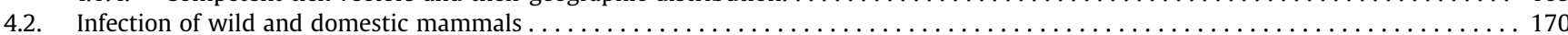

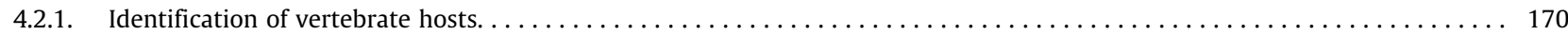

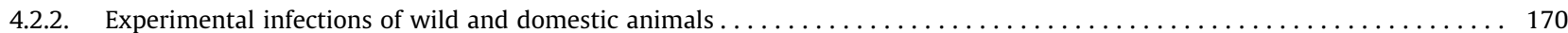

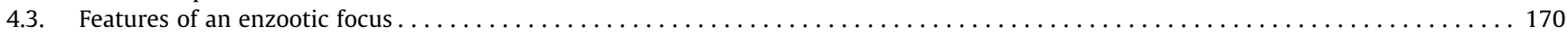

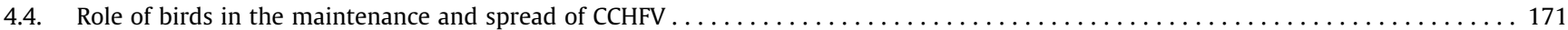

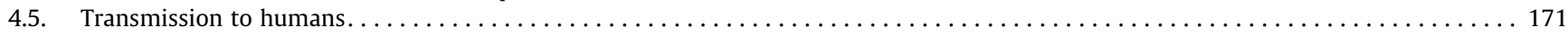

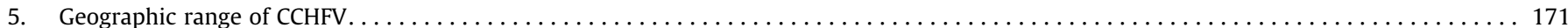

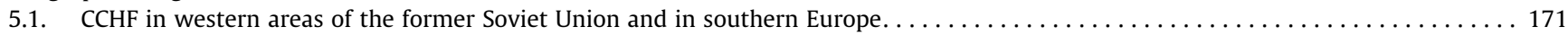

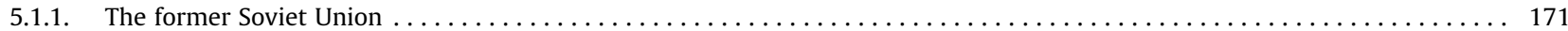

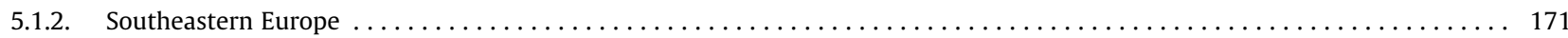

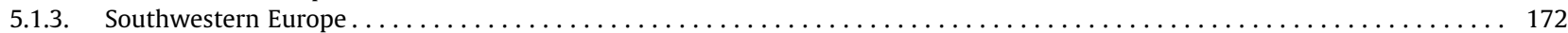

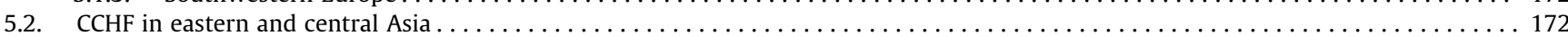

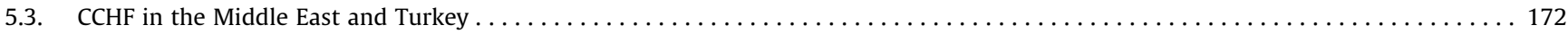

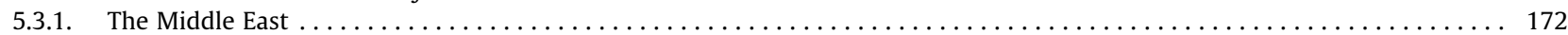

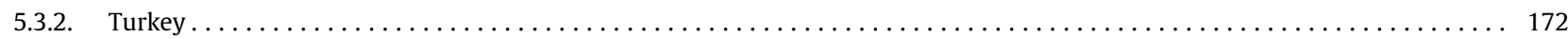

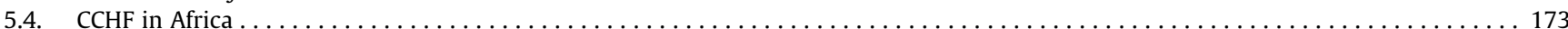

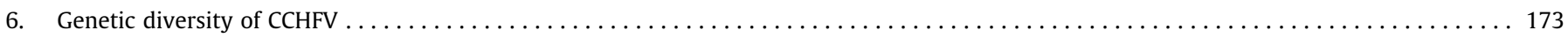

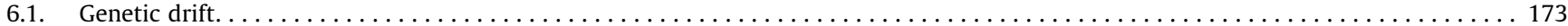

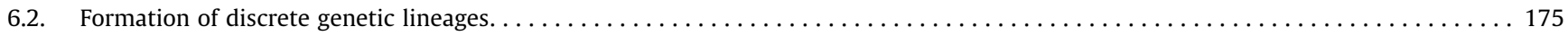

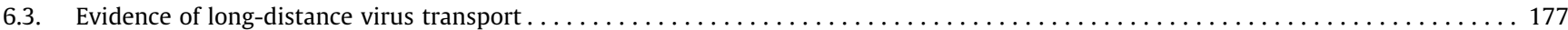

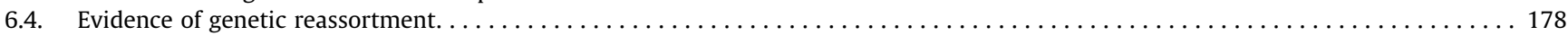

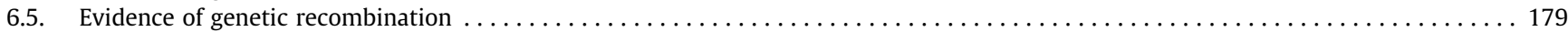

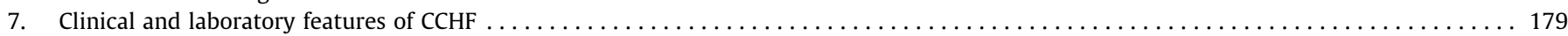

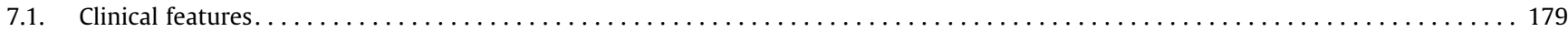

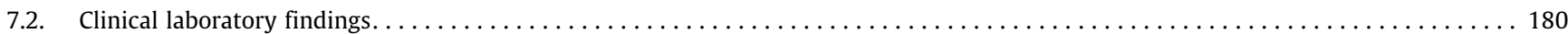

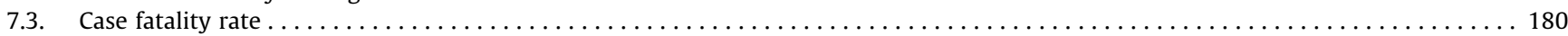

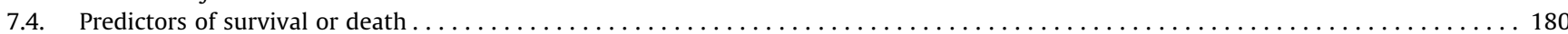

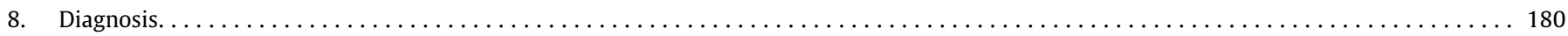

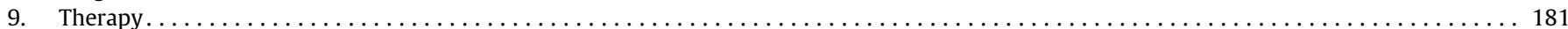

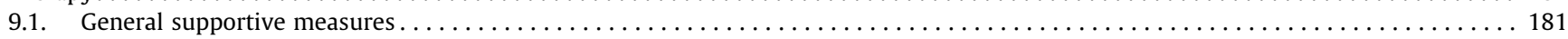

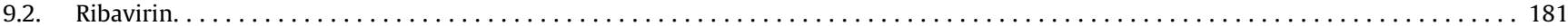

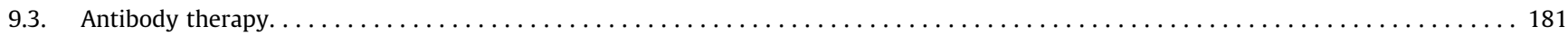

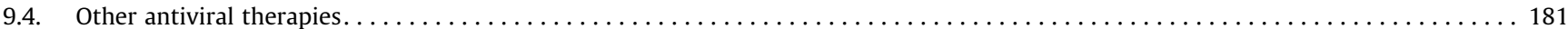

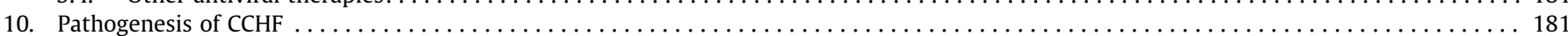

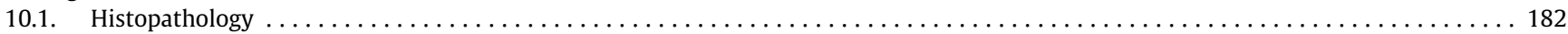

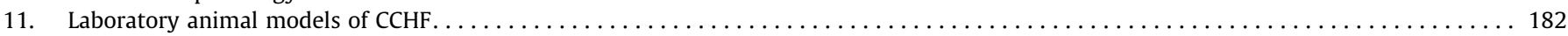

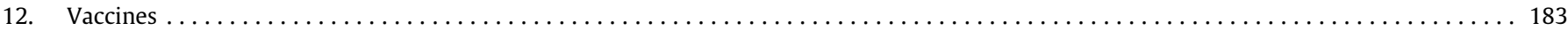

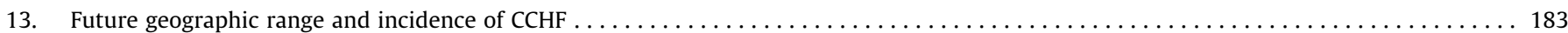

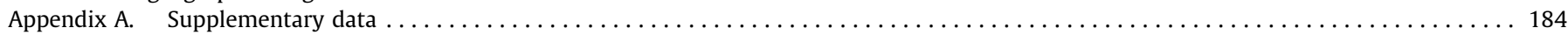

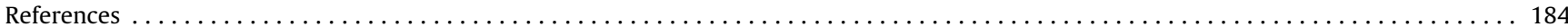

\section{Introduction}

Crimean-Congo hemorrhagic fever (CCHF) is the most widespread tick-borne viral infection of humans, occurring across a vast area from western China through southern Asia and the Middle East to southeastern Europe and throughout most of Africa. The causative agent, CCHF virus, is maintained through vertical and horizontal transmission in several genera of ixodid (hard) ticks, which spread the virus to a variety of wild and domestic mammals, which develop a transient viremia without signs of illness. Human infections occur through tick bite or exposure to the blood or other body fluids of an infected animal or of a CCHF patient. Ticks of the genus Hyalomma are the principal source of human infection, probably because both the immature and the adult forms actively seek hosts for their obligate blood meals. As Hoogstraal noted in his definitive review (1979): "[CCHFV] is remarkable among arboviruses infecting humans for the number and variety of reservoir- vector species linked with it and the numerous ecological environments in which it circulates."

CCHF was first recognized as a discrete human illness in the Crimean region of the former Soviet Union in 1944, and over subsequent decades was reported principally in a number of southern Soviet republics, Bulgaria and South Africa (Figs. 1 and 2).

Since 2000, however, the incidence and geographic range of confirmed CCHF cases have markedly increased, with the disease being reported for the first time in Turkey, Iran, India, Greece, the Republic of Georgia, and some Balkan countries, and the detection of viral RNA in Hyalomma ticks recovered from deer in Spain (see below). Remarkably, even though the first cases of CCHF in Turkey were identified in 2002, more than 6300 cases have been diagnosed in the ensuing 10 years. A large increase has also occurred in Iran since the first human infection was recognized in 1999 (Chinikar et al., 2010). 


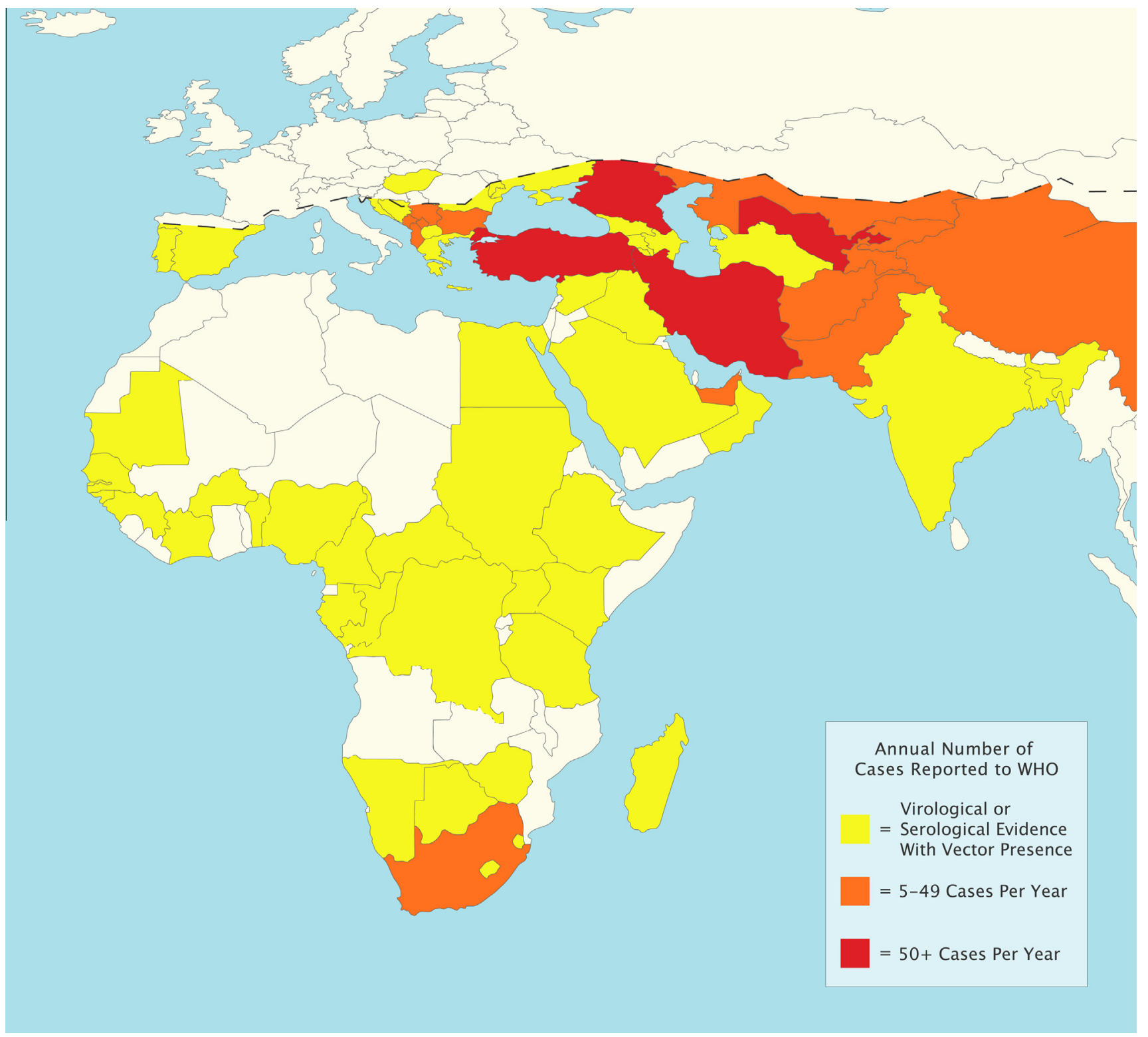

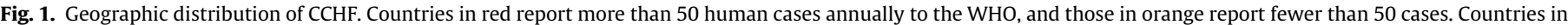

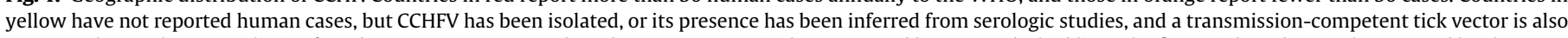

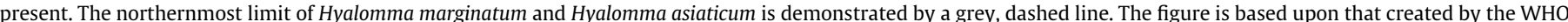

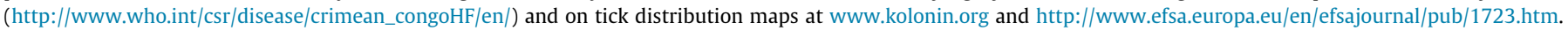

CCHF shows a spectrum of severity, from a mild, nonspecific febrile syndrome through vascular leak, multi-organ failure, shock and hemorrhage (Fig. 3). Probably because clinicians are most likely to publish descriptions of patients with severe or fatal illness, the fatality rate in case reports has ranged from $20 \%$ to $30 \%$ or higher (Tables 1-4 and Supplementary Table 1). In contrast, for large case series the case fatality rate is generally lower, probably because they also include patients with milder disease; for the more than 6000 cases reported from Turkey, it has been $5 \%$ (Table 3, Supplementary Table 1).

Increasing scientific and clinical interest in CCHF has led to the recovery and sequencing of numerous virus isolates across its geographic range, which have revealed a degree of sequence diversity greater than that of any other arthropod-borne virus. As discussed below, this marked genetic diversity suggests a lengthy history of geographic dispersion of the virus in its tick vector, while the identification of CCHF viruses with diverse sequences within the same geographic area, and of similar viruses at widely distant locations, are consistent with the transport of virus by infected ticks on migratory birds or through the international livestock trade (Mild et al., 2010). Phylogenetic analysis has also revealed evidence of genome reassortment and recombination during co-infection of a single host, indicating the potential for the future emergence of novel variants (Chamberlain et al., 2005; Hewson et al., 2004b).

\section{Discovery and naming of $\mathrm{CCHF}$}

Although some accounts of CCHF describe it as a disease that has only recently "emerged," the wide distribution of the virus in ticks and vertebrates across southern Asia, southeastern Europe and Africa suggests that human infections have occurred for millennia. A severe hemorrhagic illness attributed to the bite of a tick or louse was described in Tadjikistan in the 12th century, and 


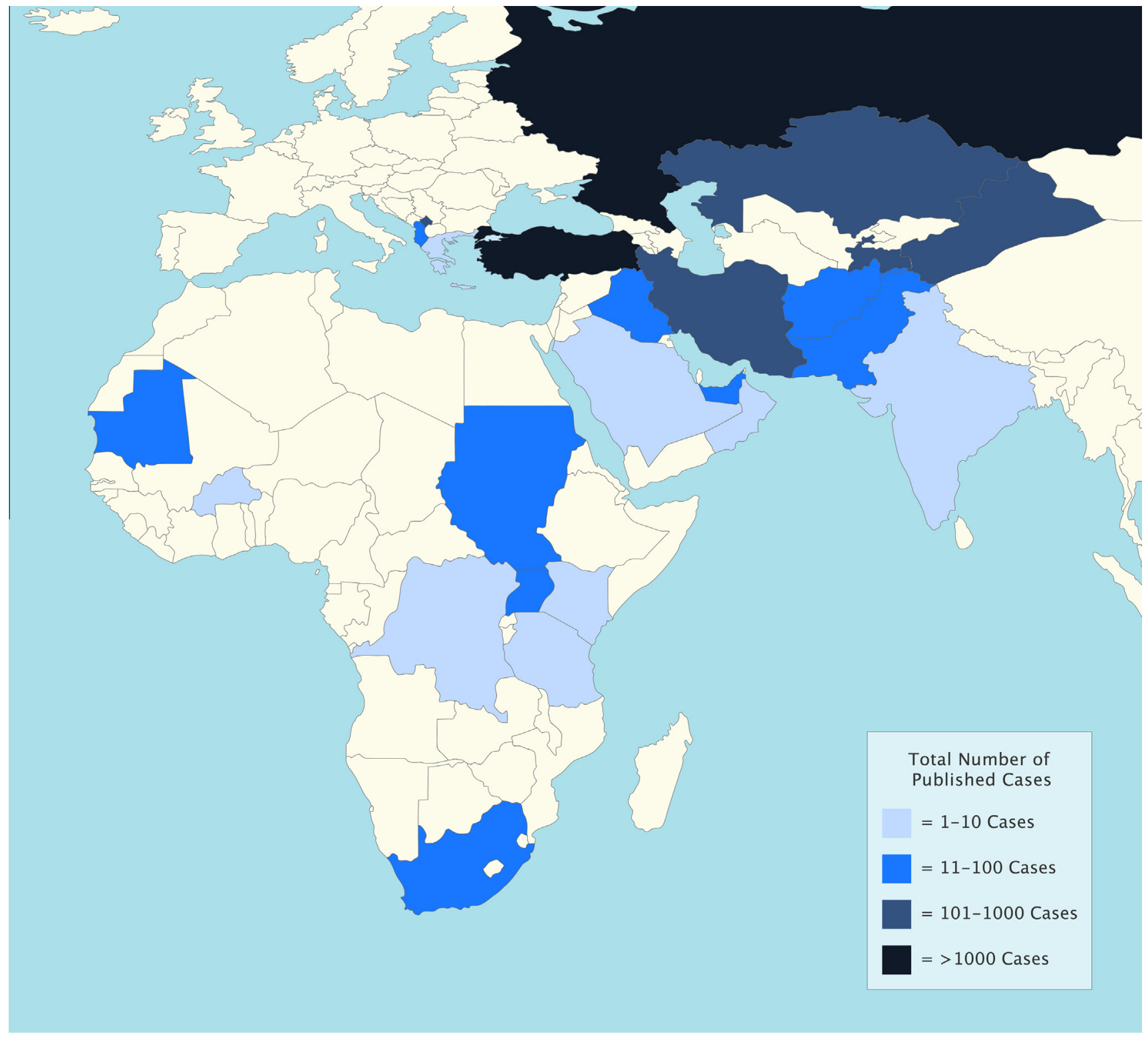

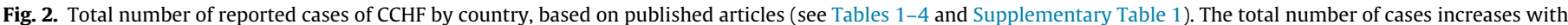

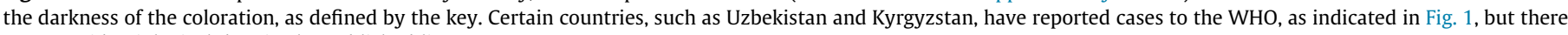
are no epidemiological data in the published literature.

similar diseases were known in other parts of Central Asia (Hoogstraal, 1979). Recognition of CCHF as a discrete human illness by modern clinicians may have been delayed because cases tend to occur singly and sporadically in rural areas, and many patients develop a mild, nonspecific illness, without a recognizable hemorrhagic fever syndrome.

The first recognized outbreak of CCHF took place in the summer of 1944 , when Soviet troops re-occupying areas of the Crimean peninsula that had been under German occupation developed an acute febrile illness with a high incidence of bleeding and shock (Grashchenkov, 1945; Chumakov 1965, 1974; Hoogstraal, 1979). Some 200 military personnel were hospitalized, and about 10\% died. An investigative team was dispatched from Moscow, led by Mikhail Chumakov, who in collaboration with Lev Zilber had isolated the causative agent of tick-borne encephalitis in the far eastern Soviet Union in the late 1930s. The researchers were quickly able to link cases of the new disease to tick exposure. They noted that, because large areas of cultivated land had been abandoned during the German occupation, the population of hares and other wild hosts of Hyalomma ticks had increased, and soldiers and farm workers engaged in restoring agricultural production were suffering large numbers of tick bites. Chumakov and his colleagues soon succeeded in proving that "Crimean hemorrhagic fever" (CHF) was a tick-borne viral infection by inoculating psychiatric patients and military volunteers with ultrafiltrates of patient serum or extracts of pooled ticks (Chumakov, 1965, 1974). Although they initially claimed to have reproduced the disease in a variety of experimental animals, their subsequent reports attributed those results to microbial contamination.

For more than two decades after the identification of CHF, laboratory research was limited by the inability to culture its causative agent. However, studies by Work, Casals and others during the early 1960s had shown that a number of arboviruses could be propagated by intracerebral inoculation in newborn mice, and a critical breakthrough in CHF research came in 1967, when Chumakov's group discovered that newborn mice developed a 

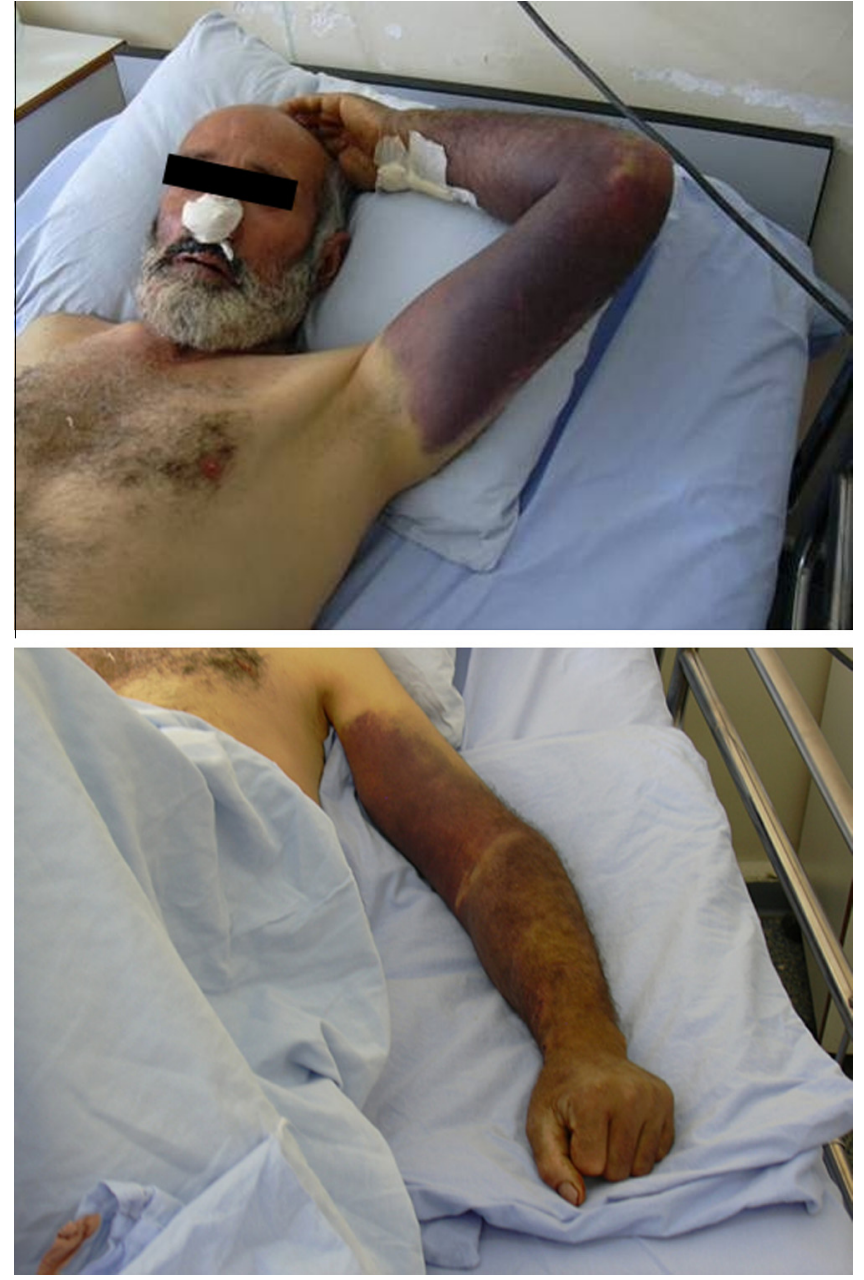

Fig. 3. Clinical presentation of Crimean-Congo hemorrhagic fever. Severely ill patients often develop a striking pattern of large ecchymoses, not seen in other types of viral hemorrhagic fever. (Courtesy of Dr. Hürrem Bodur, Ankara, Turkey.)

lethal illness when injected with samples from CCHF patients or infected ticks (Chumakov et al., 1968). The use of suckling mice to cultivate virus, titrate samples and produce antigens for immunologic assays led to a rapid increase in research on the circulation of CHFV in nature and to test human and animal sera for the presence of virus-specific antibodies. Inoculation of newborn mice continues to play an important role as a sensitive detection method for arboviruses.

By the late 1960s, Soviet researchers had selected the Drozdov isolate of CHFV, recovered from a patient in Astrakhan, as a standard reference strain (Butenko et al., 1968; Chumakov, 1974). Using the suckling mouse method and immunologic assays, they were able to show that a variety of febrile diseases found in widely separate foci in the Soviet Union and in Bulgaria were caused by strains of CHFV (Chumakov et al., 1970). The known geographic range of the disease was further widened in 1969, when Casals discovered that the Drozdov virus, provided to him by Chumakov, was identical to an agent that had been isolated in the Belgian Congo (present Democratic Republic of the Congo, DRC) in 1956 and designated "Congo virus" (Casals, 1969). Since its identification in the DRC, Congo virus had been recovered from animals and ticks in Nigeria and Uganda, and it appeared to be widespread in Africa (see below). Casals et al. (1970) proposed that all of these agents be given the single name "CHF-Congo virus", which was eventually simplified to CCHFV.

In contrast to the Drozdov strain, which was recovered from a patient, the virus used as a reference strain by western scientists, IbAr 10200, was isolated from a tick collected from an apparently healthy camel in Nigeria in 1966 (Causey et al., 1970). At that time, human infections had not been reported in the region, but this may simply have reflected a limited surveillance capacity and the sporadic nature of tick-borne diseases, as there is no evidence that African strains of CCHFV are less virulent than those in other regions. Amplified through sequential passage in suckling mice, the IbAr 10200 virus was transferred to the Yale arbovirus collection and other laboratories, and has been the only strain of CCHFV available to most investigators for the past few decades.

The introduction of the technique of virus culture in newborn mice in the late 1960s led to an explosion of research on CCHF, so that by the end of the following decade Hoogstrall was able to cite more than 500 articles in his definitive review (Hoogstraal, 1979). Many of these publications, including a large number of translations from the Russian and Bulgarian literature, are available from the web site of the US Armed Forces Pest Management Board at http://www.afpmb.org/content/literature-retrievalsystem.

\section{The causative agent}

\subsection{Classification}

CCHFV is a member of the genus Nairovirus in the family Bunyaviridae, which also includes the genera Orthobunyavirus, Hantavirus, Phlebovirus and Tospovirus. The nairoviruses are tick-borne viruses, which are distinguished from other bunyaviruses by their large L segments (see below). They are divided into seven serogroups; CCHFV and Hazara virus (HAZV) make up the CCHF serogroup. HAZV was isolated from ticks recovered from wild rodents in Pakistan (Begum et al., 1970; Dowall et al., 2012a). It has not been known to cause disease in humans.

\subsection{Virion structure, genome organization and encoded proteins}

The CCHF virion is spherical and approximately $80-100 \mathrm{~nm}$ in diameter (Fig. 4). Its lipid envelope is studded with spikes consisting of the glycoproteins $G_{N}$ and $G_{C}$, which are responsible for virion

Table 1

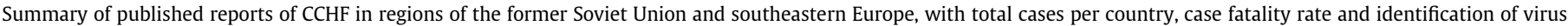
clade (when available). Data on total cases and case fatality rates were obtained from the articles cited. See Supplementary Table 1 for more detailed information.

\begin{tabular}{|c|c|c|c|c|c|}
\hline Years & Country/region & Total cases & Case fatality rate & Clade & Reference \\
\hline 1944 & Crimea & 161 & 11 & & Hoogstraal (1979) \\
\hline 1953-1963 & Astrakhan & 104 & 17 & Europe-V & Hoogstraal (1979) \\
\hline 1953-1968 & Stavropol & 25 & 44 & Europe-V & Hoogstraal (1979) \\
\hline 1963-1969 & Rostov & 323 & 15 & & Hoogstraal (1979) \\
\hline 1953-2009 & Bulgaria & 2431 & 17 & Europe-V & Hoogstraal (1979), Papa et al. (2004), ECDC (2008), Christova et al. (2009) and Ergonul (2010) \\
\hline $1995-2010$ & Kosovo & 216 & 19 & Europe-V & EpiSouth and WHO (2008), EpiSouth (2012) and WHO SEARO (2011) \\
\hline 1999-2008 & Russia & $>1150$ & 3.2 & Europe-V & Yashina et al. (2003a, 2003b), EpiSouth and WHO (2008), and Leblebicioglu, 2010 \\
\hline 2001-2006 & Albania & 32 & 3 & Europe-V & Papa et al. (2002a), EpiSouth and WHO (2008) \\
\hline 2008 & Greece & 1 & 100 & Europe-V & Papa et al. (2008) \\
\hline
\end{tabular}


Table 2

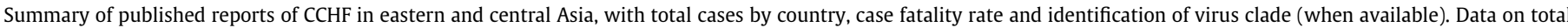
cases and case fatality rates were obtained from the articles cited. See Supplementary Table 1 for more detailed information.

\begin{tabular}{|c|c|c|c|c|c|}
\hline Years & Country/region & Cases & Case fatality rate & Clade & References \\
\hline 1965-1997 & China & 286 & 21 & Asia-2 IV; M1; M2; M3 & (Papa et al. (2002c) \\
\hline $1948-2000$ & Khazakhstan & 108 & 35 & & Hoogstraal (1979) and Yashina et al. (2003) \\
\hline $1943-2010$ & Tajikistan & 237 & 16 & Asia-2 IV; M2 & Hoogstraal (1979), Seregin et al. (2004) and Ergonul (2010) \\
\hline $1976-2000$ & Pakistan & 23 & 39 & Asia-1 IV; M1; M2; Asia-IV & Burney et al. (1980) and Smego et al. (2004) \\
\hline 2011 & India & 6 & 83 & Asia-2 IV; M2; Asia-IV & Yadav et al. (2013) \\
\hline
\end{tabular}

Table 3

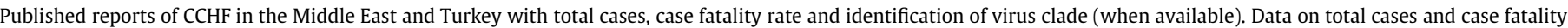
rates were obtained from the articles cited. See Supplementary Table 1 for more detailed information.

\begin{tabular}{|c|c|c|c|c|c|}
\hline Years & Country/region & Cases & $\begin{array}{l}\text { Case fatality } \\
\text { rate }\end{array}$ & Clade & References \\
\hline 1979-1995 & United Arab Emirates & 18 & 61 & Asia-2 IV & $\begin{array}{l}\text { Suleiman et al. (1980), Schwarz et al. (1997) } \\
\text { and Watts et al. (1989) }\end{array}$ \\
\hline 1990 & Saudi Arabia & 7 & 0 & & El-Azazy and Scrimgeour (1997) \\
\hline 1995-1997 & Oman & 4 & & Asia-1 IV; M1; Asia-IV & Saluzzo et al. (1985) \\
\hline $1979-1980$ & Iraq & 55 & 64 & Asia-1 IV; M2; Asia-IV & Al-Tikriti et al. (1981), Tantawi et al. (1980) \\
\hline $2000-2008$ & Iran & 534 & 15 & Asia-1 IV; Africa-3; Europe-1 V. & Chinikar et al. (2010) \\
\hline $2008-2012$ & Afghanistan & 51 & 47 & Asia-1 IV; M2; Asia-IV & $\begin{array}{l}\text { Mustafa et al. (2009), Mofleh and Ahmad (2012), } \\
\text { Olschlager et al. (2011) and Atkinson et al. (2012a, 2012b) }\end{array}$ \\
\hline 2002-2009 & Turkey & 4431 & 5 & Europe-V & Maltezou et al. (2009) \\
\hline
\end{tabular}

Table 4

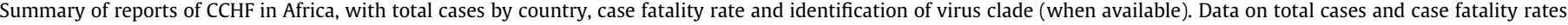
were obtained from the articles cited. See Supplementary Table 1 for more detailed information.

\begin{tabular}{|c|c|c|c|c|c|}
\hline Years & Country/region & Cases & Case fatality rate & Clade & References \\
\hline 1956 & Zaire (DRC) & 2 & 0 & Central Africa-II & Hoogstraal (1979) \\
\hline 1958-1977 & Uganda & 12 & 8 & Central Africa-II & Hoogstraal (1979) \\
\hline 1983-2004 & Mauritania & 39 & 28 & & $\begin{array}{l}\text { Watts et al. (1989), Saluzzo et al. (1985) } \\
\text { and Nabeth et al. (2004a, 2004b) }\end{array}$ \\
\hline 1983 & Burkina Faso & 1 & 0 & & Watts et al. (1989) \\
\hline 1981-1986 & South Africa & 32 & 31 & S Africa/W Africa-III; M1; M2 & Watts et al. (1989) \\
\hline 1986 & Tanzania & 1 & 0 & & Watts et al. (1989) \\
\hline 2000 & Kenya & 1 & 100 & & Dunster et al. (2002) \\
\hline $2008-2010$ & Sudan & 12 & 75 & S Africa/W Africa-III; M2 & Aradaib et al. (2011) and Elata et al. (2011) \\
\hline
\end{tabular}

binding to cellular receptors (Fig. 5). Neutralizing antibodies to $\mathrm{G}_{\mathrm{N}}$ and $\mathrm{G}_{\mathrm{C}}$ are produced during the course of infection. Virions contain the negative-sense small $(\mathrm{S})$, medium $(\mathrm{M})$ and large $(\mathrm{L})$ genome segments, encapsidated by the nucleoprotein (NP), plus the RNAdependent RNA polymerase (RdRp), to initiate transcription and genome replication in the host cell. The terminal complementary sequences 5'-UCUCAAAGA and 3'-AGAGUUUCU are conserved in all nairoviruses (Clerex-Van Haaster et al., 1982) (Morikawa et al., 2007). Intra-strand base-pairing between the terminal nucleotides leads to the formation of stable panhandle structures and non-covalently closed circular RNA molecules. By inference from other bunyaviruses, terminal base-pairing provides the functional promoter regions for interaction with the viral RdRp (Marriott and Nuttall, 1996).

\subsubsection{The S segment}

The $\mathrm{S}$ segment encodes the NP, which is made up of a large globular domain, to which $\mathrm{N}$ - and C-terminal portions of the polypeptide contribute, plus a protruding "arm" containing a conserved caspase-3 cleavage site (Karlberg et al., 2011; Carter et al., 2012). The globular region is responsible for RNA binding. Encapsidation of virion RNA involves the oligomerization of NP, brought about by head-to-tail interactions of the protein to form a helical structure (Wang et al., 2012).
The role of the caspase- 3 cleavage site in virus replication is not known. NP is cleaved in apoptotic cells late in infection (Karlberg et al., 2011); cleavage may play a regulatory role, as its inhibition enhanced RNA polymerase activity (Wang et al., 2012). Unexpectedly, structural alignment of the CCHFV NP with the NPs of other RNA viruses showed that it is most closely related to the arenavirus, Lassa virus. Bacterially-expressed NP can be used in an ELISA to detect virus-specific IgG (Samudzi et al., 2012).

\subsubsection{The $M$ segment}

The $M$ segment encodes a single polyprotein, from which two type I transmembrane glycoproteins, $G_{N}$ and $G_{C}$, are produced through cotranslational cleavage and extensive post-translational processing, beginning in the endoplasmic reticulum (ER) and concluding in the Golgi body (Figs. 5 and 6) (Altamura et al., 2007; Bertolotti-Ciarlet et al., 2005). The polyprotein is first cleaved by a host signal peptidase into $140 \mathrm{kDa}^{\mathrm{PreG}} \mathrm{N}_{\mathrm{N}}$ and $85 \mathrm{kDa} \mathrm{PreG}_{\mathrm{C}}$ segments. PreG $_{N}$ is then further cleaved at a number of conserved recognition sites by the host proteases SKI-1 and furin, generating the $58 \mathrm{kDa}$ $\mathrm{G}_{\mathrm{N}}$ and liberating several small protein fragments, including a nonstructural NSm protein, similar to that which has been identified in other bunyaviruses (Sanchez et al., 2006; Altamura et al., 2007). In cells that lack SKI-1, PreG ${ }_{N}$ and PreG $_{C}$ accumulate in the Golgi apparatus, and infected cells secrete virus particles lacking surface glycoproteins (Bergeron et al., 2007). 


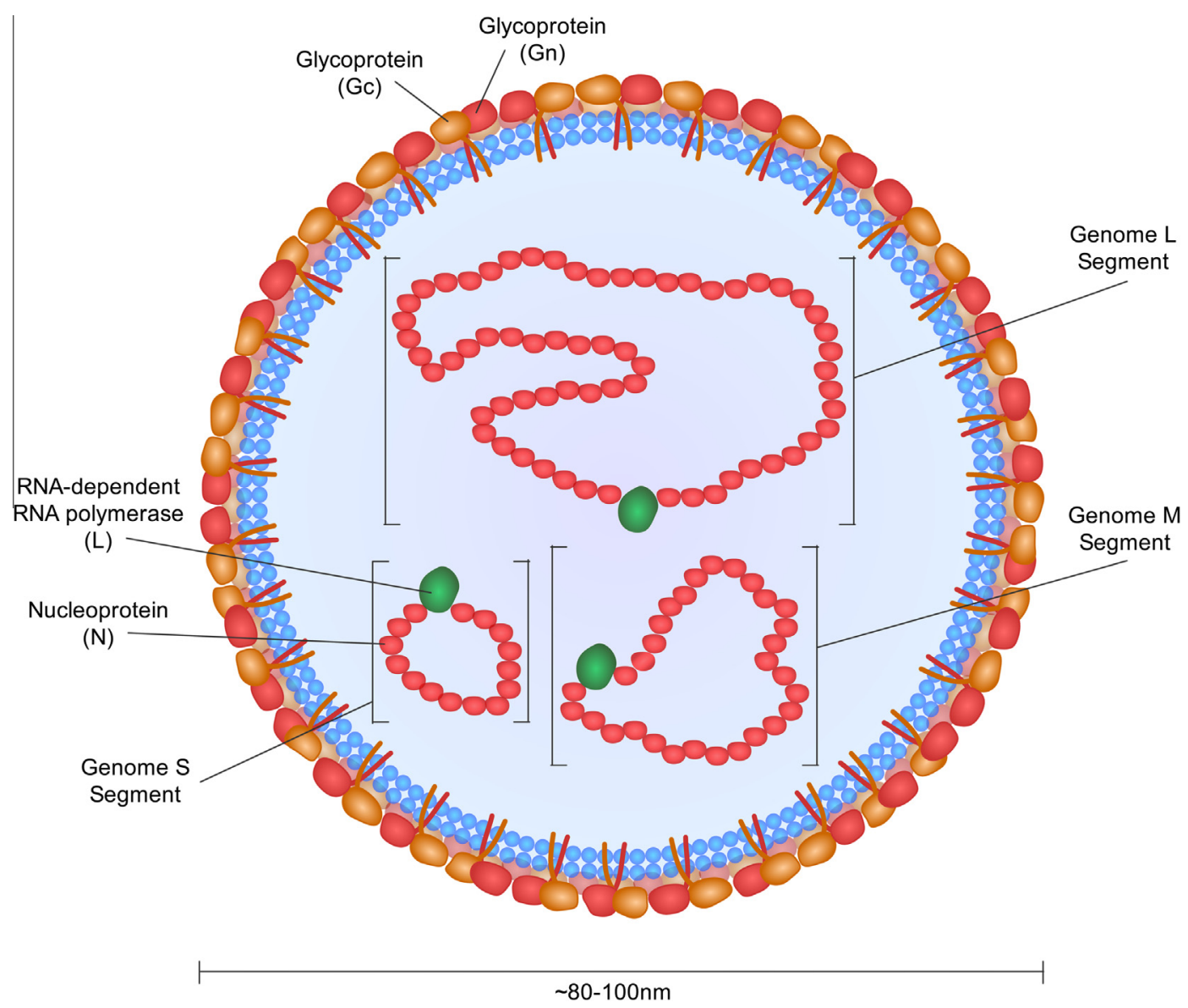

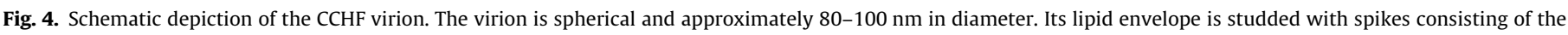

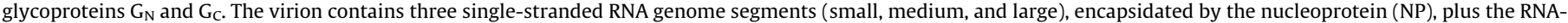
dependent RNA polymerase (RdRp).

$\mathrm{N}$-linked glycosylation of $\mathrm{G}_{\mathrm{N}}$ is also essential for the final processing of both glycoproteins (Erickson et al., 2007). $\mathrm{G}_{\mathrm{N}}$ performs a chaperone-like function for $G_{C}$, and must be present for correct folding to occur (Shi et al., 2012). CCHFV glycoproteins contain an exceptionally large number of cysteine residues, suggesting the presence of many disulfide bonds and a complex secondary structure. The $\mathrm{N}$-terminus of $\mathrm{G}_{\mathrm{N}}$ has mucin-like features, with the potential for extensive O-glycosylation (Sanchez et al., 2002; Papa et al., 2002c; Bertolotti-Ciarlet et al., 2005). Interestingly, the C-terminal cytoplasmic tail of $\mathrm{G}_{\mathrm{N}}$ contains two zinc fingers, which can bind viral RNA (Estrada and De Guzman, 2011).

\subsubsection{The $L$ segment}

The $\mathrm{L}$ segment of CCHFV and other nairoviruses is nearly twice the size of those of other bunyaviruses. Its single open reading frame, more than 12,000 nucleotides in length, encodes a nearly 4000-amino acid polyprotein, which contains an ovarian tumor protease (OTU) domain near its N-terminus, followed by segments homologous to viral topoisomerase, zinc finger and leucine zipper motifs, and a RdRp catalytic domain near the C-terminus (Honig et al., 2004a). The latter show extensive sequence identity with Dugbe virus, another member of the Nairovirus genus. The presence of the OTU cysteine protease near the $\mathrm{N}$ terminus suggests that the L polyprotein is autocatalytically cleaved during translation; however, deletion of the OTU had no apparent effect on viral replication in a minigenome system (Bergeron et al., 2010). To date, the only demonstrated role of the OTU is the removal of ubiquitin from cellular proteins, which may serve to counter host-cell antiviral mechanisms (Frias-Staheli et al., 2007).

\subsection{Replication cycle}

The cellular receptor for CCHFV has not been identified, but a recent study employing the soluble ectodomains of $G_{N}$ and $G_{C}$ suggested that $G_{C}$ plays the major role in binding to target cells, and identified the host molecule nucleolin as essential for cell entry (Xiao et al., 2011). The virus appears to enter host cells by clathrin-dependent endocytosis (Fig. 5) (Simon et al., 2009b). Once within the cytoplasm, the viral RdRp interacts with the encapsidated genome segments to synthesize complementary positive-strand intermediates, which are used as templates for negative-strand synthesis. A model has been proposed involving primer-independent synthesis of both positive-sense antigenomes and negative-sense progeny genomes. (Schmaljohn and Nichol, 2007).

The processes of internalization, virion assembly and egress are dependent on host-cell microtubules (Simon et al., 2009a). As noted above, synthesis of the virion surface glycoproteins is a complex process, which begins with synthesis of $\operatorname{PreG}_{N}$ and PreG $_{C}$ in the ER, their transit as a heterodimer to the Golgi body, and their further cleavage, glycosylation, folding and integration into virion membranes (Shi et al., 2012), Budding of mature virus particles occurs within the Golgi body. 


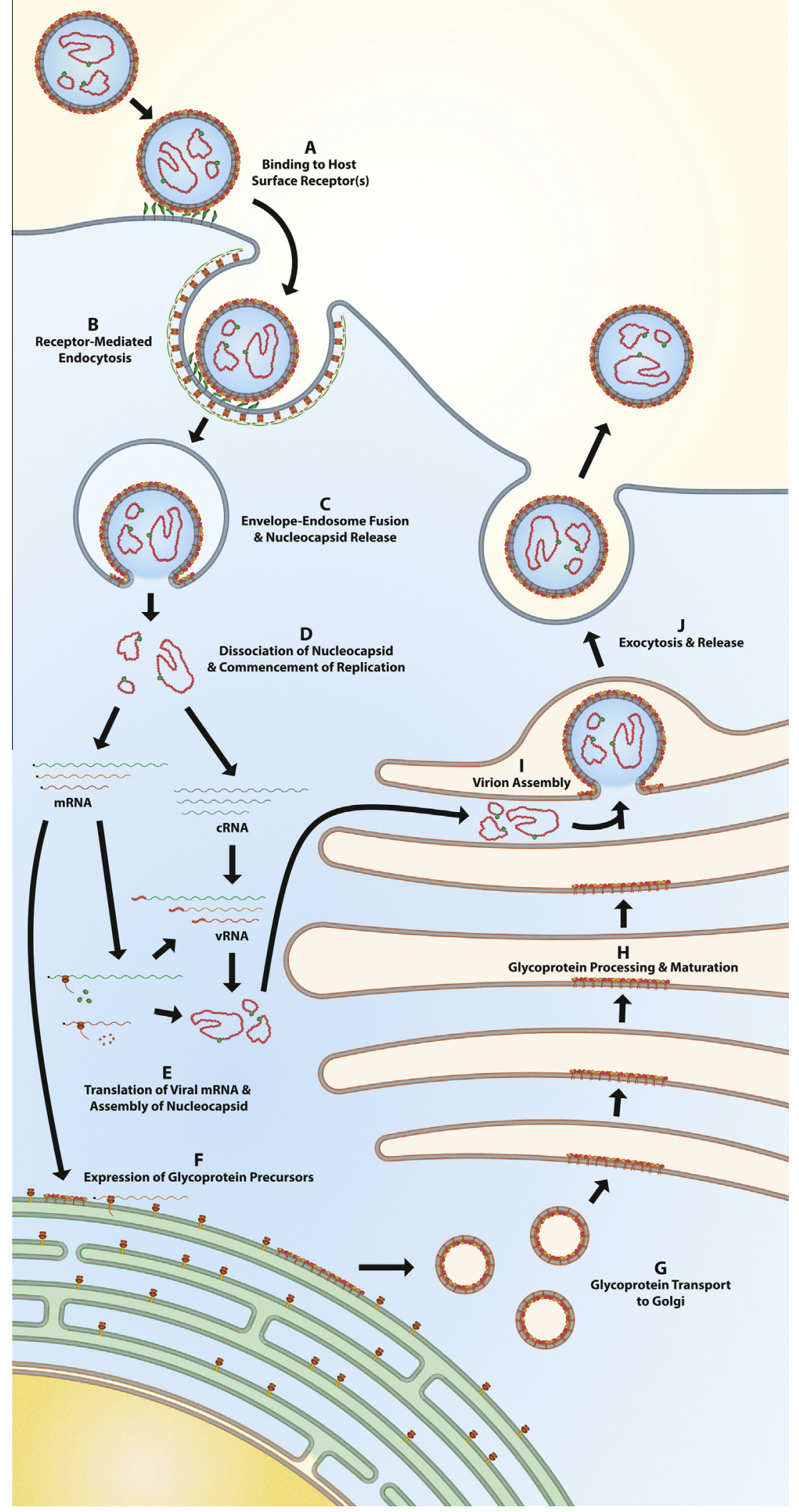

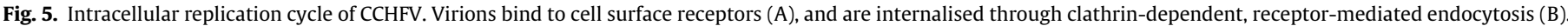

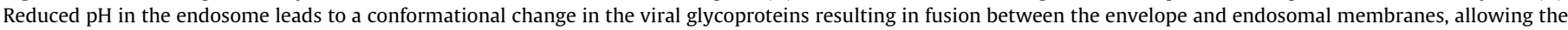

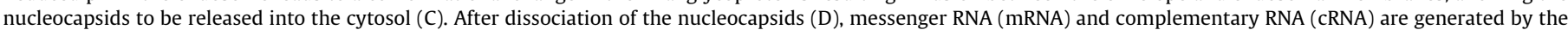

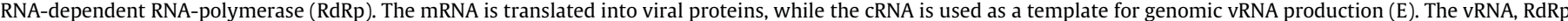

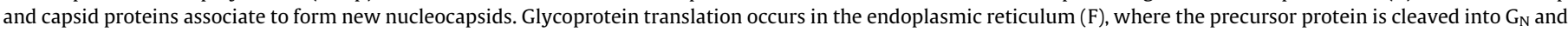

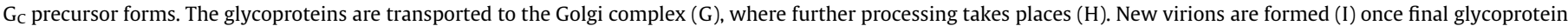
maturation has taken place, and are transported to the plasma membrane and released $(\mathrm{J})$. 

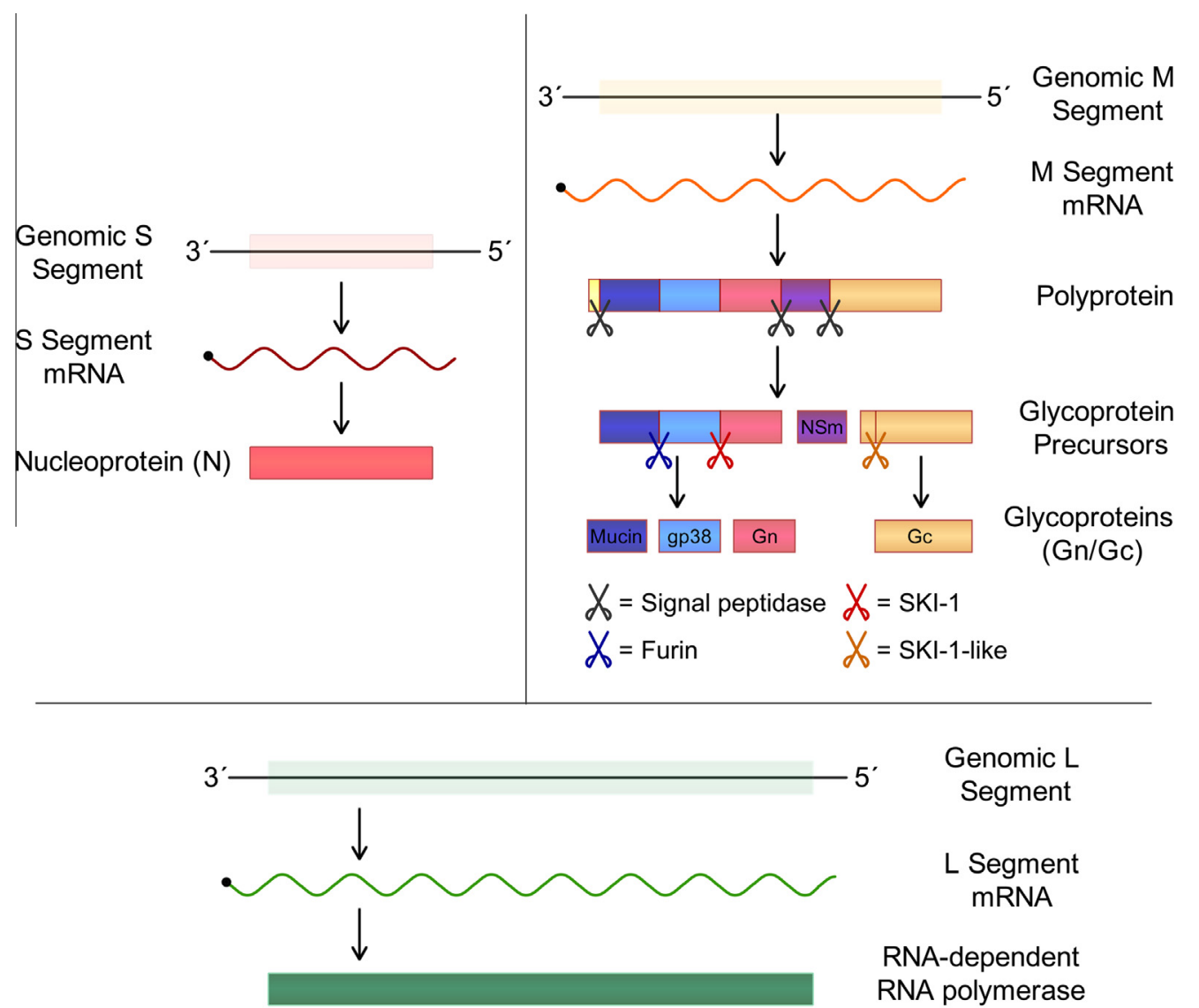

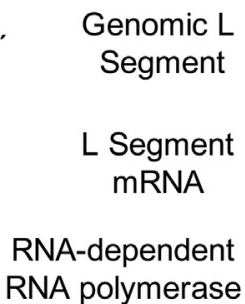

$(\mathrm{L})$

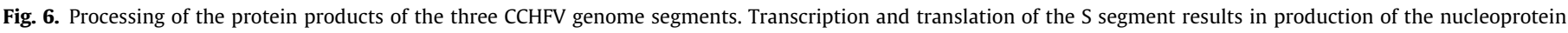

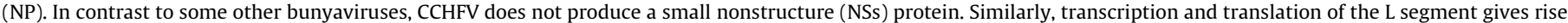

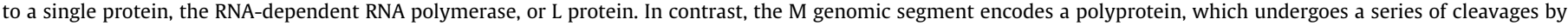
host-cell enzymes and further modifications in the Golgi apparatus to produce the glycosylated $\mathrm{G}_{\mathrm{N}}$ and $\mathrm{G}_{\mathrm{C}}$ proteins (see text for additional details).

\section{Maintenance and transmission of CCHFV}

In the nearly 70 years since CCHF was recognized as a human disease, researchers have characterized the general features of the circulation of its causative agent among ticks and various species of small and large mammals. The role of ticks in the maintenance of the virus has been established both through studies of field-collected ticks and in experimental assessments of vector competence in the laboratory. In contrast, because most vertebrates infected with CCHFV apparently develop only a transient viremia without apparent illness, the identification of mammalian hosts of CCHFV has been based largely on the detection of virusspecific antibodies in serum collected from livestock or occasionally from wild animals. Routes of transmission to humans have been identified based on the exposure histories of patients and on the detection of antibodies to CCHFV in serum samples from populations in endemic areas.

\subsection{Tick vectors of $\mathrm{CCHFV}$}

Ticks are arachnids in the class Ixodida; those in the family Argasidae have a soft body, while members of the family Ixodidae possess a rigid shield or scutum. Ticks acquire the nutrients they need for their metamorphosis from larva to nymph to adult by taking blood from a vertebrate (hematophagy) once during each developmental stage (instar). Adult females must also take a blood meal to obtain the nutrients needed to produce eggs. Feeding takes place through a specialized organ, the hypostome. It is facilitated by the presence in tick saliva of anticoagulants and immunomodulatory proteins, which may facilitate virus infection and elicit a specific immune response in the host, making it partially resistant to further infestation (Francischetti et al., 2009; Willadsen, 2004).

CCHFV is maintained through trans-stadial, transovarial and venereal transmission in several species of ixodid (hard) ticks, accompanied by bursts of amplification each spring and summer, when the ticks transmit the virus to mammals while taking the blood meals required for their maturation and for egg production (Fig. 6). The resulting viremia in mammals is transient, but ticks remain infected throughout their several-year lifetimes; they are therefore the true natural reservoirs. Because humans are not a source of infection for ticks, they are only accidental, "dead-end" hosts for the virus.

A critical area of research on the maintenance of CCHFV in nature has been the identification of its competent tick vectors, i.e. those species that undergo life-long viral infection, and in which the agent is efficiently transmitted from adult females to their eggs and from adult males to females through copulation. Unfortunately, some researchers attempting to identify tick species responsible for human disease have focused only on detecting viral antigen, genomic sequences or infectious virus in wild-caught ticks, ignoring the fact that any arthropod that has taken a blood meal from a CCHFV-infected vertebrate will be positive in such tests, whether or not it is capable of maintaining the virus through vertical and venereal transmission. As discussed below, competent vectors of CCHFV can only be identified through careful laboratory 
studies to confirm the occurrence of transovarial and venereal transmission of virus.

In considering the maintenance of CCHFV in nature, it is essential to realize that some species of ticks may harbor the virus and transmit it among small and large animal mammals, without ever serving as a source of human infection. Because humans who enter an enzootic focus are most likely to be bitten by questing Hyalomma ticks, the role of other species in maintaining the virus may not be evident. Surveys of ticks recovered from wild and domestic animals are a first step in identifying potential reservoir species, but studies of vector competence are required to confirm their role in virus maintenance.

\subsubsection{Ticks, nairoviruses and CCHFV}

Most members of the genus Nairovirus are transmitted by ticks. While most of these viruses are associated with only a single tick genus, viruses in the CCHF serogroup may be transmitted by several different genera of ticks. However, while some nairoviruses infect argasid (soft) ticks, CCHFV are maintained exclusively in ixodid ticks. Experimental studies have shown that when soft ticks are experimentally infected with CCHFV, the virus fails to spread to its tissues or persist through its trans-stadial development (Durden et al., 1993; Shepherd et al., 1989b). Although the virus has been isolated from other arthropods, such as biting midges (Causey et al., 1970), this is believed to simply reflect recent feeding on a viremic mammal; there is no evidence that mosquitoes or any arthropod species other than ixodid ticks is a competent vector for CCHFV.

The marked genetic diversity of the nairoviruses appears to reflect their long history of co-evolution with their tick reservoirs, which have themselves evolved along with the vertebrates on which they depend for sustenance (Honig et al., 2004b). Similarly, the association of CCHFV with several tick species and the exploitation by ticks of a variety of vertebrate hosts as sources of blood meals may contribute to the wide sequence diversity of the virus. Although recombination and reassortment might potentially take place in a mammal simultaneously infected with two strains of virus, the transient nature of such infections suggests that genetic exchange is much more likely to occur in persistently infected ticks, as they continue to acquire new virus variants over their life-times. The nature and extent of CCHFV evolution in ticks will be an important topic for future laboratory research.

\subsubsection{Vertical transmission}

Competent tick vectors of CCHFV are defined by their ability to support viral replication in their tissues during metamorphosis from larva to nymph to adult, to transmit the virus from adult females to their eggs and from adult males to females during copulation (Dohm et al., 1996; Gordon et al., 1993; Logan et al., 1990; Shepherd et al., 1991; Gonzalez et al., 1992). Following its ingestion by a competent vector in a blood meal, CCHFV replicates in the lining of the tick's midgut, then spreads to many different tissues, reaching the highest titers in the salivary glands and reproductive organs (Dickson and Turell, 1992). Because a female may produce thousands of eggs, even a low rate of transovarial transmission is sufficient to maintain a large population of infected ticks (Nuttall et al., 1994). However, little is known about factors that influence the percentage of eggs that become infected.

\subsubsection{Horizontal transmission}

The spread of CCHFV between ticks and mammals takes place principally during the spring and summer months, when larvae and nymphs take the blood meals required for their growth and metamorphosis, and adult females are preparing to produce eggs (Fig. 6). In some vertebrate species, the bite of an infected tick is followed by the replication of virus in tissues and its spread in the bloodstream, providing a source of infection for additional ticks. A feeding tick may remain attached for several weeks, enhancing the likelihood of virus transmission from an infected tick to its host, or from a viremic host to its feeding, virus-naïve ticks. However, experimental studies indicate that not all mammals are susceptible to infection with CCHFV, or develop a

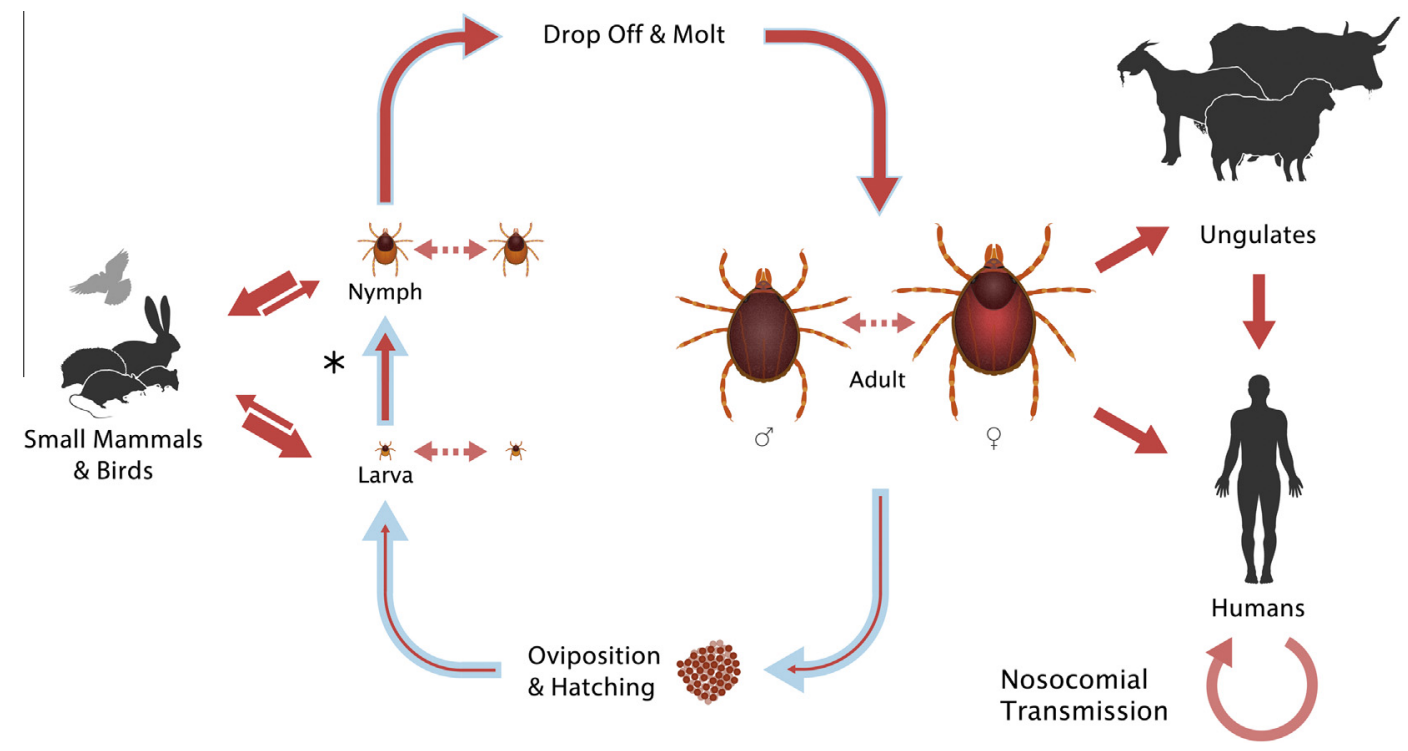

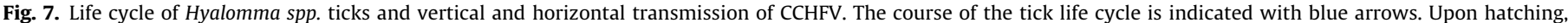

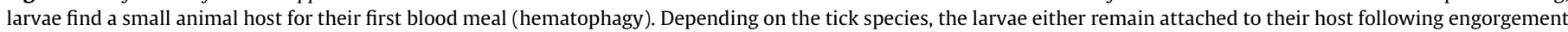

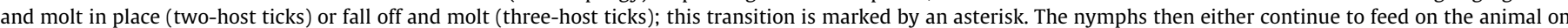

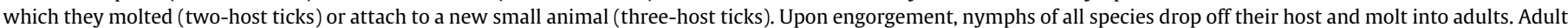

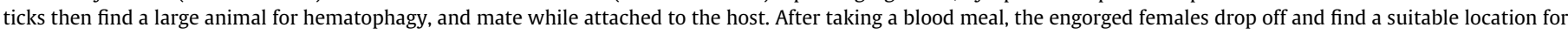

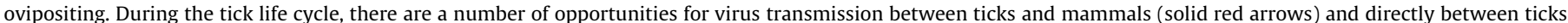

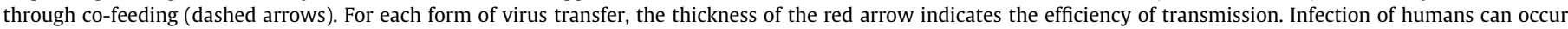
through the bite of an infected tick or through exposure to the body fluids of a viremic animal or CCHF patient. 
sufficiently high blood viral titer to efficiently infect ticks (Shepherd et al., 1989a; Shepherd et al., 1991). Tick species also differ in the quantity of ingested virus that is required to initiate infection of the lining of the midgut (Shepherd et al., 1991).

Evolution has dealt with these uncertainties by providing a second transmission mechanism, in which virus present in tick saliva can spread directly to other ticks feeding nearby ("co-feeding") (Jones et al., 1987b; Nuttall and Labuda, 2003; Nuttall and Labuda, 2004). Since it does not require the host animal to be viremic, this mechanism of virus transfer between ticks is also known as "nonviremic" transmission. Substances present in tick saliva appear to enhance the transmission of virus by co-feeding (Shepherd et al., 1989b). In adult females, such direct exposures may enhance the rate of transovarial transmission (Gonzalez et al., 1992; Nuttall et al., 1994; Randolph, 2011).

Once an immature tick has completed a blood meal, it may remain on its host while molting to its next instar, or drop off, molt and seek a new host. Certain members of the genus Hyalomma, such as Hyalomma marginatum, are "two-host" ticks, which as larvae and nymphs feed on rodents, hares, ground-feeding birds or other small animals while feeding and molting, but feed on sheep, cattle and other large mammals as adults (Fig. 7). Other species are "three-host" ticks, which drop off their host each molt. Specific tick-host cycles therefore have a strong influence on the circulation of CCHFV in its natural foci. Some species wait passively to encounter a vertebrate ("ambush ticks"), but Hyalomma are "hunting" ticks, which can quest up to $400 \mathrm{~m}$ to find their hosts (including humans). The role of ground-feeding birds in the maintenance and spread of CCHFV is discussed below.

\subsubsection{Competent tick vectors and their geographic distribution}

The geographic distribution of CCHF in Eurasia largely reflects that of Hyalomma ticks. $H$. marginatum is the principal vector in the region extending from Kosovo to Pakistan, and is the tick most commonly recovered from humans and animals in endemic regions of Turkey (Ozdarendeli et al. 2010). The broad dispersal of Hyalomma ticks reflects their tolerance of diverse environments, including savannah, steppe and lightly wooded areas, and the ability of their aggressively questing larvae and nymphs to feed on a variety of hosts, including hedgehogs, hares and ground-feeding birds, while the adults actively seek out sheep, cattle and other large animals (reviewed in Hoogstraal (1979)). The northern limit for members of the genus appears to be set by the length of the warm season; thus, Hyalomma lusitanicum, from which CCHFV RNA was recently recovered (Estrada-Pena et al., 2012c), is found in southern Spain, but not in colder northern parts of the country (Barandika et al., 2011).

Other members of the genus Hyalomma, including Hyalomma marginatum rufipes, are the major vectors of CCHFV in Africa, where the proximity of numerous wild vertebrates to livestock farms may favor the existence of large tick populations and human exposures to the virus (Rechav, 1986). The virus has also been recovered from other thermophilic tick species, including Rhipicephalus ticks in Turkey, Greece and Albania (Yesilbag et al., 2013) (Gargili et al., 2011) (Papadopoulos and Koptopoulos 1978) (Papa et al., 2011; Papa et al., 2009b) and Dermacentor marginatus in Turkey (Yesilbag et al., 2013).

As noted above, the detection of CCHFV in a wild-caught tick may only indicate that it has recently fed on an infected mammal, not that it is a competent vector. To avoid reaching incorrect conclusions as to the role of various tick species in maintaining the virus, some researchers have attempted to identify competent vectors by confirming the persistence of virus throughout the maturation process and across generations, and by testing the ability of experimentally infected ticks to transmit infection to suckling mice or other laboratory animals. Hoogstraal (1979) reviewed a large number of such studies performed by Soviet and other investigators from 1945 to the late 1970s, demonstrating trans-stadial and transovarial transmission of CCHFV in $H$. marginatum and other species. Table 5 summarizes a number of experimental studies performed since that time, which have investigated CCHFV infection of Hyalomma, Rhipicephalus and Dermacentor ticks. In many cases, ticks were infected through intracoelomic or intraanal inoculation, bypassing the normal route of infection through the ingestion of a blood meal; only those studies in which ticks were fed on viremic suckling mice provide solid evidence of vector competence. As shown in the table, little research in this area has been published since 1999, possibly reflecting the introduction of more rigorous biocontainment measures for work with CCHFV.

\section{Table 5}

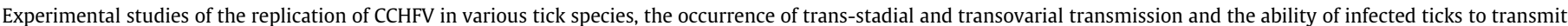

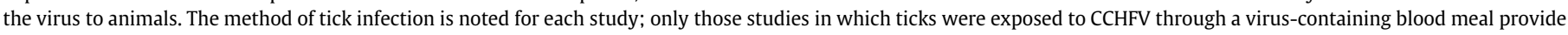
evidence of vector competence, by duplicating the natural infection cycle.

\begin{tabular}{|c|c|c|}
\hline Year & Experimental design and principal findings & References \\
\hline 1970 & Nymphal H. marginatum rufipes parenterally inoculated with Congo virus remained persistently infected and transmitted virus to a calf & Lee and Kemp (1970) \\
\hline 1976 & $\begin{array}{l}\text { Demonstrated trans-stadial and transovarial virus transmission and infection of vertebrates by H. plumbeum, Rhipicephalus rossicus and } \\
\text { Dermacentor marginatus fed on infected susliks }\end{array}$ & Kondratenko (1976) \\
\hline 1989 & $\begin{array}{l}\text { Infected adult } H \text {. } m \text {. rufipes, } H \text {. truncatum and } R \text {.e. mimeticus ticks transmitted CCHFV to sheep; virus inoculated intracoelomically into } \\
\text { nymphs persisted in adults }\end{array}$ & $\begin{array}{l}\text { Shepherd et al. } \\
\text { (1989b) }\end{array}$ \\
\hline 1989 & $\begin{array}{l}\text { Larval H. truncatum were fed on viremic newborn mice; trans-stadial and horizontal transmission were demonstrated; no transovarial } \\
\text { spread }\end{array}$ & Logan et al. (1989) \\
\hline 1990 & $\begin{array}{l}\text { Hyalomma and Rhipicephalus ticks were inoculated intracoelomically; virus persisted longer in ticks given a blood meal; no transovarial } \\
\text { transmission }\end{array}$ & Logan et al. (1990) \\
\hline 1991 & Nymphs and adults of $H$. rufipes and Amblyomma variegatum were infected by intracoelomic inoculation with Congo virus & Okorie (1991) \\
\hline 1991 & $\begin{array}{l}\text { Compared levels of viremia and transmission of CCHFV from infected sheep, cattle and scrub hares to immature and adult Hyalomma } \\
\text { and Rhipicephalus }\end{array}$ & $\begin{array}{l}\text { Shepherd et al. } \\
\text { (1991) }\end{array}$ \\
\hline 1991 & Adult $H$. truncatum inoculated intra-anally with CCHFV remained infected for several months & $\begin{array}{l}\text { Gonzalez et al. } \\
\text { (1991) }\end{array}$ \\
\hline 1992 & Adult $H$. truncatum infected intra-anally with CCHFV transmitted virus by co-feeding and from male to female by the venereal route & Gonzalez et al. \\
\hline 1992 & $\begin{array}{l}\text { H. truncatum were infected intracoelomically; virus titers reached highest levels in salivary glands and reproductive tissues, were } \\
\text { boosted by a blood meal }\end{array}$ & $\begin{array}{l}\text { Dickson and Turell } \\
(1992)\end{array}$ \\
\hline 1993 & Argasid ticks (Ornithodoros sonrai) fed on viremic suckling mice did not remain persistently infected & Durden et al. (1993) \\
\hline 1996 & Larval $H$. impeltatum fed on infected newborn mice transmitted virus transstadially and to guinea pigs & Dohm et al. (1996) \\
\hline 1999 & $\begin{array}{l}\text { Intracoelomic inoculation of larval } H \text {. m. rufipes and } H \text {. truncatum resulted in trans-stadial and transovarial persistence, but virus lost } \\
\text { from subsequent generation }\end{array}$ & Faye et al. (1999) \\
\hline 2007 & $\begin{array}{l}\text { H. marginatum experimentally infected through a blood meal and held at } 4{ }^{\circ} \mathrm{C} \text { transmitted virus after } 10 \text { months, and virus remained } \\
\text { detectable after two years }\end{array}$ & Turell (2007) \\
\hline
\end{tabular}


Table 6

Experimental infections of wild and domestic animals with CCHFV.

\begin{tabular}{|c|c|c|}
\hline Year & Experimental design and principal findings & References \\
\hline 1970 & Two calves inoculated with Congo virus developed a mild illness; a tick fed on one of them tested positive for virus & Causey et al. (1970) \\
\hline 1989 & $\begin{array}{l}\text { Infected } 11 \text { different wild animal species; viremia was detected in scrub hares and some rodents, but only in scrub hares was it high } \\
\text { enough to infect ticks }\end{array}$ & $\begin{array}{l}\text { Shepherd et al. } \\
\text { (1989a) }\end{array}$ \\
\hline 1991 & $\begin{array}{l}\text { Compared levels of viremia and transmission of CCHFV from infected sheep, cattle and scrub hares to immature and adult Hyalomma and } \\
\text { Rhipicephalus }\end{array}$ & $\begin{array}{l}\text { Shepherd et al. } \\
\text { (1991) }\end{array}$ \\
\hline 1991 & Adult $H$. truncatum fed on experimentally infected sheep became infected and transmitted virus transovarially & Wilson et al. (1991) \\
\hline 1994 & H. m. rufipes larvae became infected when fed on hornbills and starlings inoculated with CCHFV & Zeller et al. (1994) \\
\hline 1998 & West African sheep inoculated with CCHFV developed viremia, fever and mild hepatic dysfunction & $\begin{array}{l}\text { Gonzalez et al. } \\
(1998)\end{array}$ \\
\hline 1998 & Young ostriches inoculated with CCHFV were viremic on days 1-4 postinfection & $\begin{array}{l}\text { Swanepoel et al. } \\
\text { (1998) }\end{array}$ \\
\hline
\end{tabular}

\subsection{Infection of wild and domestic mammals}

The three decades following the identification of CHF in 1944 saw a remarkable effort, principally by Soviet and Bulgarian scientists, to identify tick vectors and vertebrate hosts of the virus in the Soviet Union and neighboring countries (Hoogstraal, 1979). Beginning in the late 1960s, the use of newborn mice to isolate and propagate the virus led to a further expansion of research, including numerous studies of the circulation of "Congo virus" in ticks and vertebrates in central Africa in the 1970s and of CCHFV in South Africa in the 1980s (reviewed by Nalca and Whitehouse, 2007).

\subsubsection{Identification of vertebrate hosts}

Serosurveys of domestic animals have been the traditional means of identifying regions where CCHFV is circulating. In general, such studies have shown that antibody positivity in livestock animals correlates with the occurrence of human cases; that the percentage of positive animals tends to rise and fall with seasonal levels of tick parasitism; and that seropositivity is more common in adult than young animals. Wild and domestic animal hosts that have been identified through serosurveys and other ecologic studies are discussed below.

The requirement of Hyalomma and other tick vectors for blood meals from both small and large animals during the course of their maturation helps to explain some epidemiologic features of CCHF. In regions where small mammals such as hares and hedgehogs and large mammals such as sheep and cattle are abundant, the virus may circulate silently, with human cases occurring only occasionally, when farmers handling livestock are bitten by infected ticks. In contrast, when a region has many small mammals, but few large ones, any humans who enter the area may be actively sought out by questing adult ticks, resulting in a large number of infections. This appears to have been the situation in 1944 in the Crimea, where wild hares had proliferated on abandoned farms during the German occupation, but the number of livestock was sharply reduced. The explosion of cases among soldiers and collective farm workers re-settling the area reflected the urgent need of questing adult Hyalomma to find a large animal source for their next blood meal. Similar situations may explain the presence of "hot spots" of CCHFV in other regions, such as in Turkey.

\subsubsection{Experimental infections of wild and domestic animals}

A number of experimental studies have attempted to characterize CCHFV infection of wild or domestic vertebrates. This work has provided a limited amount of data on the duration and magnitude of viremia, in some cases quantitating virus transmission from and to feeding ticks. Many such reports appeared in the Russian-language literature in the period 1945-1978, and most are available in translation from the AFPMB web site cited above; they are reviewed in detail by Hoogstraal (1979), and some are summarized by Nalca and Whitehouse (2007). In general, these studies found low-level viral replication in horses, donkeys, sheep, cattle and other animals in CCHF-endemic areas, in the absence of any clear signs of illness. Since they have not been repeated using modern laboratory methods, the validity of the findings is uncertain.

Since 1970 , only 7 reports of the experimental infection of wild and domestic animals with CCHFV have been published in the English-language literature (Table 6). These studies found that sheep, calves, scrub hares and ostriches became viremic, and in some cases transmitted the virus to feeding ticks. These limited data permit few conclusions as to role of various animal species in the maintenance of CCHFV in enzootic areas. There is a great need to perform similar studies, using modern research methods, to characterize in detail the ability of domestic animals to support the circulation of CCHFV and to serve as a source of human infection via ticks or exposure to tissues and body fluids.

\subsection{Features of an enzootic focus}

Ticks are most abundant where sources of blood meals are numerous and a long warm season permits their maturation from larva to adult before the onset of cold weather. The geographic distribution of each CCHFV-competent tick vector is therefore defined by the range of its vertebrate hosts and the environmental conditions required for it to reach adulthood. At any given location, the vector's population density will change from year to year, depending on the availability of vertebrate hosts, weather conditions, changes in vegetation and other factors that affect the success of molting and egg production (Estrada-Pena et al., 2012b).

Because CCHFV does not cause overt signs of illness in host animals, the only evidence that the virus is circulating in a given geographic focus is the occurrence of disease in human "sentinels." In the presence of a competent tick vector, the hazard to local residents will depend upon the population density of the tick, the prevalence of infected ticks, and the frequency of bites. The tickhuman contact rate is increased by activities such as farming and hunting, and may be further multiplied if a population is deprived of shelter or otherwise forcibly exposed to their local environment, as may occur during warfare or natural disasters.

Although cases of CCHF resulting from tick bite tend to occur sporadically, epidemics may be seen under conditions of heavy tick exposure. As noted above, this occurred in the Crimea in 1944, when soldiers sent to reclaim abandoned collective farms were exposed to large numbers of ticks infesting a markedly expanded wild hare population. A similar phenomenon was apparently responsible for the sharply increased incidence of CCHF in Bulgaria in the 1950s, as forest, wetlands and other uncultivated areas were converted to farming during the enforced collectivization of agriculture. Human exposure to an expanded number of small vertebrate hosts of Hyalomma ticks may also have contributed to the recent explosion of cases in Central Turkey, when residents returned to farms abandoned during civil strife. Such geographic 
Table 7

Designations of genetic lineages/clades of CCHFV, based on analysis of complete or partial sequences of the viral S-segment.

\begin{tabular}{|c|c|c|c|}
\hline $\begin{array}{l}\text { Designation by Carroll et al. } \\
(2010)\end{array}$ & Countries where isolated & $\begin{array}{l}\text { Designation by Atkinson et al. } \\
\text { (2012a, 2012b) }\end{array}$ & $\begin{array}{l}\text { Designation by Mild et al. } \\
\text { (2010) }\end{array}$ \\
\hline I & Iran, South Africa, Senegal, Mauritania & Africa 3 & 6 \\
\hline II & South Africa, Namibia, DRC, Uganda & Africa 2 & 5 \\
\hline III & $\begin{array}{l}\text { South Africa, Namibia, UAE, Senegal, Mauritania, Nigeria, Burkina } \\
\text { Faso, CAR }\end{array}$ & Africa 1 & 3 \\
\hline IV & $\begin{array}{l}\text { Iran, Pakistan, UAE, Madagascar, Oman, Iraq, China, Uzbekistan, } \\
\text { Kasakhstan, Tadjikistan }\end{array}$ & Asia 1, Asia 2 & 1,2 \\
\hline V & Iran, Turkey, Greece, Russia, Bulgaria, Kosovo, Albania & Europe 1 & 4 \\
\hline VI & Greece, Turkey & Europe 2 & 7 \\
\hline
\end{tabular}

"foci" of intense disease transmission are also seen in other tickborne diseases, such as Omsk hemorrhagic fever and Kyasanur forest disease.

\subsection{Role of birds in the maintenance and spread of CCHFV}

The larvae and nymphs of Hyalomma and other multiple-host ixodid ticks frequently take their blood meals from ground-feeding birds, and often remain attached to them while molting. However, there is no evidence that birds fed upon by CCHFV-infected ticks become viremic. Hoogstraal (1979) cited a number of Russian reports of the recovery of infected ticks from a variety of bird species, but noted that birds were apparently not hosts for viral replication.

This conclusion was supported by the only two subsequent studies, as researchers were unable to detect antibodies to CCHFV in 37 different species of wild birds in South Africa (Shepherd et al., 1987a), and could not demonstrate viremia in experimentally inoculated hornbills and starlings, even though $H$. rufipes larvae feeding on them became infected (Zeller et al., 1994). The potential role of migratory birds in the spread of CCHFV to new geographic areas, through the transport of virus-infected larvae and nymphs, is discussed below.

\subsection{Transmission to humans}

Human beings are dead-end hosts for CCHFV. Infections are usually observed as single, sporadic cases, when people in rural areas are bitten by virus-infected ticks (Fig. 7). As discussed above, the disease is seen most commonly in the spring and summer, when adult stages of Hyalomma and other vector species are seeking the blood meals required for their maturation. An increased number of cases is often seen following mild winters, which favor the survival of infected ticks (Estrada-Pena et al., 2012a).

In addition to tick exposure, $\mathrm{CCHF}$ can also result from contact with the blood of infected animals, principally among abattoir workers. Because the rapid acidification of muscle following death appears to inactivate the virus, persons who purchase freshly butchered meat are not at risk of infection. Person-to-person transmission can occur through contact with the virus-containing body fluids of a patient during the first 7-10 days of illness (Fig. 7). However, numerous studies have shown that standard barrier nursing methods are sufficient to prevent the transmission of CCHF in the patient care setting (Athar et al., 2005; Maltezou et al., 2009). Asymptomatic infection of health care workers apparently does not occur (Ergonul et al., 2007). Imported cases of CCHF have occurred in France (Jaureguiberry et al., 2005) and the United Kingdom, but without further person-to-person transmission.

\section{Geographic range of CCHFV}

Since CCHF was first recognized in 1944, the known geographic distribution of its causative agent has expanded from the Crimea in the southern Soviet Union to cover a huge area, from western China across southern Asia to the Middle East, Bulgaria and the Balkans, and throughout most of Africa (Figs. 1 and 2). Most nations within this region have reported cases of CCHF in humans. In some countries where the disease has never been diagnosed, evidence of virus circulation is based on the recovery of viral sequences or live virus from ticks or from wild or domestic animals, or the detection of virus-specific antibodies in serosurveys of humans and animals.

The following sections summarize the history of detection of CCHFV in four geographic regions: western areas of the former Soviet Union and in southeastern and southwestern Europe; eastern and central Asia; the Middle East and Turkey; and Africa. Each section is accompanied by a table listing the total number of cases of CCHF for individual countries, with the overall CFR, as reported in the medical literature (Tables 1-4). The articles from which the data were obtained are listed in Supplementary Table 1. To designate the lineages/clades of viruses isolated in various countries, we utilize both the Roman numeral system of Carroll et al. (2010) and the geographic naming system of Hewson and co-workers (Atkinson et al., 2012b) (Table 7).

\subsection{CCHF in western areas of the former Soviet Union and in southern Europe}

\subsubsection{The former Soviet Union}

The identification of Crimean HF by Chumakov and his colleagues in 1944 led to extensive research on the disease at the Institute of Poliomyelitis and Viral Encephalitis in Moscow. Initial studies were limited by the inability of investigators to cultivate the virus, but the discovery in 1967 that the agent could be propagated in suckling mice led to the recovery of numerous isolates, including the Drozdov strain from a patient in Astrakhan (Chumakov et al., 1968). Since the breakup of the Soviet Union, outbreaks of CCHF in the territory of the Russian Federation have been described only in Russian-language journals (Onishchenko et al., 2005). The incidence of the disease has clearly been increasing; from 2002 to 2008, there were more than 1000 confirmed cases, with a 3.2\% mortality rate (Butenko and Karganova, 2007; EpiSouth and WHO (2008), Leblebicioglu, 2010). Viruses circulating in southern Russia appear to belong to a single clade (Yashina et al., 2003a).

\subsubsection{Southeastern Europe}

Within a few years after the identification of CHF in 1944, a similar condition was recognized in Bulgaria, which subsequently became a center for research on the disease. Work in Bulgaria resulted in the development of a mouse brain-derived CCHF vaccine, which has been in use since the early 1970s, and the preparation of specific immune globulin from hyperimmunized volunteers, which is banked and utilized for treatment of patients (see sections on vaccines and therapy below). 
More than 1500 cases of $\mathrm{CHF} / \mathrm{CCHF}$ were diagnosed in Bulgaria during the period 1953-2008 (Papa et al., 2004). Human infections are seen principally in the eastern portion of the country in the spring and summer months, among men engaged in farming and other work involving tick exposure. Surveys have detected CCHFV-specific antibodies in livestock where the disease is most prevalent, and identified CCHFV by RT-PCR in $2 \%$ of some 900 ticks sampled (Gergova et al., 2012). A cluster of cases was recently reported in southwestern Bulgaria, where the disease had not previously been seen (Christova et al., 2009).

To the south, CCHF is endemic throughout the Balkan states. Outbreaks were identified in Kosovo in the early 1950s, and cases continue to be reported (Duh et al., 2008). Virus-specific antibodies have been detected in some 10-20\% of livestock and humans in endemic areas (Papa et al., 2002b). In Albania, CCHF was first recognized in 1986, and sporadic cases and outbreaks have occurred since that time (Papa et al. 2002a).

In Greece, CCHFV was first identified in 1975, through the isolation of the AP92 virus strain from ticks of the species Rhipicephalus bursa that had been recovered from goats (Papadopoulos and Koptopoulos 1978). Despite the detection of anti-CCHFV antibodies in the local population (Antoniadis and Casals, 1982), no cases of disease were identified over the subsequent 33 years, leading to the proposal that the AP92 strain, which diverged markedly in sequence from other CCHFV isolates, did not cause illness in humans. This hypothesis was partially confirmed by the finding that a child with mild CCHF in the Balkan portion of Turkey in 2007 was infected by an AP92-like virus, and a local serosurvey identified 38 people with IgM antibodies to CCHFV, but no history of illness (Midilli et al., 2009). The first case of CCHF in Greece was identified in 2008, in a person living close to the Bulgarian border, who developed hemorrhagic fever after a tick bite (Papa et al., 2009a). The virus was closely related to other strains isolated in the Balkans. A recent nationwide serosurvey revealed significant variation in the prevalence of anti-CCHFV antibodies, with high levels among older men in contact with livestock (Sidira et al., 2011).

With the exception of a single human case in Hungary in 2004 (Hornok and Horvath, 2012), CCHF has not been reported in any country north of Bulgaria. However, adult $H$. marginatum ticks have been identified on livestock in Hungary and Romania, indicating that they are capable of carrying out their entire maturation cycle in areas further north than was previously thought possible (Ceianu et al., 2012; Hornok and Horvath, 2012). The detection of CCHFV-specific antibodies in sheep has provided further evidence of virus circulation in Hungary and Romania.

\subsubsection{Southwestern Europe}

No indigenous cases of CCHF have been reported in any European country west of the Balkans. Until recently, evidence of virus activity was limited to the detection of anti-CCHFV antibodies in bats in France (cited by Hoogstraal (1979)) and in Portugal in the 1980s (Filipe et al., 1985). However, in early 2012, Spanish researchers reported the detection of CCHFV RNA in H. lusitanicum ticks recovered from wild deer (Estrada-Pena et al., 2012c). The isolate was most closely related to African strains, suggesting that it might have been introduced by migratory birds.

\subsection{CCHF in eastern and central Asia}

An outbreak of HF that occurred in western China in 1965 was retrospectively identified as CCHF by testing samples from humans, sheep and ticks (Yen et al., 1985). The virus was first isolated from Hyalomma ticks in Pakistan in the 1960s (Begum et al., 1970), and repeated outbreaks and sporadic cases have been seen since that time, especially in persons handling or slaughtering livestock (Jamil et al., 2005). In early 2011, the first cases of CCHF were identified in India, in a nosocomial outbreak in Gujarat state, which adjoins Pakistan (Mishra et al., 2011). A recent serosurvey and sampling of $H$. anatolicum ticks showed that infection was present in local livestock (Mourya et al., 2012).

\subsection{CCHF in the Middle East and Turkey}

\subsubsection{The Middle East}

The presence of CCHFV in Iran was first demonstrated in the 1970s, when specific antibodies were found in the sera of humans, cattle and sheep (Saidi et al., 1975); viral antigen was detected in sheep in an abattoir in Teheran (Hoogstraal, 1979); and viruses were isolated from ixodid ticks (Sureau and Klein, 1980). Cases in humans were first observed in 1999, and have since been reported in most provinces (Chinikar et al., 2004; Chinikar et al., 2010). In neighboring Iraq, surveillance was interrupted by civil unrest and war for nearly a decade, but a number of cases of CCHF have recently been reported (Majeed et al., 2012). Following an outbreak of some 60 cases in Herat, Afghanistan, in 2009, a serosurvey found high levels of specific IgG in cattle and sheep in the surrounding area (Mustafa et al., 2009).

CCHF was first detected in the Arabian Peninsula in a hospital outbreak in 1979 in Dubai (Suleiman et al., 1980). Additional cases were not seen until 1994, when an epidemic occurred among abattoir workers in the United Arab Emirates (Khan et al., 1997). A serosurvey performed as part of the investigation found that many livestock animals raised in the region had antibodies to CCHFV, while imported animals were negative. Human infections were identified in Oman in the mid-1990s, and a subsequent survey of livestock and ticks confirmed the local circulation of the virus (Scrimgeour, 1996; Williams et al., 2000)

\subsubsection{Turkey}

Turkey represents a special case in CCHF epidemiology, as the past decade has seen its transformation from a country free of human infections to the "epicenter" of the disease, with more than 1000 confirmed cases per year. It is likely that CCHF has long been present, but unrecognized, but the surge in human infections may also reflect an environmental situation similar to that which occurred in the Crimea at the end of World War II, in which the reoccupation of abandoned agricultural lands resulted in a marked increase in tick exposure.

The first case of CCHF was identified in Turkey in 2002 (Karti et al., 2004), in patients in the eastern Black Sea region. As of 2009, nearly 5000 infections had been diagnosed, with a mean fatality rate of approximately 5\% (Ozkaya et al., 2010). Because the early signs and symptoms of the disease are nonspecific, some 2/3 of CCHF patients are initially misdiagnosed (Tasdelen Fisgin et al., 2010). Most cases occur in the Anatolian plateau region of central and eastern Turkey, where a serosurvey detected specific antibodies in almost $80 \%$ of domestic animals (Gunes et al., 2009), and virus was isolated from some $20 \%$ of Hyalomma ticks (Gunes et al., 2011). A recent serosurvey of more than 3500 residents of this hyperendemic area found a $10 \%$ positivity rate, indicating the occurrence of numerous subclinical infections (Bodur et al., 2012). Older age, farming and a history of tick bites were risk factors for seropositivity.

Almost all viruses isolated from humans or ticks in the Anatolian region belong to European clades (see below) (Ozkaya et al., 2010). In cases in western Turkey, a survey identified RNA from viral clades Europe 1 and Europe 2 in $H$. marginatum and $R$. bursa ticks, and a 10\% prevalence of anti-CCHFV IgG in the local population (Gargili et al., 2011). However, a case of mild illness in the European portion of the country in 2009 was caused by a virus closely related to the Greek AP92 strain (Midilli et al., 2009). 


\subsection{CCHF in Africa}

As noted above, CCHF was first identified in Africa in 1967, when the virus was isolated by suckling mouse brain passage from a blood sample collected 11 years earlier from a young boy in the Belgian Congo (Simpson et al., 1967; Woodall et al., 1967); the agent was later shown to be identical to CHFV (Casals, 1969). Over the next few years, this "Congo virus" was also recovered from patient blood specimens, serum samples from domestic goats and cattle and from various species of Hyalomma ticks in Uganda and Nigeria (Causey et al., 1970). Analysis of virus recovered from a recent case in the DRC indicates that the same strain continues to circulate (Grard et al., 2011).

The majority of CCHF cases in Africa have been reported from South Africa, where the first case was identified in 1981, when a boy who returned from camping with a Hyalomma tick on his scalp died of hemorrhagic fever (Gear et al., 1982). In 1985, a cluster of cases was seen in farmers and other persons exposed to cattle and sheep, many of whom reported recent tick bites; an ensuing nosocomial outbreak at Tygerberg Hospital permitted detailed study of the disease (van Eeden et al., 1985a; Joubert et al., 1985; van Eeden et al., 1985b). Cases that occurred about the same time in ostrich workers are described below. By 1989, Swanepoel and his colleagues were able to review clinical pathologic findings in $50 \mathrm{CCHF}$ patients treated in South African hospitals (Swanepoel et al., 1989).

Ecological studies have shown that CCHFV circulates among a variety of wild and domestic animals in South Africa. An analysis of nearly 4000 serum samples from 87 species demonstrated the presence of anti-CCHFV antibodies in scrub hares and in buffalo and other large animals, suggesting that the virus is maintained among wild vertebrates and "spills over" into domestic animals (Shepherd et al., 1987b). On the dairy farm where the 1985 outbreak occurred, many cattle were positive for anti-CCHFV antibodies (Swanepoel et al., 1985). While nearly 30\% of cattle were seropositive in regions where Hyalomma ticks were present, few positives were detected in coastal areas, where that tick species was not observed (Swanepoel et al., 1987). A later study found that the prevalence of antibody-positive sheep was highest on farms where human infections had occurred (Fisher-Hoch et al., 1992).

A unique feature of CCHF in South Africa is the occurrence of the disease in workers on ostrich farms, through exposure to ticks while slaughtering and skinning the birds (van Eeden et al., 1985a) (Swanepoel et al., 1998). A survey found that about onefourth of ostriches in farms where CCHF was seen had antibodies to CCHFV, but none of some 500 other birds showed evidence of virus exposure (Shepherd et al., 1987a). Experimental infection showed that ostriches develop several days of viremia of sufficiently high titer to infect ticks. The hazard to humans who handle ostriches has been reduced through the use of acaricides and the imposition of a 30-day quarantine before slaughter.

CCHFV also circulates in Sudan, as indicated by the detection of seropositive livestock, the occurrence of sporadic human cases and a recent nosocomial outbreak (Aradaib et al., 2011). In Kenya, the virus has been identified by RT-PCR in Hyalomma ticks collected from livestock, and antibodies were detected in local residents (Lwande et al., 2012; Sang et al., 2011). Reports published during the past decade of cases or outbreaks in Mauritania and Senegal include summaries of earlier studies of the circulation of CCHFV in those and other African countries (Nabeth et al., 2004a) (Nabeth et al., 2004b).

\section{Genetic diversity of CCHFV}

As a means of studying the evolutionary history of CCHFV and the mechanisms responsible for its marked degree of sequence diversity, a number of research groups have generated phylogenetic trees of the S-, M- and L-segments of the viral genome. Such trees have often been based on partial or complete sequences of the S-segment, because the largest number of sequences have been archived. However, the most informative phylogenetic analyses have made use of the more limited number of complete S-, Mand L-gene sequences that are available in GenBank.

To create up-to-date phylogenetic trees for this paper, we utilized 52 full-length S-segment, $35 \mathrm{M}$-segment and $30 \mathrm{~L}$-segment sequences (for methods, see the legend of Fig. 8). Because trees generated using ML and Bayesian algorithms exhibited the same topology, only the ML trees are shown (Figs. 8-10). Within each of the trees, we identified six separate viral lineages or clades originating from the same branch points, indicating that their members share a common ancestor. We have labeled these clades I$\mathrm{VI}$, using the system employed by some other investigators (Carroll et al., 2010). As shown in Table 7, other researchers have identified 7 , rather than 6 virus lineages, and have utilized a different labeling system. However, this apparent disagreement seems to reflect differing perceptions of the relationships among closely-related branches, rather than an actual difference in the structures of phylogenetic trees.

As noted above, CCHFV displays the greatest degree of sequence diversity of any arbovirus, with divergence of 20,22 and $31 \%$ among the S-, L- and M-segments of virus isolates. This marked variation, reflected in the breadth of the phylogenetic trees, can be attributed to the progressive accumulation of copying errors by the RNA-dependent RNA-polymerase (RdRp) (genetic "drift"). Analysis of the phylogenetic trees shown in Figs. 8-10 also reveals evidence of the following:

- the existence of discrete lineages or clades of viruses that share a common ancestor, most (but not all) of which were isolated in the same geographic region;

- the occurrence of long-distance virus transfer, as shown by the presence within the same clade of viruses isolated in widely distant locations;

- the occurrence of genetic reassortment, as shown by the nonhomologous locations of the $\mathrm{S}, \mathrm{M}$ and $\mathrm{L}$ segments of some viruses within their respective phylogenetic trees, indicating that the segments have different evolutionary histories;

- the occurrence of genetic recombination, resulting in more subtle differences in the location of individual viruses within phylogenetic trees, reflecting the abrupt sequence discontinuities found when genome segments are aligned.

These 5 processes have all contributed to the present genetic diversity of CCHFV; each will now be discussed in turn.

\subsection{Genetic drift}

Sequence changes introduced by the error-prone RdRp have provided the underlying diversity required for natural selection to shape the evolution of CCHFV, facilitating its adaptation to many different tick and vertebrate hosts. Its broad genetic diversity contrasts with the much closer sequence homology of other arboviruses, such as Rift Valley fever virus, whose evolution appears to have been more constrained by the requirement to replicate in a few vertebrate and mosquito species (Weaver, 2006). The extensive sequence diversity of CCHFV may increase the likelihood that strains introduced into new geographic regions will be able to circulate in local ticks and infect local vertebrates. Future research should therefore examine the vector competence of ticks in regions potentially threatened by the geographic spread of CCHFV.

The greater genetic diversity of the CCHFV M segment, compared to the S- and L-segments, reflects the critical role the $G_{N}$ 


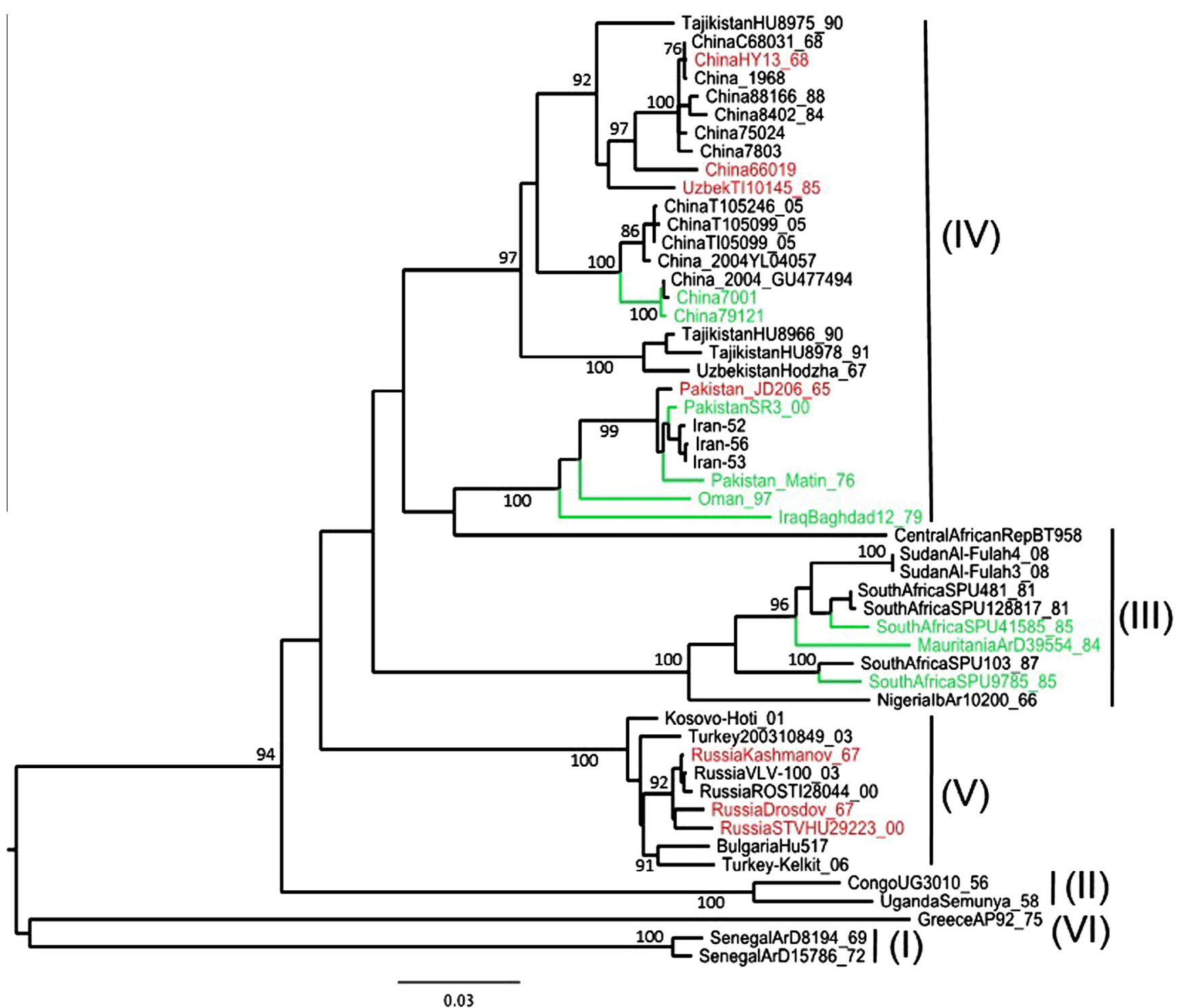

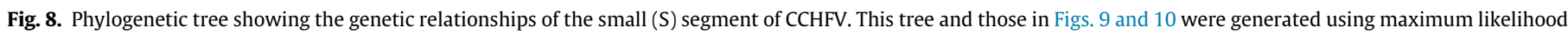

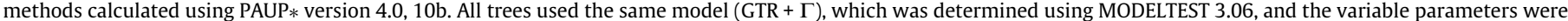

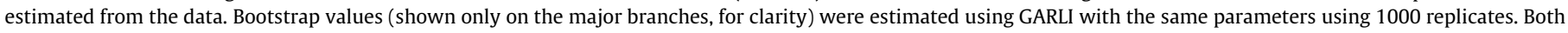

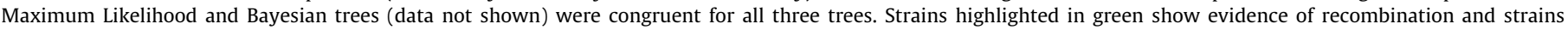
highlighted in red show evidence of reassortment.

and $G_{C}$ glycoproteins in the viral life cycle. Because they are responsible for binding to cell-surface receptors, underlying diversity in the sequence of these proteins facilitates the infection by CCHFV of many different tick and vertebrate hosts. Recent efforts to determine whether $M$ segment sequence diversity is greater in viruses recovered from vertebrates or from ticks have been inconclusive (Ozkaya et al., 2010). Within the M segment, the greatest degree of diversity is seen in the region encoding the glycoprotein mucin-like domain, while regions encoding portions of protein structure involved in intracellular processing and maturation are more highly conserved (Papa et al., 2002c; Vincent et al., 2003).

Interestingly, even though $\mathrm{G}_{\mathrm{N}}$ and $\mathrm{G}_{\mathrm{C}}$ show a high level of diversity at the nucleotide level, this does not appear to translate to greater antigenic diversity. There in fact appears to be little variation in antigenic sites among CCHF viruses, which form a single antigenic group, by which they are distinguished from other nairoviruses, such as HAZV (Buckley, 1974; Foulke et al., 1981). More subtle antigenic difference within the CCHFV group have been de- fined using monoclonal antibodies (Ahmed et al., 2005), but it is unclear how such variation affects cross-protection among viruses in vertebrate hosts. Improved understanding of cross-protection among CCHFV strains is needed for vaccine development; such data may be difficult to derive from naturally occurring infections of humans or animals, but could potentially be obtained through studies in recently developed mouse models of CCHF (see below).

In contrast to the $\mathrm{M}$ segment, the $\mathrm{L}$ segment shows a much greater degree of sequence conservation, with up to $90 \%$ amino acid identity across strains (Deyde et al., 2006; Kinsella et al., 2004; Meissner et al., 2006a). This analysis indicates that the segment has evolved more slowly, and shows a correspondingly longer time to the most recent common ancestor, than the S- and Msegments (Carroll et al., 2010). Such reduced variation presumably reflects essential requirements for the efficient function of the $\mathrm{RdRp}$. However, closer analysis of the $\mathrm{L}$ gene has revealed a region of enhanced variability from amino acid positions 760-810, which shares only $40 \%$ sequence identity among CCHFV strains sequenced to date. The existence of this variable region has been 


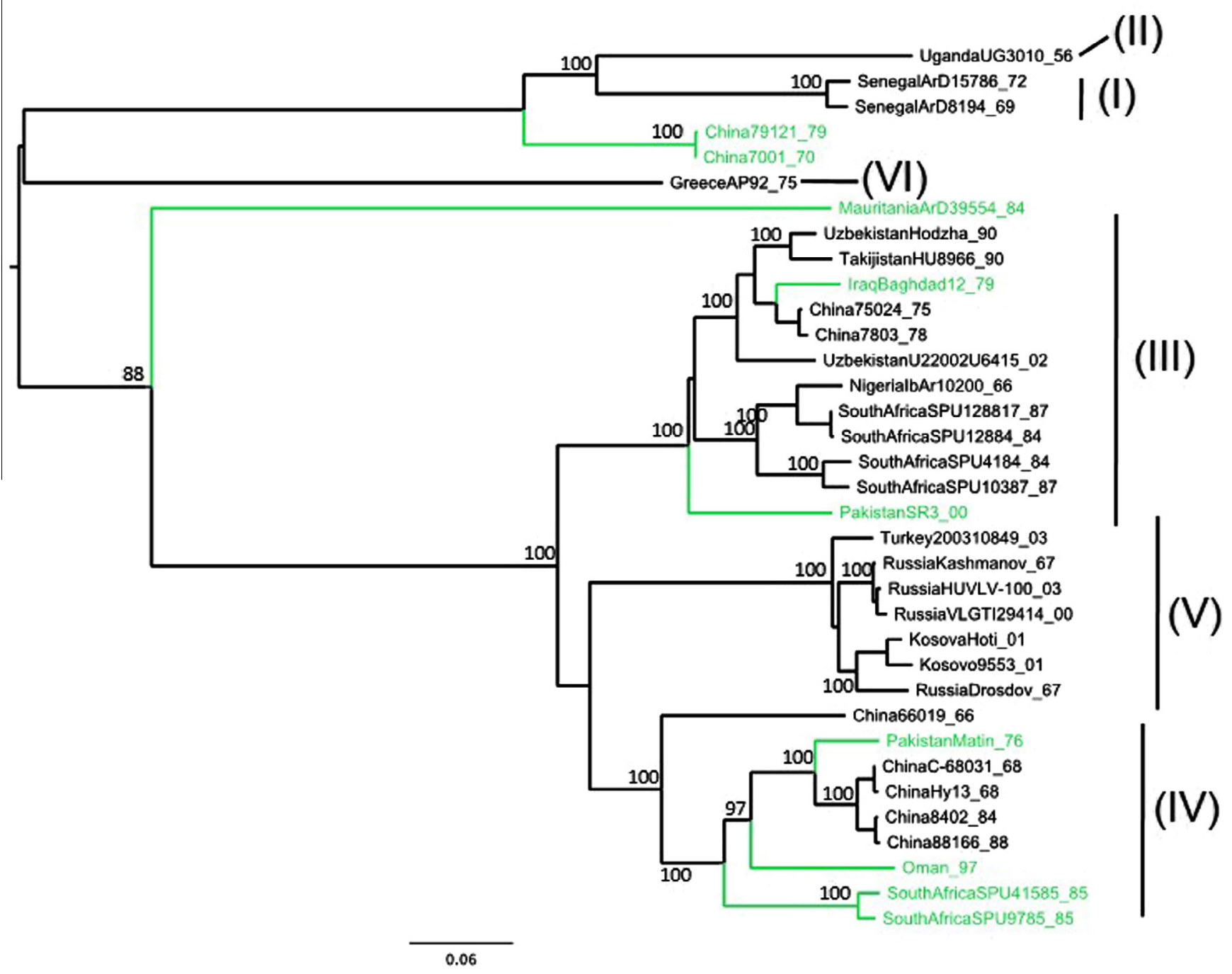

Fig. 9. Phylogenetic tree showing the genetic relationship of CCHFV medium (M) segments. For methods and color coding, see legend of Fig. 8.

exploited for phylogenetic analysis (Meissner et al., 2006a; Meissner et al., 2006b).

Three research groups have used sequence data to estimate the rate at which CCHFV is evolving over time (Anagnostou and Papa, 2009; Carroll et al., 2010; Chen, 2012). Both found that the three genome segments undergo roughly $10^{-4}$ changes per nucleotide per year, or about two base changes per year for the entire genome. Carroll et al. observed that the rate of evolution of CCHFV was somewhat slower than that reported for the mosquito-borne bunyavirus, Rift Valley fever virus and the tick-borne flavivirus, Kyasanur Forest disease virus (Bird et al., 2008; Mehla et al., 2009), but the differences were modest. Because the evolutionary rate of a virus is simply a way of measuring its genetic diversity, both groups reported that the CCHFV $M$ segment was evolving more rapidly than the $\mathrm{S}$ or $\mathrm{L}$ segment. A more recent paper investigated whether the presence of reassortant viruses influenced the calculated evolutionary rates, and concluded that this resulted in some inherent bias (Chen, 2012); this finding should be confirmed using a larger dataset. Based on their data, Carroll et al. concluded that current CCHF viruses have evolved from an ancestral agent that existed roughly 3000 years ago, and suggested that the spread of livestock farming may have contributed to its geographic dispersion.

To date, no studies have focused on the extent of genetic diversity among the population of viruses infecting a single tick or vertebrate host. Factors that might influence such diversity for tick-borne viruses might include a low level of viral replication within the tick, resulting in a smaller population, or bottlenecks created by transstadial and vertical transmission. CCHFV population diversity might also be affected by the occurrence of co-feeding transmission, which would reduce the need for viral replication in vertebrate hosts (Ebel and Kramer, 2004; Labuda et al., 1994).

\subsection{Formation of discrete genetic lineages}

As discussed above, phylogenetic analysis has revealed the existence of some 6 or 7 discrete CCHFV lineages or clades; the labels assigned to these clades by various investigators are listed in Table 7 (Anagnostou and Papa, 2009; Burt and Swanepoel, 2005; Deyde et al., 2006; Duh et al., 2008; Hewson et al., 2004a; Meissner et al., 2006a; Morikawa et al., 2002; Yashina et al., 2003a; Yashina et al., 2003b). The existence of such clades appears to reflect the fact that CCHFV is not found across a single homogenous geographic region, but circulates in multiple areas that are separated from each other to varying degrees by topographic barriers. Differences of climate, vegetation and other conditions among these areas have led to the evolution of distinct species of ticks and vertebrates, and the progressive adaptation of CCHFV to these regionspecific hosts has led to the emergence of local virus variants. This pattern is most visible in the overlapping distribution of virus clades and various Hyalomma species, consistent with a lengthy 


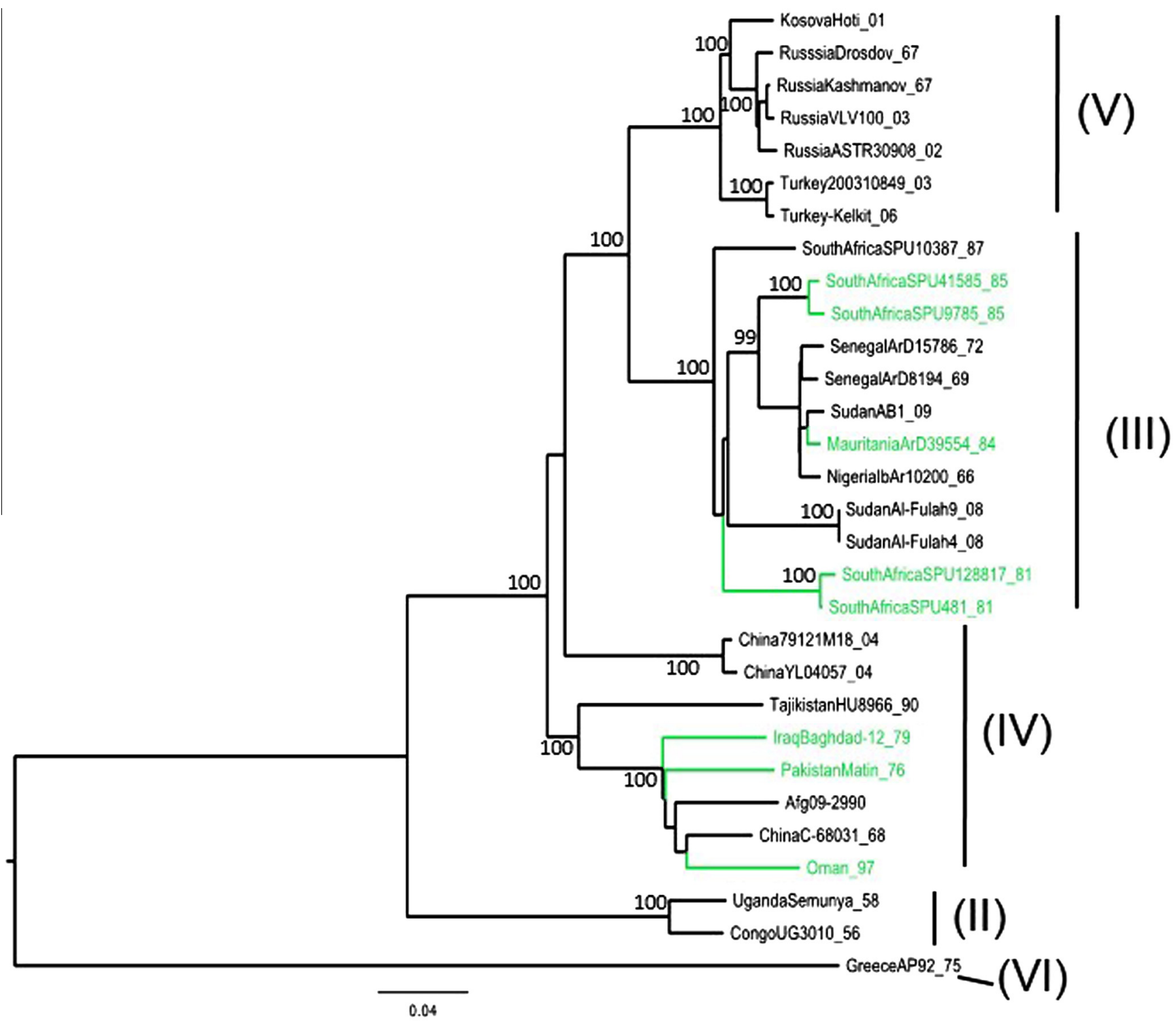

Fig. 10. Phylogenetic tree showing the genetic relationship of CCHFV large (L) segments. For methods and color coding, see legend of Fig. 8.

history of co-evolution of the virus with its tick vectors. A similar pattern has been observed for tick-borne flaviviruses (Lobo et al., 2009). The relative regional homogeneity of CCHFV has been demonstrated in Turkey by a systematic sampling of local isolates, which showed little genetic diversity and no evidence of "invasion" by strains from other regions, suggesting that the marked increase in CCHF that has occurred in Turkey over the past decade has been caused by viruses indigenous to the country (Kalaycioglu et al., 2012).

In an attempt to understand the relationship between the evolution over time and geographic distribution of the various clades/lineages of CCHFV, we have superimposed phylogenetic trees of the three viral genome segments onto maps, collapsing each clade into a single node and locating each clade on the map, based on the geographic location of most or all of its member viruses (Figs. 11-13). The phylogeography of the S-segment is shown in Fig. 11. When the S-segment tree is presented as a traditional phylogram, with midpoint rooting, the Greek (clade VI) and West African isolates (clade I) form the root (Fig. 3 and inset). When superimposed on a map, the pattern of branching of clades over their evolutionary history appears to indicate a gradual movement of the virus out of Africa into Europe, then the Middle East and finally to Asia.

The phylogeography of the CCHFV M-segment appears to show the same pattern as the S-segment, with the root (as defined by midpoint rooting) being the Greek (VI) and W. Africa (I) strains (Fig. 12). The reassortant Chinese strain is indicated; for the sake of clarity, other reassortant viruses highlighted in green in Fig. 8 are not shown on the map. The branching pattern of the superimposed M-segment tree also appears to show a progression of the virus out of Africa, but with Europe/Turkey appearing to be a later lineage, compared to the map of the S-segment. In contrast, the L segment shows a very different phylogeography (Fig. 13). While groups (VI) and (II) are basal to the tree, as defined by midpoint rooting, the Asian strains appear to be older than the Europe/Turkey, South Africa and West Africa II strains. As defined by the phylograms (Figs. 8-10), the Greek AP and West African viruses are the oldest lineages, suggesting that CCHFV originated in the European/ African area, probably within the Mediterranean basin. Many more sequences of viruses isolated across the broad geographic range of CCHFV will be required to obtain a clear understanding of its evolutionary history. 


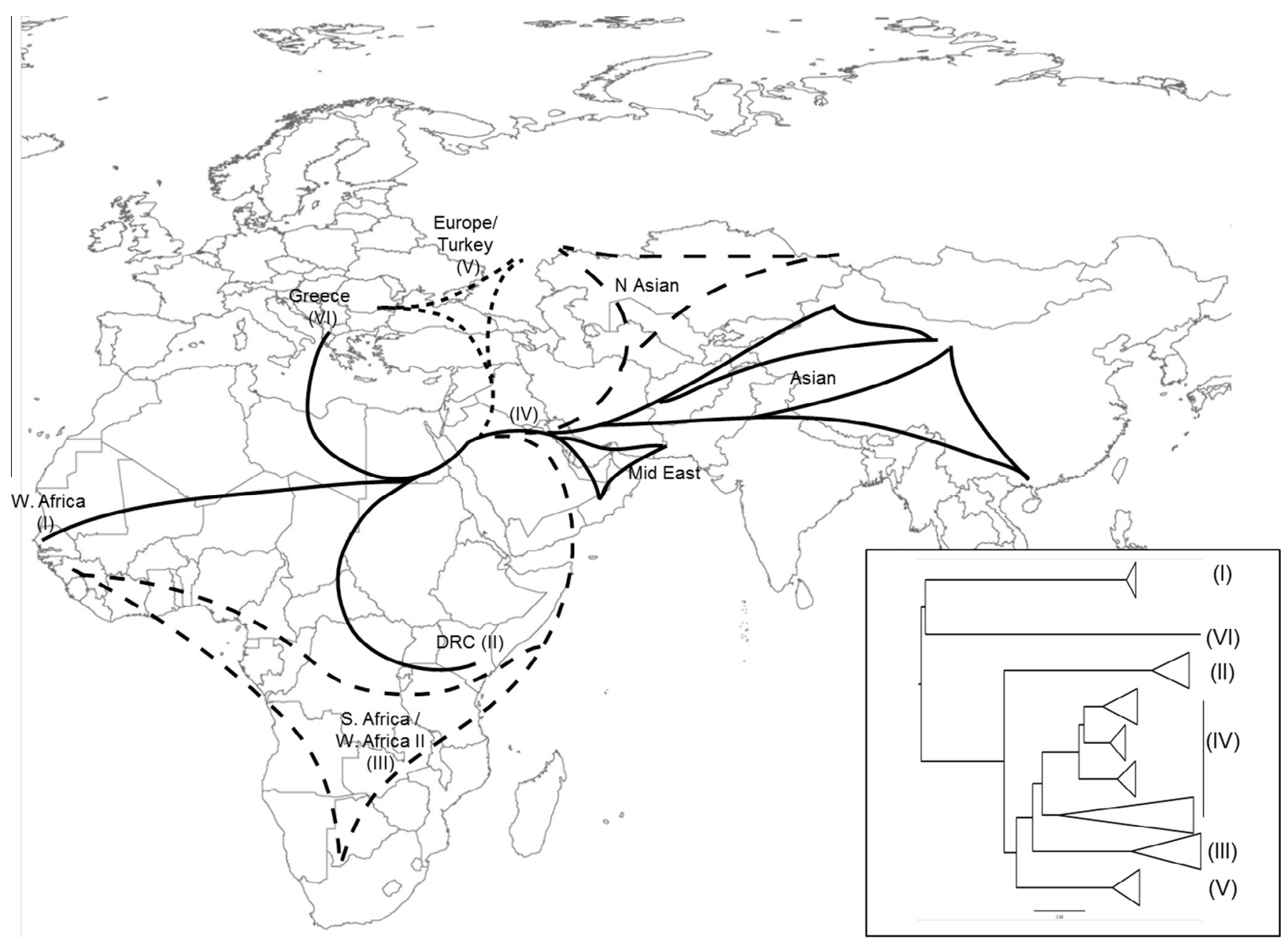

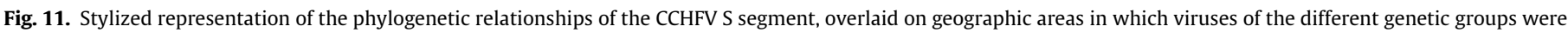

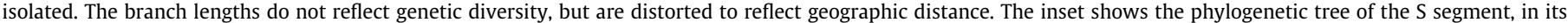
standard presentation.

The adaptation of CCHFV to region-specific hosts, leading to clade formation, could potentially result in differences in its pathogenicity for humans. Careful clinical studies will be required to determine whether viruses with different levels of virulence actually exist. This is well illustrated by the history of the AP92 strain, which was recovered from Rhipicephalus ticks in Greece in 1978 (Papadopoulos and Koptopoulos, 1978), and which differs sufficiently in sequence from other strains to constitute its own clade (Fig. 3). Because no similar viruses were recovered from patients during subsequent decades, the AP92 strain was thought to be avirulent for humans. However, investigators recently recovered closely related agents from patients with mild CCHF in the European portion of Turkey (Elevli et al., 2010; Midilli et al., 2009; Ozkaya et al., 2010). Although the source of infection was not identified, a survey of local tick species revealed that, in addition to Hyalomma, some $30 \%$ were R. bursa. If further investigation confirms that the AP92 virus is less virulent for humans than other strains, it will be of interest to determine if it is maintained exclusively in Rhipicephalus ticks.

\subsection{Evidence of long-distance virus transport}

Examination of the phylogenetic trees in Figs. 3-5 and of the geographic origin of viruses in individual clades (Table 7) shows that several clades contain members from widely distant regions. The geographic separation of viruses with closely related sequences indicates that, although some areas in which CCHF is endemic are separated from each other by topographic barriers, they have apparently been connected through the long-distance transfer of infected ticks, which has made it possible for a strain of CCHFV to leave its "ancestral home" and become established in a new area. The possibility that a vertebrate host might be simultaneously infected by both a local and a newly introduced virus, and that such viruses might be exchanged among ticks during co-feeding, increases the potential for reassortment and recombination to serve as mechanisms of CCHFV evolution (see below).

The long-distance transfer of CCHF viruses could occur through at least two different mechanisms (Mild et al., 2010). The first, which has presumably taken place for millennia, is the transport of infected ticks by migratory birds. As noted above, with the exception of ostriches, there is no evidence that birds are hosts for the replication of CCHFV (Shepherd et al., 1987a). However, many competent tick vectors of CCHFV feed on birds during their larval and nymph stages, and could potentially be carried great distances, should they attach to a bird before it sets off on its migration.

The second possible mechanism of long-distance virus transfer, which has begun relatively recently on the biological time-scale, is the international shipment of livestock, which can introduce infected animals and ticks into areas previously free of disease, or add novel virus strains in regions where CCHFV already circulates. The spread of virus by human migration and trade is a likely 


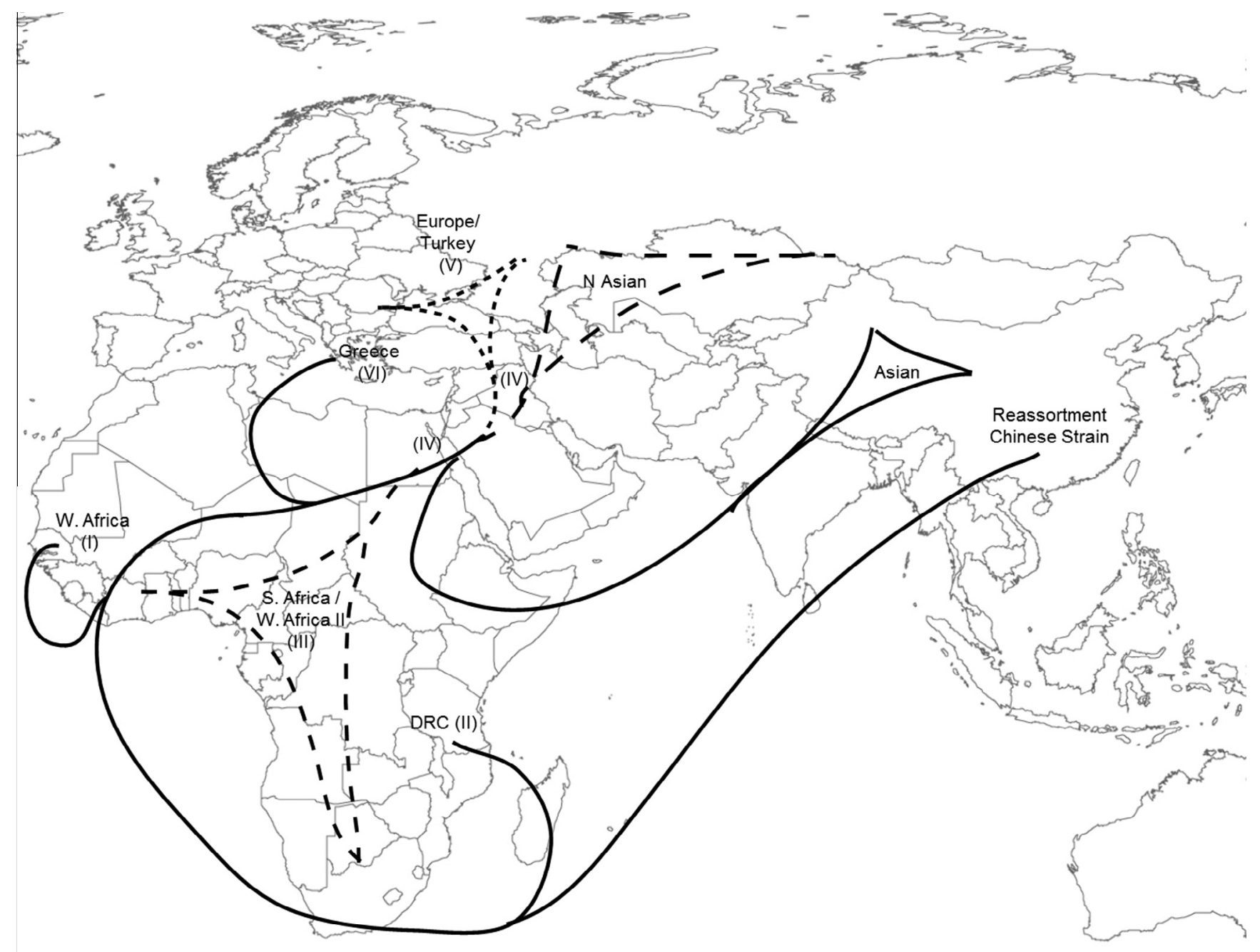

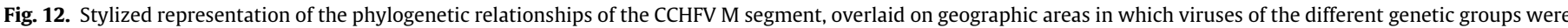

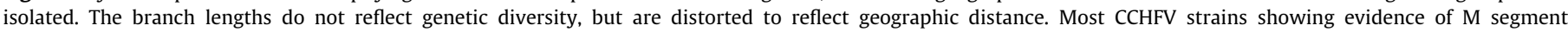
reassortment, as highlighted in Figs. 8-10, have been excluded.

scenario, based on the recent finding that the CCHFV S and the M segments both originated approximately 3000-3500 years ago (Carroll et al., 2010). Interestingly, the investigators found that currently existing $\mathrm{L}$ segments pre-dated them, sharing a common ancestor some 7000 years before the present. This disparity was resolved if the Greek AP92 strain was eliminated from the analysis, suggesting that the L segment of that virus resulted from reassortment with another, unidentified virus. The recovery and sequencing of are large number of CCHFV isolates from many areas will be needed to provide a reliable history of its geographic origin and long-distance transport.

\subsection{Evidence of genetic reassortment}

As discussed above, the movement of CCHFV-infected ticks or livestock between geographic regions makes it possible for a vertebrate or tick to be simultaneously infected by two virus strains with different evolutionary histories. Because the virus has a trisegmented genome, co-infection can potentially generate viruses with novel S, M and L segment combinations \{Burt, 2009 \#99; Hewson, 2004 \#8; Chen, 2013 \#43\}. Because replication in mammals is relatively brief, while ticks remain infected throughout their several-year lifetimes, and may accumulate multiple strains of CCHFV during repeated rounds of blood feeding, co-infection of cells by two viruses is more likely to occur in ticks than in vertebrates (Davies et al., 1987; Jones et al., 1987a).

The occurrence of reassortment is easiest to recognize when the two parental viruses are genetically diverse, such that their $\mathrm{S}, \mathrm{M}$ and L segments are located in different clades, or occupy different relative positions within the same clade. For CCHFV, evidence of reassortment is seen most frequently as an anomaly in the position of the $\mathrm{M}$ segment, while the $\mathrm{S}$ and $\mathrm{L}$ segments occupy similar positions within their phylogenetic trees (Chamberlain et al., 2005). Several viruses showing evidence of such M-segment reassortment are highlighted in green in Figs. 3-5. This tendency of the S and L segments to remain together suggests that virus with a NP and RdRp that have evolved together will replicate more efficiently than one in which those proteins have separate evolutionary histories, while variation in $G_{N}$ and $G_{C}$ has less effect (Chamberlain et al., 2005).

Although co-infection of a tick or vertebrate by differing CCHFV strains has presumably occurred throughout the history the virus, the development of distinct viral clades has increased the importance of genetic reassortment as an evolutionary mechanism, as progeny viruses may potentially display novel phenotypes, including an altered capacity for transmission among ticks and vertebrates and reduced or increased virulence for humans. Studies of another bunyavirus, Ngari virus, have shown that reassortment 


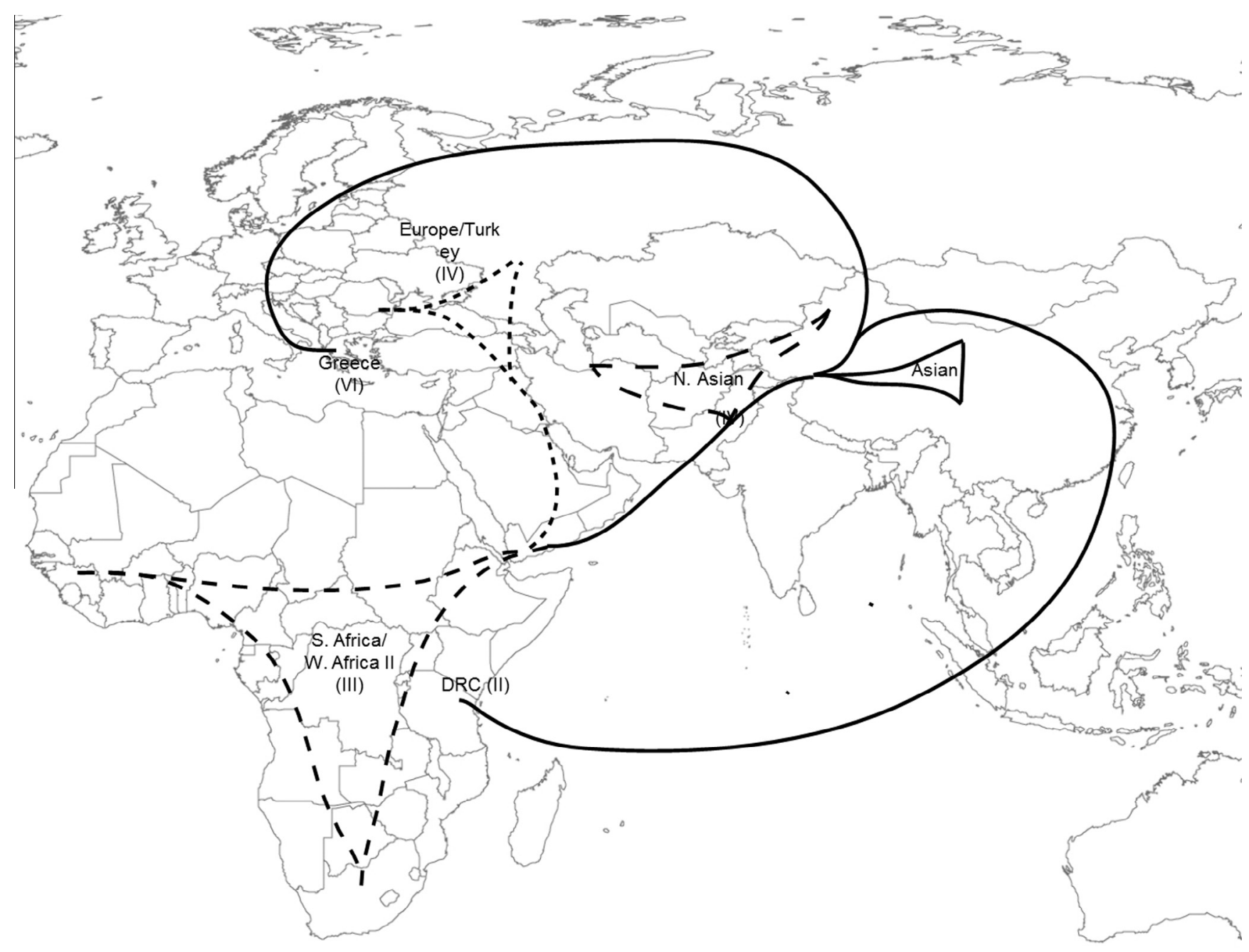

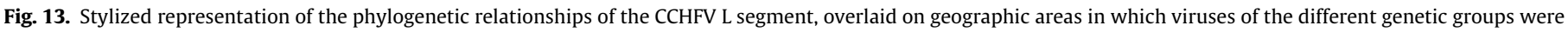
isolated. The branch lengths do not reflect genetic diversity, but are distorted to reflect geographic distance.

can result in changes in virulence (Briese et al., 2004). In the only study that has attempted to assess such differences for CCHFV, Burt and colleagues observed a higher mortality rate among South African patients infected by viruses whose $M$ segments mapped to Asian clades (Burt et al., 2009).

\subsection{Evidence of genetic recombination}

Alignment of the genome segments of some CCHF viruses has revealed points of abrupt discontinuity, consistent with a history of strand exchange through recombination (Hewson et al., 2004a; Lukashev, 2005). Bootscan analysis has shown the clearest evidence of recombination in the S segment (Lukashev, 2005). The data suggest that genetic exchanges were rare events, and that strand exchanges had not occurred during the recent history of the virus. Potential recombinant strains identified by Carroll et al. (2010) are highlighted in red in Figs. 8-10.

\section{Clinical and laboratory features of CCHF}

\subsection{Clinical features}

Although many infections with CCHFV result in a mild, nonspecific febrile illness, some patients develop severe hemorrhagic disease. In the 1944 Crimean outbreak, hospitalized patients showed a sudden onset of fever, accompanied by weakness, headache and muscular pains, vomiting, marked hyperemia of the face and oropharynx, a hemorrhagic rash with development of ecchymoses and bleeding from the nasopharynx, gastrointestinal tract and other sites (Grashchenkov, 1945). Similar findings were reported in case series and outbreak reports from South Africa, Turkey and Kosovo (Swanepoel et al., 1989; Ergonul, 2006).

As summarized by Hoogstraal (1979), the course of CCHF can be divided into four phases: incubation, prehemorrhagic, hemorrhagic and convalescent. The length of the incubation period appears to depend in part on the mode of acquisition of virus. Following a tick bite, it ranges from 1-5 days, while it is usually 5-7 days following contact with infected blood or tissues, with a maximum of 13 days (Ergonul, 2006; Ergonul et al., 2006c). It has been suggested that immunological effects of substances in tick saliva play a role in accelerating viral dissemination (Jones et al., 1992; Kocakova et al., 1999; Nuttall and Labuda, 2004).

The prehemorrhagic phase of CCHF is characterized by fever, lassitude and a variety of nonspecific signs and symptoms; clinicians aware of an appropriate exposure history may make a diagnosis by RT-PCR. The hemorrhagic phase typically begins on day 3-5 of illness (Ergonul, 2006). Its most common initial manifestation is a petechial rash of the skin, conjunctiva and other mucous membranes, which progresses to large cutaneous ecchymoses 
(Fig. 7) and bleeding from the gastrointestinal and urinary tracts (Swanepoel et al., 1989). Hepato- and splenomegally are common. In fatal cases, death generally occurs on day 5-14, as a result of hemorrhage, multi-organ failure and shock. Cerebral hemorrhage may occur, as well as bleeding from the vagina and the abdominal musculature.

In patients who survive CCHF, full recovery may take up to a year (Ergonul, 2006). An early report from South Africa noted that recovering patients often experienced a variety of health problems, including weakness, hair loss, poor appetite, polyneuritis, hearing loss, impaired memory and vision and hepatorenal insufficiency (Swanepoel et al., 1989). However, more recent articles from Turkey and Iran have not described such problems (Bakir et al., 2005; Mardani and Keshtkar-Jahromi, 2007). There has been no documented relapse of infection.

\subsection{Clinical laboratory findings}

Common abnormalities of CCHF patients in standard hospital laboratory tests were described by Swanepoel et al. (1989) and summarized more recently by Ergonul (2008). Hematology testing shows an early leukopenia, with the development of thrombocytopenia during the first week of illness; platelet counts may be extremely low in fatal cases. A fall in the hemoglobin level is also typical of severe disease. At the same time, coagulation abnormalities develop, with prolongation of the prothrombin time (PT) and activated partial thromboplastin time (aPTT), and detection of fibrin degradation products and D-dimers, indicative of disseminated intravascular coagulation (DIC). Progressive hepatic involvement results in increased levels of liver-associated enzymes, alanine and aspartate aminotransferase (ALT and AST), in the serum. As patients become hypotensive, increased blood urea nitrogen (BUN) and creatinine provide a measure of renal insufficiency.

\subsection{Case fatality rate}

As noted above, the reported CFR of CCHF has varied widely, with the percentage of fatal cases in some small series exceeding $30 \%$ (see Supplementary Table 1). However, the often small samples size of outbreaks and the lack of diagnostic capabilities make it difficult to ensure that all patients with mild illness have been detected and included in the denominator. However, the average CFR for the more than 6000 cases that have occurred in Turkey over the past decade has been approximately $5 \%$, suggesting that the higher rates reported in earlier outbreaks reflect a failure to recognize less severe infections. Despite such observational bias, it is possible that variation in the CFR at different times and places reflects either the quality of medical care and treatment or differences in virulence of circulating CCHFV strains.

\subsection{Predictors of survival or death}

Early identification of severely ill CCHF patients is important, both to ensure that they receive optimal care and to identify those with the highest viral loads, who pose the greatest hazard to health care workers. Experience over the past decade in Turkey has shown that gingival bleeding, ecchymoses, hematemesis, diarrhea, melena, confusion and somnolence are significantly more common in fatal cases (Ergonul et al., 2006a; Cevik et al., 2008; Hatipoglu et al., 2010). Lethal illness was associated with more severe thrombocytopenia, more prolonged PT and aPTT, lower fibrinogen levels and increased serum AST and ALT (Ergonul et al., 2006a; Ozkurt et al., 2006; Onguru et al., 2010). Serum levels of neopterin, a derivative of GTP released by activated macrophages, were higher in fatal than nonfatal cases of CCHF (Onguru et al., 2008). A scoring system for CCHF severity, based on a combination of the patient's age and underlying health status and the clinical and laboratory findings on the day of hospital admission, has recently been proposed (Bakir et al., 2012).

Fatal cases of CCHF reflect the inability of the immune system to control infection, as reflected in weak or absent antibody responses, high titers of circulating virus and markedly elevated serum cytokine levels. Early studies in South Africa found that most patients who went onto survive the disease had detectable antiCCHFV IgM by day 7 and IgG by day 7-9 of illness, while no response was detected in fatally infected individuals (Burt et al., 1994; Shepherd et al., 1989c; van Eeden et al., 1985b). The correlation of antibody responses with survival has been demonstrated more recently in patients in Turkey and Kosovo (Ergonul et al., 2006a; Saksida et al., 2010).

Failure to control viral replication results in elevated serum virus titers ("viral load") and more intense systemic inflammatory responses. For example, a study of 36 patients in Turkey found that 8 of 9 fatal cases had peak serum virus levels $>10^{9}$ viral genome copies/mL, whereas the peak levels of 25 of 26 survivors were below that level (Cevik et al., 2007). Similar observations have been made in Kosovo and Albania (Duh et al., 2007; Papa et al., 2006). Studies in both countries have shown that serum viral load is directly related to disease severity (Ergonul et al., 2006b; Saksida et al., 2010). In Kosovo, fatally infected patients had the highest levels of TNF- $\alpha$, IFN- $\gamma$ and IL-10, while the Turkish study found that fatality was correlated with elevated IL- 6 and TNF- $\alpha$, but not IL-10.

\section{Diagnosis}

CCHF should be suspected when a person with an appropriate exposure history becomes acutely ill with fever, malaise and other nonspecific signs and symptoms, together with physical findings suggestive of vascular leak and coagulation defects. Suspicion is strengthened if the initial laboratory evaluation shows leukopenia, thrombocytopenia and elevated serum AST and ALT levels. A specific diagnosis may be made by testing a serum specimen for viral RNA by RT-PCR and for virus-specific IgM and/or IgG by ELISA or other methods. The recovery of infectious virus was long considered the "gold standard" for diagnosis, but it requires Biosafety Level 4 containment, which is not available in any CCHF-endemic country except for South Africa. In view of its speed, sensitivity and safety, RT-PCR should now be considered the standard diagnostic method.

CCHF patients are usually viremic during the first 7-10 days of illness. Virus-specific IgM becomes detectable by the end of the first week, with IgG appearing shortly thereafter. Clinicians caring for an acutely ill patient should therefore test for viral RNA and for IgM, if both assays are available. However, because severely ill patients may fail to develop an antibody response, RT-PCR is the most reliable diagnostic method; by measuring viral load, it also provides an index of disease severity and the likelihood of death. Virus-specific IgM clears after several months, while IgG persists much longer. The presence of anti-CCHFV IgG in a person with an appropriate illness history may therefore be used to make a retrospective diagnosis.

A number of recent articles have reviewed diagnostic techniques for CCHF or assessed their sensitivity and accuracy. Current laboratory assays and commercially available kits are listed by Mertens et al. (2013). Dowall et al. (2012b) have described a novel ELISA method, based on recombinant viral NP that was able to sensitively detect virus-specific IgM and IgG in patient samples from Turkey, Tadjikistan and Kosovo. An international quality assessment of conventional and real-time RT-PCR assays for CCHFV found that nearly half of the 44 participating laboratories 
performed suboptimally on a panel of samples (Escadafal et al., 2012). A comparison of several commercially available IFA, ELISA and RT-PCR kits found them all to have excellent specificity, but their sensitivities were generally less than 90\% (Vanhomwegen et al., 2012).

Concerns that sequence-based diagnostic assays may not detect all strains of CCHFV are based on its wide genetic diversity. Although the first RT-PCR assays could identify viruses from most clades or geographic regions (Duh et al., 2006; Garrison et al., 2007; Wolfel et al., 2007), they were unable to recognize the highly divergent AP92 strain. However, a recently reported assay targeting a highly conserved portion of the $5^{\prime}$-noncoding region of the viral S segment, which is apparently required for "panhandle" formation and genome replication, is able to detect viruses in all 7 clades, including AP92 (Atkinson et al., 2012a). As more specimens are obtained from humans, animals and ticks throughout endemic regions, and as the virus continues to evolve over time, further refinements in sequence-based diagnostic methods may be needed.

\section{Therapy}

\subsection{General supportive measures}

Most CCHFV infections are either asymptomatic or result in a nonspecific febrile illness that does not require hospitalization or specific therapy. In the small percentage of patients who develop hypotension and hemorrhage, current medical management is largely supportive. The fall in blood pressure and diminished organ perfusion that result from increased vascular permeability call for volume replacement, usually with intravenous fluids, with careful monitoring to prevent the development of pulmonary edema. Coagulation abnormalities may be countered through the provision of fresh frozen plasma and platelets, while the occurrence of significant hemorrhage will require blood transfusion. Several recent articles by clinicians experienced with the therapy of CCHF provide advice and algorithms for the treatment of adult and pediatric patients (Ergonul, 2008; Leblebicioglu et al., 2012; Mardani et al., 2010). A recent report from Turkey suggested that a combination of high-dose methylprednisolone, intravenous immunoglobulin and fresh-frozen plasma was beneficial, but the authors did not include a control group (Erduran et al., 2012).

\subsection{Ribavirin}

Ribavirin, a guanosine analogue licensed for the treatment of respiratory syncytial virus infections and hepatitis $C$, has been used to treat CCHF patients for more than two decades. Inhibition of CCHFV replication has been demonstrated in a minigenome system (Bergeron et al., 2010), in virus-infected cells (Huggins, 1989; Watts et al., 1989; Paragas et al., 2004), in newborn mice (Tignor and Hanham, 1993) and in STAT-1 KO mice (Bente et al., 2010). Comparisons of a number of virus strains found that they differed no more than a few-fold in sensitivity to the drug (Watts et al., 1989; Paragas et al., 2004).

The use of ribavirin for the treatment of CCHF has been reviewed in detail in two recent articles (Soares-Weiser et al., 2010; Keshtkar-Jahromi et al., 2011). The drug was first employed in 1985, when it was given as postexposure prophylaxis in a nosocomial outbreak in South Africa (van de Wal et al., 1985). Ten years later, 3 CCHF patients in Pakistan were treated with ribavirin and appeared to respond rapidly to therapy (Fisher-Hoch et al., 1995). Apparently beneficial results were subsequently described in observational studies from Iran and Turkey, which lacked control groups (Smego et al., 2004; Jabbari et al., 2006; Midilli et al., 2007).
As the increased numbers of CCHF patients seen during the past decade have made larger comparisons possible, investigators have generally found that ribavirin is beneficial, so long as it is initiated early in the course of illness (Mardani et al., 2003; Ergonul et al., 2004; Alavi-Naini et al., 2006). (Tasdelen Fisgin et al., 2009). However, a recent attempt to identify a benefit of ribavirin in a randomized clinical trial was unable to show that treatment significantly altered the disease (Koksal et al., 2010). A review of 21 published observational and experimental studies of ribavirin therapy concluded that, although most reports claimed a therapeutic benefit, the quality of the evidence was low (Soares-Weiser et al., 2010). The authors concluded that "a randomized controlled trial in the context of good quality supportive care is justified." No report has described any serious adverse effects of ribavirin therapy.

\subsection{Antibody therapy}

Anti-CCHF immune globulin, prepared from the plasma of disease survivors, was recommended as therapy by Chumakov at the time of the 1944-1945 Crimean outbreak, but subsequent assessments in the Soviet Union found little evidence of benefit (Leschinskaya, 1970). Nonetheless, immune globulin therapy was introduced in Bulgaria, where it remains in use (Vassilev et al., 1991; Papa et al., 2004; Christova et al., 2009). A 1990 article described the rapid improvement of patients treated with intramuscular and intravenous anti-CCHF immunoglobulin, but its efficacy has still not been assessed in a randomized clinical trial (Vassilenko et al., 1990). In the 1985 nosocomial outbreak in South Africa, clinicians prepared hyperimmune serum from recovering individuals and administered it to 6 patients, and noted that 4 of them showed transient improvement in symptoms (van Eeden et al., 1985b). Similarly, a study of hyperimmune globulin therapy in Turkey described clinical improvement of patients following treatment, but it did not include a control group (Kubar et al., 2011).

\subsection{Other antiviral therapies}

Type I interferon (IFN) inhibits CCHFV replication in vitro; the mechanism appears to include the induction of MxA expression (Andersson et al., 2004; Andersson et al., 2006; Karlberg et al., 2010). In the only reported clinical use, human IFN was given to 6 patients in the 1985 Tygerberg outbreak in South Africa, but no benefit was observed (van Eeden et al., 1985b).

\section{Pathogenesis of CCHF}

When CCHF was first identified in 1944, it was clear that its major pathologic abnormality was vascular dysfunction, resulting in hemorrhage and loss of fluid from the plasma into the interstitial space. Soviet clinicians referred to the disease as "infectious capillary toxicosis," based on autopsy findings that "the main pathologic process in the organs is caused by blood circulatory disturbances, chiefly in capillaries and small vessels..." (Grashchenkov, 1945). Since that time, it has been found that CCHF patients display abnormal coagulation parameters from an early stage of illness, and that severe disease is characterized by disseminated intravascular coagulation (DIC) (Burt et al., 1997; Swanepoel et al., 1989). However, it is not known whether vascular dysfunction is brought about directly, through viral infection of the endothelium, or indirectly, through the effects of circulating proinflammatory mediators.

The only current evidence that CCHFV can directly infect the human vasculature is a 1997 report on necropsies of 12 cases, which described the detection of viral RNA and antigens in 
mononuclear phagocytes, hepatocytes and endothelial cells (Burt et al., 1997). However, the presence of virus in the endothelium at the time of death does not necessarily mean that it was the cause of increased vascular permeability, which apparently begins soon after the onset of illness. Instead, vascular leak, a procoagulant state and hemorrhage can all be brought about by an intense systemic inflammatory response, and are typical features of septic shock induced by Gram-negative bacterial infection (Bray and Mahanty, 2003). Laboratory animal studies of Ebola HF, which shares many features with CCHF, suggest that altered vascular function results from host-induced mechanisms, including the induction of proinflammatory cytokines, platelet aggregation and degranulation, leukocyte adhesion and activation of the intrinsic coagulation cascade (Mahanty and Bray, 2004; Schnittler and Feldmann, 2003). Two recent studies in Turkey found that serum markers of vascular activation, including SICAM-1 and SVCAM-1, were elevated in CCHF patients, and were higher in fatal cases (Ozturk et al., 2010; Bodur et al., 2010); conflicting results were obtained for the marker VEGF. CCHFV infection of cultured human endothelial cells has been shown to cause up-regulation of ICAM-1 and VCAM- 1 and the secretion of IL- 6 and IL-8 (Connolly-Andersen et al., 2009).

The importance of proinflammatory cytokine responses in the pathogenesis of CCHF is supported by several reports. In a study of mild and severe cases in Turkey, high serum levels of TNF- $\alpha$ were associated with serious illness, while IL- 6 was elevated in both mild and severe cases (Ergonul et al., 2006b). The levels of both mediators were significantly higher in fatal than in nonfatal cases. In a large study in Kosovo, fatally infected CCHF patients had high levels of IFN- $\gamma$, TNF- $\alpha$ and interleukin (IL)-10 (Saksida et al., 2010); similarly, an Albanian patient dying of the disease had high serum levels of TNF- $\alpha$, sTNF-R, IL-6, and IL-10 (Papa et al., 2006). These clinical observations are mirrored in laboratory studies showing that CCHFV replicates in human monocyte-derived dendritic cells (DCs), which release proinflammatory cytokines (Connolly-Andersen et al., 2009). Supernatants of infected DCs activated cultured endothelial cells, but this could be blocked by antibodies to TNF$\alpha$. Peyrefitte and colleagues also showed that CCHFV infection of primary human macrophages and DCs induced the release of proinflammatory cytokines (though levels were higher in cells infected with Dugbe virus, a nairovirus that produces only a moderately severe febrile illness in humans) (Peyrefitte et al., 2010).

As noted above, many of these findings are replicated in CCHFVinfected STAT-1 KO mice, which develop elevated serum levels of IL-6, IL-10, IFN- $\gamma$ and TNF- $\alpha$ early in the course of illness (Bente et al., 2010). A loss of lymphocytes through apoptosis, which occurs in Ebola HF through the action of inflammatory mediators, may also occur in CCHF. Recent studies in Turkey and Greece have also documented the occurrence of reactive hemophagocytic lymphohistiocytosis in many patients, which could contribute to pancytopenia (Karti et al., 2004; Tasdelen Fisgin et al., 2008; Papa et al., 2009a). This phenomenon may reflect intense activation of monocytes by high levels of Th1 cytokines.

The lack of animal models of CCHF has hindered research on mechanisms of protective immunity. However, the fact that IFN$\mathrm{KO}$ mice are susceptible to lethal infection indicates the critical role of this antiviral mechanism (Bente et al., 2010; Bereczky et al., 2010). Nitric oxide (NO), a mediator of innate responses, also suppresses CCHFV replication (Simon et al., 2006). A recent study found that natural killer (NK) cells appear to play a role in the host response to CCHF, as greater numbers of circulating NK cells were observed in severe than mild cases, as indicated by serum liver enzyme levels; the highest counts were seen in two fatal cases (Yilmaz et al., 2008). Another study showed a higher percentage of cytotoxic $\mathrm{T}$ cells among circulating lymphocytes in fatal than nonfatal cases; the percentage correlated with viral load (Akinci et al., 2009). As noted, fatally infected CCHF patients typically do not produce detectable IgM or IgG antibodies to the virus, indicating the protective role of the humoral response; whether this failure is linked to the loss of lymphocytes through apoptosis is unclear.

\subsection{Histopathology}

Because of the sporadic nature of the disease and safety concerns in performing necropsies, only a few reports have described histologic abnormalities in fatal cases of CCHF (Baskerville et al., 1981; Joubert et al., 1985; Burt et al., 1997). The principal findings in the liver were eosinophilic necrosis, Kupffer cell hyperplasia and the presence of "Councilman bodies" (eosinophilic necrotic hepatocytes); the overall severity ranged from mild necrosis to widespread damage of hepatic lobules (Burt et al., 1997). Prominent splenic lymphoid apoptosis, with marked lymphocyte depletion, and interstitial pneumonia were also observed.

STAT1-KO mice infected with the 10,200 strain of CCHFV showed pathologic changes at necropsy similar to those seen in humans (Bente et al., 2010). Gross examination of viscera showed petechial hemorrhages of the serosa and intestinal hyperemia, while microscopic study revealed multiple foci of hepatocellular necrosis and prominent lymphocyte depletion and karyrrhectic debris in the spleen, consistent with lymphocyte apoptosis.

\section{Laboratory animal models of CCHF}

Although Soviet scientists claimed the successful transmission of CCHFV to a variety of laboratory animals soon after the 1944 Crimea outbreak, these infections were subsequently recognized to be the result of microbial contamination (Grashchenkov, 1945). Since that time, many researchers have tried unsuccessfully to reproduce the features of human CCHF in mice, rats, hamsters, guinea pigs, rabbits and other laboratory animals (Nalca and Whitehouse, 2007), but only newborn mice were found to be susceptible to infection (see below). Unlike the filoviruses, which produce severe hemorrhagic fever in humans and in all nonhuman primate species tested, CCHFV has not been reported to cause disease in any laboratory primate, though results have been published only for African green monkeys, baboons, and patas monkeys (Butenko et al., 1968; Fagbami et al., 1975; Smirnova, 1979). The failure of CCHFV to cause illness in common laboratory animals has seriously impaired efforts to develop new antiviral drugs and vaccines against the disease.

In vivo laboratory studies of CCHF still focus entirely on its replication in mice. Adult, immunocompetent mice are resistant to the virus, but reports in the 1960s demonstrated that it replicates to high titer in newborn mice when inoculated by the intracerebral or intraperitoneal route (Smirnova, 1979; Tignor and Hanham, 1993). More detailed studies revealed high virus titers in the blood and liver, with infection of macrophages and systemic viral dissemination (Tignor and Hanham, 1993). Although newborn mice can be used to evaluate antiviral drugs that directly inhibit viral replication, they cannot be employed to investigate the pathogenesis of CCHF, elucidate immune responses or assess the protective efficacy of vaccines.

Recent success in developing an infection model in adult mice lacking a type I IFN response were based on in vitro findings that IFN plays a critical role in controlling CCHFV replication (Andersson et al., 2006). Two recent studies using knockout (KO) mice lacking the cell-surface IFN- $\alpha, \beta$ receptor (Bereczky et al., 2010) or the intracellular signal transducer and activator of transcription (STAT)-1 protein (Bente et al., 2010) have shown the importance of the type I IFN response in controlling disease manifestations. IFN receptor-KO mice develop a rapidly progressive disease, with 
high tissue viral RNA levels and hepatomegaly. Similarly, STAT1KO mice develop a lethal systemic infection after exposure to small quantities of CCHFV; many of the clinical manifestations, hematologic and serum chemistry abnormalities, histopathologic changes and immune responses in mice resemble those in CCHF patients (Bente et al., 2010). The mice develop leukopenia and thrombocytopenia, and show progressive elevation of ALT in the serum. Highlevel viral replication in the spleen is accompanied by depletion of lymphocytes, consistent with apoptosis, while hepatic infection results in extensive necrosis. Like human patients, infected mice showed elevated levels of circulating IL-6, IL-10 and TNF- $\alpha$. KO mice express IFN-stimulated genes later in the illness than normal mice, explaining their inability to prevent early viral dissemination (Bowick et al., 2012).

Despite their lack of a functional type I IFN response, IFN-receptor- and STAT1-KO mice can still be used to study CCHF pathogenesis, test the virulence of individual virus strains, evaluate novel antiviral therapeutics and assess cross-protective immunity induced by candidate vaccines. Alternatively, researchers who lack access to BSL-4 containment might perform experiments using another member of the CCHFV serogroup, Hazara virus, which also causes lethal disseminated infection in type I IFN receptor-KO mice, with histopathological changes similar to those described above (Dowall et al., 2012a). This model could potentially be used for initial in vivo screening of antiviral drugs; however, because Hazara virus is apparently avirulent for humans, efficacy against Hazara virus in mice may not accurately predict drug activity against CCHFV in humans.

\section{Vaccines}

A formalin-inactivated mouse-brain CCHF vaccine was developed in the Soviet Union and approved for use in 1970 (Tkachenko et al., 1970). Testing of serum samples from several thousand recipients demonstrated that repeated vaccination induced a low-level neutralizing antibody response; however, its protective efficacy was not evaluated (Tkachenko et al., 1971). A similar vaccine continues to be used in Bulgaria, where it is given to soldiers, medical personnel and other high-risk groups in endemic areas (Papa et al., 2004) (Christova et al., 2010). Sequencing showed that the Bulgarian V42/81 vaccine strain, isolated prior to 1970 , is closely related to other viruses isolated in Bulgaria, Kosovo and Turkey (Papa et al., 2010). Evidence of the vaccine's protective efficacy is based on the recorded incidence of CCHF in the country: in the 21 years before vaccination began in 1974, more than 1100 cases were recorded, but in the subsequent 22 years, the total was only 279. CCHF has never been observed in vaccinated individuals (Todorov et al., 2001). A recent study found that the Bulgarian vaccine elicited both a cellular and humoral response to CCHFV, but neutralizing antibody titers were low, even in persons who had received it 4 times (Mousavi-Jazi et al., 2012).

The lack of laboratory animal models has hampered efforts to develop more effective vaccines for CCHF, and only two studies have appeared in the recent literature. In the first, an experimental multivalent DNA vaccine against Rift Valley fever, tick-borne encephalitis, Hantaan and CCHF viruses proved to be poorly immunogenic in mice (Spik et al., 2006). In a proof-of-concept study, mice exposed orally or parentally to transgenic tobacco plants expressing the CCHFV GN and GC developed antibodies to the virus (Ghiasi et al., 2011).

\section{Future geographic range and incidence of CCHF}

A number of investigators have expressed concern that the trend toward warmer climates in central and northern Europe might permit CCHFV to expand outside its current geographic range, through the introduction of infected Hyalomma or other reservoir ticks by migratory birds or the international livestock trade (Gray et al., 2009; Estrada-Pena et al., 2012e; Heyman et al., 2010; Maltezou and Papa, 2010; Mild et al., 2010). It has long been known that larvae and nymphs of ticks indigenous to the Mediterranean region and Africa can be found on birds returning to central and northern Europe from their winter migration. For example, investigators recently identified immature $H$. marginatum on several species of birds in the United Kingdom, and estimated that tens of thousands of such ticks arrive each spring (Jameson et al., 2012). Similarly, the African tick H. rufipes has been recovered from birds as far north as Norway (Hasle et al., 2009). As it has been generally believed that lower mean environmental temperatures north of the Balkans, Alps and Pyrenees (north of $50^{\circ}$ latitude) would prevent these thermophilic ticks from reaching adulthood, the discovery of a matureH. marginatum attached to a person in Germany (Kampen et al., 2007) and of adult ticks of the African species $H$. rufipes feeding on cattle in Hungary (Hornok and Horvath, 2012) was sufficiently unusual to warrant a published report.

Minimum or mean winter temperatures do not appear to be significant factors determining the geographic range of CCHFV vectors, as adult ticks can usually survive prolonged cold (Turell, 2007). Instead, a low cumulative autumn temperature, which prevent the completion of molting of nymphs to adults, appears to be the principal barrier to the spread of competent tick vectors northwards into Europe (Gray et al., 2009; Estrada-Pena et al., 2012d). In addition to the ability to complete the maturation cycle, the establishment of a stable population of Hyalomma or other ticks in a new area requires that newly introduced males and female ticks are able to locate each other, for purposes of copulation, and that they are able to find small and large vertebrates for their blood meals. Although it is possible that global warming will eventually raise temperatures in central Europe to those required for Hyalomma ticks to reach adulthood before the onset of cold weather, a recent mathematical analysis concluded that the establishment of new enzootic foci of CCHF is very unlikely in the foreseeable future (Gale et al., 2011).

The above scenarios are based upon the introduction of competent tick vectors of CCHFV into new regions. A more realistic fear is that the virus might expand its range to countries such as Italy and Spain, where Hyalomma ticks are already present, but CCHF has not been reported. As noted above, this concern was reinforced by the recent detection of CCHFV RNA in H. lusitanicum recovered from wild deer in Spain (Estrada-Pena et al., 2012c). Careful monitoring for human infections in these countries is clearly indicated.

Another route by which CCHFV might expand its geographic range would be to "jump" to ticks other than its current vectors, such as the various ixodid ticks that now transmit tick-borne encephalitis in central Europe and Russia. The opportunity for such a host-switch might occur if ticks of more than one species feed on the same viremic host, or if infected and uninfected ticks of two different species take blood meals in close proximity. Such transmission between tick species presumably occurs in areas such as Turkey, where CCHFV circulates widely and more than one competent vector is present. Careful study of the vector competence of ticks in regions neighboring CCHF-endemic areas is warranted, to evaluate this potential route of virus spread.

\section{Appendix A. Supplementary data}

Supplementary data associated with this article can be found, in the online version, at http://dx.doi.org/10.1016/j.antiviral.2013. 07.006. 


\section{References}

Ahmed, A.A., McFalls, J.M., Hoffmann, C., Filone, C.M., Stewart, S.M., Paragas, J., Khodjaev, S., Shermukhamedova, D., Schmaljohn, C.S., Doms, R.W., BertolottiCiarlet, A., 2005. Presence of broadly reactive and group-specific neutralizing epitopes on newly described isolates of Crimean-Congo hemorrhagic fever virus. J. Gen. Virol. 86, 3327-3336.

Akinci, E., Yilmaz, M., Bodur, H., Onguru, P., Bayazit, F.N., Erbay, A., Ozet, G., 2009. Analysis of lymphocyte subgroups in Crimean-Congo hemorrhagic fever. Int. J. Infect. Dis. 13, 560-563.

Alavi-Naini, R., Moghtaderi, A., Koohpayeh, H.R., Sharifi-Mood, B., Naderi, M., Metanat, M., Izadi, M., 2006. Crimean-Congo hemorrhagic fever in Southeast of Iran. J. Infect. 52, 378-382.

Altamura, L.A., Bertolotti-Ciarlet, A., Teigler, J., Paragas, J., Schmaljohn, C.S., Doms, R.W., 2007. Identification of a novel C-terminal cleavage of Crimean-Congo hemorrhagic fever virus PreGN that leads to generation of an NSM protein. J. Virol. 81, 6632-6642.

Al-Tikriti, S.K., Al-Ani, F., Jurji, F.J., et al., 1981. Congo/Crimean haemorrhagic fever in Iraq. Bull. World Health Organ. 59, 85-90.

Anagnostou, V., Papa, A., 2009. Evolution of Crimean-Congo hemorrhagic fever virus. Infect. Genet. Evol. 9, 948-954.

Andersson, I., Bladh, L., Mousavi-Jazi, M., Magnusson, K.E., Lundkvist, A., Haller, O., Mirazimi, A., 2004. Human MxA protein inhibits the replication of CrimeanCongo hemorrhagic fever virus. J. Virol. 78, 4323-4329.

Andersson, I., Lundkvist, A., Haller, O., Mirazimi, A., 2006. Type I interferon inhibits Crimean-Congo hemorrhagic fever virus in human target cells. J. Med. Virol. 78, 216-222.

Antoniadis, A., Casals, J., 1982. Serological evidence of human infection with CongoCrimean hemorrhagic fever virus in Greece. Am. J. Trop. Med. Hyg. 31, $1066-$ 1067.

Aradaib, I.E., Erickson, B.R., Karsany, M.S., Khristova, M.L., Elageb, R.M., Mohamed, M.E., Nichol, S.T., 2011. Multiple Crimean-Congo hemorrhagic fever virus strains are associated with disease outbreaks in Sudan, 2008-2009. PLoS Negl. Trop. Dis. 5, e1159.

Athar, M.N., Khalid, M.A., Ahmad, A.M., Bashir, N., Baqai, H.Z., Ahmad, M., Balouch, A.H., Bashir, K., 2005. Crimean-Congo hemorrhagic fever outbreak in Rawalpindi, Pakistan, February 2002: contact tracing and risk assessment. Am. J. Trop. Med. Hyg. 72, 471-473.

Atkinson, B., Chamberlain, J., Logue, C.H., Cook, N., Bruce, C., Dowall, S.D., Hewson, R., 2012a. Development of a real-time RT-PCR assay for the detection of Crimean-Congo hemorrhagic fever virus. Vector Borne Zoonotic Dis. 12, 786793.

Atkinson, B., Latham, J., Chamberlain, J., Logue, C., O’Donoghue, L., Osborne, J., Carson, G., Brooks, T., Carroll, M., Jacobs, M., Hopkins, S., Hewson, R., 2012b. Sequencing and phylogenetic characterisation of a fatal Crimean-Congo haemorrhagic fever case imported into the United Kingdom, October 2012. Euro Surveill. 17.

Bakir, M., Engin, A., Gozel, M.G., Elaldi, N., Kilickap, S., Cinar, Z., 2012. A new perspective to determine the severity of cases with Crimean-Congo hemorrhagic fever. J. Vector Borne Dis. 49, 105-110.

Bakir, M., Ugurlu, M., Dokuzoguz, B., Bodur, H., Tasyaran, M.A., Vahaboglu, H., 2005. Crimean-Congo haemorrhagic fever outbreak in Middle Anatolia: a multicentre study of clinical features and outcome measures. J. Med. Microbiol. 54, 385389.

Barandika, J.F., Olmeda, S.A., Casado-Nistal, M.A., Hurtado, A., Juste, R.A., Valcarcel, F., Anda, P., Garcia-Perez, A.L., 2011. Differences in questing tick species distribution between Atlantic and continental climate regions in Spain. J. Med. Entomol. 48, 13-19.

Baskerville, A., Satti, A., Murphy, F.A., Simpson, D.I., 1981. Congo-Crimean haemorrhagic fever in Dubai: histopathological studies. J. Clin. Pathol. 34, $871-874$.

Begum, F., Wisseman Jr., C.L., Casals, J., 1970. Tick-borne viruses of West Pakistan. IV. Viruses similar to or identical with, Crimean hemorrhagic fever (CongoSemunya), Wad Medani and Pak Argas 461 isolated from ticks of the Changa Manga Forest, Lahore District, and of Hunza, Gilgit Agency, W. Pakistan. Am. J. Epidemiol. 92, 197-202.

Bente, D.A., Alimonti, J.B., Shieh, W.J., Camus, G., Stroher, U., Zaki, S., Jones, S.M., 2010. Pathogenesis and immune response of Crimean-Congo hemorrhagic fever virus in a STAT-1 knockout mouse model. J. Virol. 84, 11089-11100.

Bereczky, S., Lindegren, G., Karlberg, H., Akerstrom, S., Klingstrom, J., Mirazimi, A., 2010. Crimean-Congo hemorrhagic fever virus infection is lethal for adult type I interferon receptor-knockout mice. J. Gen. Virol. 91, 1473-1477.

Bergeron, E., Albarino, C.G., Khristova, M.L., Nichol, S.T., 2010. Crimean-Congo hemorrhagic fever virus-encoded ovarian tumor protease activity is dispensable for virus RNA polymerase function. J. Virol. 84, 216-226.

Bergeron, E., Vincent, M.J., Nichol, S.T., 2007. Crimean-Congo hemorrhagic fever virus glycoprotein processing by the endoprotease SKI-1/S1P is critical for virus infectivity. J. Virol. 81, 13271-13276.

Bertolotti-Ciarlet, A., Smith, J., Strecker, K., Paragas, J., Altamura, L.A., McFalls, J.M., Frias-Staheli, N., Garcia-Sastre, A., Schmaljohn, C.S., Doms, R.W., 2005. Cellular localization and antigenic characterization of Crimean-Congo hemorrhagic fever virus glycoproteins. J. Virol. 79, 6152-6161.

Bird, B.H., Githinji, J.W., et al., 2008. Multiple virus lineages sharing recent common ancestry were associated with a Large Rift Valley fever outbreak among livestock in Kenya during 2006-2007. J. Virol. 82, 11152-11166.
Bodur, H., Akinci, E., Ascioglu, S., Onguru, P., Uyar, Y., 2012. Subclinical infections with Crimean-Congo hemorrhagic fever virus, Turkey. Emerg. Infect. Dis. 18, 640-642.

Bodur, H., Akinci, E., Onguru, P., Uyar, Y., Basturk, B., Gozel, M.G., Kayaaslan, B.U., 2010. Evidence of vascular endothelial damage in Crimean-Congo hemorrhagic fever. Int. J. Infect. Dis. 14, e704-e707.

Bowick, G.C., Airo, A.M., Bente, D.A., 2012. Expression of interferon-induced antiviral genes is delayed in a STAT1 knockout mouse model of Crimean-Congo hemorrhagic fever. Virol. J. 9, 122.

Bray, M., Mahanty, S., 2003. Ebola hemorrhagic fever and septic shock. J. Infect. Dis. 188, 1613-1617.

Briese, T., Rambaut, A., Lipkin, W.I., 2004. Analysis of the medium (M) segment sequence of Guaroa virus and its comparison to other orthobunyaviruses. J. Gen. Virol. 85, 3071-3077.

Buckley, S.M., 1974. Cross plaque neutralization tests with cloned crimean hemorrhagic fever-congo ( $\mathrm{CHF}-\mathrm{C})$ and Hazara viruses. Proc. Soc. Exp. Biol. Med. 146, 594-600.

Burney, M.I., Ghafoor, A., Saleen, M., Webb, P.A., Casals, J., 1980. Nosocomical outbreak of viral hemorrhagic fever caused by crimean hemorrhagic feverCongo virus in Pakistan, 1976. Am. J. Trop. Med. Hyg. 29, 941-947.

Burt, F.J., Leman, P.A., Abbott, J.C., Swanepoel, R., 1994. Serodiagnosis of CrimeanCongo haemorrhagic fever. Epidemiol. Infect. 113, 551-562.

Burt, F.J., Paweska, J.T., Ashkettle, B., Swanepoel, R., 2009. Genetic relationship in southern African Crimean-Congo haemorrhagic fever virus isolates: evidence for occurrence of reassortment. Epidemiol. Infect. 137, 1302-1308.

Burt, F.J., Swanepoel, R., 2005. Molecular epidemiology of African and Asian Crimean-Congo haemorrhagic fever isolates. Epidemiol. Infect. 133 659-666.

Burt, F.J., Swanepoel, R., Shieh, W.J., Smith, J.F., Leman, P.A., Greer, P.W., Coffield, L.M., Rollin, P.E., Ksiazek, T.G., Peters, C.J., Zaki, S.R., 1997. Immunohistochemical and in situ localization of Crimean-Congo hemorrhagic fever (CCHF) virus in human tissues and implications for CCHF pathogenesis. Arch. Pathol. Lab. Med. $121,839-846$.

Butenko, A.M., Chumakov, M.P., Smirnova, S.E., Vasilenko, T.I., Zavodova, T.I., Tkachenko, E.A., Rubin, S.G., Stolbov, D.N., 1968. Isolation and Investigation of Astrakhan Strain ("Drozdov") of Crimean Hemorrhagic Fever Virus. Materials From the 15th Scientific Session (English translation NAMRU3-T866). Institute of Poliomyelitis and Viral Encephalitides, pp. 88-90.

Butenko, A.M., Karganova, G.G., 2007. Crimean-Congo hemorrhagic fever in Russia and other countries of the former Soviet Union. In: Ergonul, O., Whitehouse, C. (Eds.), Crimean-Congo Hemorrhagic Fever. Springer, Dordrecht, Netherlands, pp. 99-114.

Carroll, S.A., Bird, B.H., Rollin, P.E., Nichol, S.T., 2010. Ancient common ancestry of Crimean-Congo hemorrhagic fever virus. Mol. Phylogenet. Evol. 55, 1103-1110.

Carter, S.D., Surtees, R., Walter, C.T., Ariza, A., Bergeron, E., Nichol, S.T., Hiscox, J.A., Edwards, T.A., Barr, J.N., 2012. Structure, function, and evolution of the Crimean-Congo hemorrhagic fever virus nucleocapsid protein. J. Virol. 86, 10914-10923.

Casals, J., 1969. Antigenic similarity between the virus causing Crimean hemorrhagic fever and Congo virus. Proc. Soc. Exp. Biol. Med. 131, 233-236.

Casals, J., Henderson, B.E., Hoogstraal, H., Johnson, K.M., Shelokov, A., 1970. A review of Soviet viral hemorrhagic fevers. J. Infect. Dis. 122, 437-453.

Causey, O.R., Kemp, G.E., Madbouly, M.H., David-West, T.S., 1970. Congo virus from domestic livestock, African hedgehog, and arthropods in Nigeria. Am. J. Trop. Med. Hyg. 19, 846-850.

Ceianu, C.S., Panculescu-Gatej, R.I., Coudrier, D., Bouloy, M., 2012. First serologic evidence for the circulation of Crimean-Congo hemorrhagic fever virus in Romania. Vector Borne Zoonotic Dis. 12, 718-721.

Cevik, M.A., Erbay, A., Bodur, H., Eren, S.S., Akinci, E., Sener, K., Onguru, P., Kubar, A., 2007. Viral load as a predictor of outcome in Crimean-Congo hemorrhagic fever. Clin. Infect. Dis. 45, e96-e100.

Cevik, M.A., Erbay, A., Bodur, H., Gulderen, E., Bastug, A., Kubar, A., Akinci, E., 2008. Clinical and laboratory features of Crimean-Congo hemorrhagic fever: predictors of fatality. Int. J. Infect. Dis. 12, 374-379.

Chamberlain, J., Cook, N., Lloyd, G., Mioulet, V., Tolley, H., Hewson, R., 2005. Coevolutionary patterns of variation in small and large RNA segments of CrimeanCongo hemorrhagic fever virus. J. Gen. Virol. 86, 3337-3341.

Chen, S., 2012. Molecular evolution of Crimean-Congo hemorrhagic fever virus based on complete genomes. J. Gen. Virol. 94, 843-850.

Chinikar, S., Ghiasi, S.M., Hewson, R., Moradi, M., Haeri, A., 2010. Crimean-Congo hemorrhagic fever in Iran and neighboring countries. J. Clin. Virol. 47, 110-114.

Chinikar, S., Persson, S.M., Johansson, M., Bladh, L., Goya, M., Houshmand, B., Mirazimi, A., Plyusnin, A., Lundkvist, A., Nilsson, M., 2004. Genetic analysis of Crimean-Congo hemorrhagic fever virus in Iran. J. Med. Virol. 73, 404-411.

Christova, I., Di Caro, A., Papa, A., Castilletti, C., Andonova, L., Kalvatchev, N. Papadimitriou, E., Carletti, F., Mohareb, E., Capobianchi, M.R., Ippolito, G., Rezza, G., 2009. Crimean-Congo hemorrhagic fever, southwestern Bulgaria. Emerg. Infect. Dis. 15, 983-985.

Christova, I., Kovacheva, O., Georgieva, G., Ivanova, S., Argirov, D., 2010. Vaccine against Congo-Crimean haemorrhagic fever virus - Bulgarian input in fighting the disease. Problems Infect. Parasitic Dis. 37, 7-8.

Chumakov, M.P., 1965. A short review of the investigation of the virus of Crimean hemorrhagic fever [Russian; NAMRU-3 translation T189]. In: Chumakov, M.P. (Ed.), Endemic Viral Infections, vol. 7. Sborn. Trud. Inst. Polio. Virus. Encefal., Akad. Med. Nauk USSR, Moscow, pp. 193-196. 
Chumakov, M.P., 1974. On 30 years of investigation of Crimean hemorrhagic fever [Russian; English translation NAMRU3-T950]. Trudi Inst Polio Virusn Entsefalitov Akad Med Nauk SSSR 22, 5-18.

Chumakov, M.P., Butenko, A.M., Shalunova, N.V., Mart'ianova, L.I., Smirnova, S.E., Bashkirtsev Iu, N., Zavodova, T.I., Rubin, S.G., Tkachenko, E.A., Karmysheva, V., Reingol'd, V.N., Popov, G.V., Savinov, A.P., 1968. New data on the viral agent of Crimean hemorrhagic fever. Vopr. Virusol. 13, 377.

Chumakov, M.P., Smirnova, S.E., Tkachenko, E.A., 1970. Relationship between strains of Crimean haemorrhagic fever and Congo viruses. Acta Virol. 14, 82-85.

Clerex-Van Haaster, C.M., Clerex, J.P., Ushijima, H., Akashi, H., Fuller, F., Bishop, D.H. 1982. The $3^{\prime}$ terinal RNA sequences of bunyaviruses and nairoviruses (Bunyaviridae): evidence of end sequence genetic differences within the virus family. J. Gen. Virol. 61, 289-293.

Connolly-Andersen, A.M., Douagi, I., Kraus, A.A., Mirazimi, A., 2009. Crimean Congo hemorrhagic fever virus infects human monocyte-derived dendritic cells. Virology 390, 157-162.

Davies, C.R., Jones, L.D., Green, B.M., Nuttall, P.A., 1987. In vivo reassortment of Thogoto virus (a tick-borne influenza-like virus) following oral infection of Rhipicephalus appendiculatus ticks. J. Gen. Virol. 68 (Pt 9), 2331-2338.

Deyde, V.M., Khristova, M.L., Rollin, P.E., Ksiazek, T.G., Nichol, S.T., 2006. CrimeanCongo hemorrhagic fever virus genomics and global diversity. J. Virol. 80, 88348842.

Dickson, D.L., Turell, M.J., 1992. Replication and tissue tropisms of Crimean-Congo hemorrhagic fever virus in experimentally infected adult Hyalomma truncatum (Acari: Ixodidae). J. Med. Entomol. 29, 767-773.

Dohm, D.J., Logan, T.M., Linthicum, K.J., Rossi, C.A., Turell, M.J., 1996. Transmission of Crimean-Congo hemorrhagic fever virus by Hyalomma impeltatum (Acari: Ixodidae) after experimental infection. J. Med. Entomol. 33, 848-851.

Dowall, S.D., Findlay-Wilson, S., Rayner, E., Pearson, G., Pickersgill, J., Rule, A Merredew, N., Smith, H., Chamberlain, J., Hewson, R., 2012a. Hazara virus infection is lethal for adult type I interferon receptor-knockout mice and may act as a surrogate for infection with the human-pathogenic Crimean-Congo hemorrhagic fever virus. J. Gen. Virol. 93, 560-564.

Dowall, S.D., Richards, K.S., Graham, V.A., Chamberlain, J., Hewson, R., 2012b. Development of an indirect ELISA method for the parallel measurement of IgC and IgM antibodies against Crimean-Congo haemorrhagic fever (CCHF) virus using recombinant nucleoprotein as antigen. J. Virol. Methods 179, 335-341.

Duh, D., Nichol, S.T., Khristova, M.L., Saksida, A., Hafner-Bratkovic, I., Petrovec, M., Dedushaj, I., Ahmeti, S., Avsic-Zupanc, T., 2008. The complete genome sequence of a Crimean-Congo hemorrhagic fever virus isolated from an endemic region in Kosovo. Virol. J. 5, 7

Duh, D., Saksida, A., Petrovec, M., Ahmeti, S., Dedushaj, I., Panning, M., Drosten, C. Avsic-Zupanc, T., 2007. Viral load as predictor of Crimean-Congo hemorrhagic fever outcome. Emerg. Infect. Dis. 13, 1769-1772.

Duh, D., Saksida, A., Petrovec, M., Dedushaj, I., Avsic-Zupanc, T., 2006. Novel onestep real-time RT-PCR assay for rapid and specific diagnosis of Crimean-Congo hemorrhagic fever encountered in the Balkans. J. Virol. Methods 133, 175-179.

Dunster, L., Dunster, M., Ofula, V., Beti, D., Kazooba-Voskamp, F., Burt, F., Swanepoel, R., DeCock, K.M., 2002. First documentation of human Crimean-Congo haemorrhagic fever. Kenya. Emerg. Infect. Dis. 8, 1005-1006.

Durden, L.A., Logan, T.M., Wilson, M.L., Linthicum, K.J., 1993. Experimental vector incompetence of a soft tick, Ornithodoros sonrai (Acari: Argasidae), for Crimean-Congo hemorrhagic fever virus. J. Med. Entomol. 30, 493-496.

Ebel, G.D., Kramer, L.D., 2004. Short report: duration of tick attachment required for transmission of powassan virus by deer ticks. Am. J. Trop. Med. Hyg. 71, 268271.

Elata, A.T., Karsany, M.S., Elageb, R.M., Hussain, M.A., Eltom, K.H., Elbashir, M.I., Aradaib, I.E., 2011. A nosocomial transmission of Crimean-Congo haemorrhagic fever to an attending physician in North Kordufan. Sudan. Virol. J. 8, 303.

El-Azazy, O.M., Scrimgeour, E.M., 1997. Crimean-Congo haemorrhagic fever virus infection in the western province of Saudi Arabia. Trans. R. Soc. Trop. Med. Hyg. 91, 275-278.

Elevli, M., Ozkul, A.A., Civilibal, M., Midilli, K., Gargili, A., Duru, N.S., 2010. A newly identified Crimean-Congo hemorrhagic fever virus strain in Turkey. Int. J. Infect. Dis. 14 (Suppl. 3), e213-e216.

EpiSouth, WHO, 2008. Epidemiology of Crimean-Congo Haemorrhagic Fever Virus: Albania, Bulgaria, Greece, Islamic Republic of Iran, Kosovo, Russian Federation, Turkey. EpiSouth, Rome, Italy.

EpiSouth, 2012. EpiSouth Weekly Epi Bulletin - No. 230. EpiSouth, Rome, Italy.

Erduran, E., Bahadir, A., Palanci, N., Gedik, Y., 2012. The treatment of CrimeanCongo hemorrhagic fever with high-dose methylprednisolone, intravenous immunoglobulin, and fresh frozen plasma. J. Pediatr. Hematol. Oncol. 35, 19-24.

Ergonul, O., 2006. Crimean-Congo haemorrhagic fever. Lancet Infect. Dis. 6, 203214.

Ergonul, O., 2008. Treatment of Crimean-Congo hemorrhagic fever. Antiviral Res. $78,125-131$

Ergonul, O., 2010. Crimean-Congo hemorrhagic fever (Presentation). In: Second FAO/OIE/WHO Joint Scientific Consultation on Influenza and other Emerging Zoonotic Diseases at the Human-Animal Interface, 27-29 April 2010, Verona, Italy.

Ergonul, O., Celikbas, A., Baykam, N., Eren, S., Dokuzoguz, B., 2006a. Analysis of riskfactors among patients with Crimean-Congo haemorrhagic fever virus infection: severity criteria revisited. Clin. Microbiol. Infect. 12, 551-554.

Ergonul, O., Celikbas, A., Dokuzoguz, B., Eren, S., Baykam, N., Esener, H., 2004. Characteristics of patients with Crimean-Congo hemorrhagic fever in a recent outbreak in Turkey and impact of oral ribavirin therapy. Clin. Infect. Dis. 39, 284-287.

Ergonul, O., Tuncbilek, S., Baykam, N., Celikbas, A., Dokuzoguz, B., 2006b. Evaluation of serum levels of interleukin (IL)-6, IL-10, and tumor necrosis factor-alpha in patients with Crimean-Congo hemorrhagic fever. J. Infect. Dis. 193, 941-944.

Ergonul, O., Zeller, H., Celikbas, A., Dokuzoguz, B., 2007. The lack of Crimean-Congo hemorrhagic fever virus antibodies in healthcare workers in an endemic region, Int. J. Infect. Dis. 11, 48-51.

Ergonul, O., Zeller, H., Kilic, S., Kutlu, S., Kutlu, M., Cavusoglu, S., Esen, B., Dokuzoguz, B., 2006c. Zoonotic infections among veterinarians in Turkey: Crimean-Congo hemorrhagic fever and beyond. Int. J. Infect. Dis. 10, 465-469.

Erickson, B.R., Deyde, V., Sanchez, A.J., Vincent, M.J., Nichol, S.T., 2007. N-linked glycosylation of $G_{N}$ (but not $G_{C}$ ) is important for Crimean Congo hemorrhagic fever virus glycoprotein localization and transport. Virology 361, 348-355.

Escadafal, C., Olschlager, S., Avsic-Zupanc, T., Papa, A., Vanhomwegen, J., Wolfel, R., Mirazimi, A., Teichmann, A., Donoso-Mantke, O., Niedrig, M., 2012. First international external quality assessment of molecular detection of CrimeanCongo hemorrhagic fever virus. PLoS Negl. Trop. Dis. 6, e1706.

Estrada, D.F., De Guzman, R.N., 2011. Structural characterization of the CrimeanCongo hemorrhagic fever virus $\mathrm{G}_{\mathrm{N}}$ tail provides insight into virus assembly. J. Biol. Chem. 286, 21678-21686.

Estrada-Pena, A., Ayllon, N., de la Fuente, J., 2012a. Impact of climate trends on tickborne pathogen transmission. Front. Physiol. 3, 64

Estrada-Pena, A., Jameson, L., Medlock, J., Vatansever, Z., Tishkova, F., 2012b. Unraveling the ecological complexities of tick-associated Crimean-Congo hemorrhagic Fever virus transmission: a gap analysis for the Western palearctic. Vector Borne Zoonotic Dis. 12, 743-752.

Estrada-Pena, A., Palomar, A.M., Santibanez, P., Sanchez, N., Habela, M.A., Portillo, A. Romero, L., Oteo, J.A., 2012c. Crimean-Congo hemorrhagic fever virus in ticks, Southwestern Europe, 2010. Emerg. Infect. Dis. 18, 179-180.

Estrada-Pena, A., Ruiz-Fons, F., Acevedo, P., Gortazar, C., de la Fuente, J., 2012d. Factors driving the circulation and possible expansion of Crimean-Congo hemorrhagic fever virus in the western Palearctic. J. Appl. Microbiol. 114, 278 286.

Estrada-Pena, A., Sanchez, N., Estrada-Sanchez, A., 2012e. An assessment of the distribution and spread of the tick Hyalomma marginatum in the western Palearctic under different climate scenarios. Vector Borne Zoonotic Dis. 12, $758-768$.

European Centre for Disease Prevention and Control, 2008. Consultation on Crimean-Congo Haemorrhagic Fever Prevention and Control. ECDC, Stockholm.

Fagbami, A.H., Tomori, O., Fabiyi, A., Isoun, T.T., 1975. Experimantal Congo virus (IbAN 7620) infection in primates. Virologie 26, 33-37.

Faye, O., Cornet, J.P. Camicas, J.L., Fontenille, D., Gonzalez, J.P., 1999. Experimental transmission of Crimean-Congo hemorrhagic fever virus: role of 3 vector species in the maintenance and transmission cycles in Senegal. Parasite 6, 2732.

Filipe, A.R., Calisher, C.H., Lazuick, J., 1985. Antibodies to Congo-Crimean haemorrhagic fever, Dhori, Thogoto and Bhanja viruses in southern Portugal. Acta Virol. 29, 324-328.

Fisher-Hoch, S.P., Khan, J.A., Rehman, S., Mirza, S., Khurshid, M., McCormick, J.B., 1995. Crimean Congo-haemorrhagic fever treated with oral ribavirin. Lancet 346, 472-475.

Fisher-Hoch, S.P., McCormick, J.B., Swanepoel, R., Van Middlekoop, A., Harvey, S. Kustner, H.G., 1992. Risk of human infections with Crimean-Congo hemorrhagic fever virus in a South African rural community. Am. J. Trop. Med. Hyg. 47, 337-345.

Foulke, R.S., Rosato, R.R., French, G.R., 1981. Structural polypeptides of Hazara virus. J. Gen. Virol. 53, 169-172.

Francischetti, I.M., Sa-Nunes, A., Mans, B.J., Santos, I.M., Ribeiro, J.M., 2009. The role of saliva in tick feeding. Front Biosci 14, 2051-2088.

Frias-Staheli, N., Giannakopoulos, N.V., Kikkert, M., Taylor, S.L., Bridgen, A., Paragas, J., Richt, J.A., Rowland, R.R., Schmaljohn, C.S., Lenschow, D.J., Snijder, E.J., GarciaSastre, A., Virgin, H.W., 2007. Ovarian tumor domain-containing viral proteases evade ubiquitin- and ISG15-dependent innate immune responses. Cell Host Microbe 2, 404-416.

Gale, P., Stephenson, B., Brouwer, A., Martinez, M., de la Torre, A., Bosch, J., FoleyFisher, M., Bonilauri, P., Lindstrom, A., Ulrich, R.G., de Vos, C.J., Scremin, M., Liu, Z., Kelly, L., Munoz, M.J., 2011. Impact of climate change on risk of incursion of Crimean-Congo haemorrhagic fever virus in livestock in Europe through migratory birds. J. Appl. Microbiol. 112, 246-257.

Gargili, A., Midilli, K., Ergonul, O., Ergin, S., Alp, H.G., Vatansever, Z., Iyisan, S., Cerit, C., Yilmaz, G., Altas, K., Estrada-Pena, A., 2011. Crimean-Congo hemorrhagic fever in European part of Turkey: genetic analysis of the virus strains from ticks and a seroepidemiological study in humans. Vector Borne Zoonotic Dis. 11, 747-752.

Garrison, A.R., Alakbarova, S., Kulesh, D.A., Shezmukhamedova, D., Khodjaev, S., Endy, T.P., Paragas, J., 2007. Development of a TaqMan minor groove binding protein assay for the detection and quantification of Crimean-Congo hemorrhagic fever virus. Am. J. Trop. Med. Hyg. 77, 514-520.

Gear, J.H., Thomson, P.D., Hopp, M., Andronikou, S., Cohn, R.J., Ledger, J., Berkowitz, F.E., 1982. Congo-Crimean haemorrhagic fever in South Africa. Report of a fatal case in the Transvaal. S. Afr. Med. J. 62, 576-580.

Gergova, I., Kunchev, M., Kamarinchev, B., 2012. Crimean-Congo hemorrhagic fever virus-tick survey in endemic areas in Bulgaria. J. Med. Virol. 84, 608-614. 
Ghiasi, S.M., Salmanian, A.H., Chinikar, S., Zakeri, S., 2011. Mice orally immunized with a transgenic plant expressing the glycoprotein of Crimean-Congo hemorrhagic fever virus. Clin. Vaccine Immunol. 18, 2031-2037.

Gonzalez, J.P., Camicas, J.L., Cornet, J.P., Faye, O., Wilson, M.L., 1992. Sexual and transovarian transmission of Crimean-Congo haemorrhagic fever virus in Hyalomma truncatum ticks. Res. Virol. 143, 23-28.

Gonzalez, J.P., Camicas, J.L., Cornet, J.P., Wilson, M.L., 1998. Biological and clinical responses of west African sheep to Crimean-Congo haemorrhagic fever virus experimental infection. Res. Virol. 149, 445-455.

Gonzalez, J.P., Cornet, J.P., Wilson, M.L., Camicas, J.L., 1991. Crimean-Congo haemorrhagic fever virus replication in adult Hyalomma truncatum and Amblyomma variegatum ticks. Res. Virol. 142, 483-488.

Gordon, S.W., Linthicum, K.J., Moulton, J.R., 1993. Transmission of Crimean-Congo hemorrhagic fever virus in two species of Hyalomma ticks from infected adults to cofeeding immature forms. Am. J. Trop. Med. Hyg. 48, 576-580.

Grard, G., Drexler, J.F., Fair, J., Muyembe, J.J., Wolfe, N.D., Drosten, C., Leroy, E.M., 2011. Re-emergence of Crimean-Congo hemorrhagic fever virus in Central Africa. PLoS Negl. Trop. Dis. 5, e1350.

Grashchenkov, N.I., 1945. Investigation of Etiology, Pathogenesis, and Clinical Symptomatology of Crimean Hemorrhagic Fever, Reports on the 1944 Scientific Investigation of the Institute of Neurology. Akad. Med. Nauk SSR, Moscow, pp. 100-107.

Gray, J.S., Dautel, H., Estrada-Pena, A., Kahl, O., Lindgren, E., 2009. Effects of clinmate change on ticks and tick-borne diseases. Interdiscip. Perspect. Infect. Dis., 1-12.

Gunes, T., Engin, A., Poyraz, O., Elaldi, N., Kaya, S., Dokmetas, I., Bakir, M., Cinar, Z., 2009. Crimean-Congo hemorrhagic fever virus in high-risk population, Turkey. Emerg. Infect. Dis. 15, 461-464.

Gunes, T., Poyraz, O., Vatansever, Z., 2011. Crimean-Congo hemorrhagic fever virus in ticks collected from humans, livestock, and picnic sites in the hyperendemic region of Turkey. Vector Borne Zoonotic Dis. 11, 1411-1416.

Hasle, B., Bjune, G., Edvardsen, E., Jakobsen, C., Linnehol, B., Roer, J.E., Mehls, R., Roed, K.H., Pedersen, J., Leinaas, H.P., 2009. Transport of ticks by migratory passerine birds to Norway. J. Parasitol. 95, 1342-1351.

Hatipoglu, C.A., Bulut, C., Yetkin, M.A., Ertem, G.T., Erdinc, F.S., Kilic, E.K., Sari, T., Kinikli, S., Oral, B., Demiroz, A.P., 2010. Evaluation of clinical and laboratory predictors of fatality in patients with Crimean-Congo haemorrhagic fever in a tertiary care hospital in Turkey. Scand. J. Infect. Dis. 42, 516-521.

Hewson, R., Chamberlain, J., Mioulet, V., Lloyd, G., Jamil, B., Hasan, R., Gmyl, A., Gmyl, L., Smirnova, S.E., Lukashev, A., Karganova, G., Clegg, C., 2004a. CrimeanCongo haemorrhagic fever virus: sequence analysis of the small RNA segments from a collection of viruses world wide. Virus Res. 102, 185-189.

Hewson, R., Gmyl, A., Gmyl, L., Smirnova, S.E., Karganova, G., Jamil, B., Hasan, R., Chamberlain, J., Clegg, C., 2004b. Evidence of segment reassortment in Crimean-Congo haemorrhagic fever virus. J. Gen. Virol. 85, 3059-3070.

Heyman, P., Cochez, C., Hofhuis, A., van der Giessen, J., Sprong, H., Porter, S.R., Losson, B., Saegerman, C., Donoso-Mantke, O., Niedrig, M., Papa, A., 2010. A clear and present danger: tick-borne diseases in Europe. Expert Rev. Anti Infect. Ther. $8,33-50$.

Honig, J.E., Osborne, J.C., Nichol, S.T., 2004a. Crimean-Congo hemorrhagic fever virus genome L RNA segment and encoded protein. Virology 321, 29-35.

Honig, J.E., Osborne, J.C., Nichol, S.T., 2004b. The high genetic variation of viruses of the genus Nairovirus reflects the diversity of their predominant tick hosts. Virology 318, 10-16.

Hoogstraal, H., 1979. The epidemiology of tick-borne Crimean-Congo hemorrhagic fever in Asia, Europe, and Africa. J. Med. Entomol. 15, 307-417.

Hornok, S., Horvath, G., 2012. First report of adult Hyalomma marginatum rufipes (vector of Crimean-Congo haemorrhagic fever virus) on cattle under a continental climate in Hungary. Parasit. Vectors 5, 170.

Huggins, J.W., 1989. Prospects for treatment of viral hemorrhagic fevers with ribavirin, a broad-spectrum antiviral drug. Rev. Infect. Dis. 11 (Suppl 4), S750S761.

Jabbari, A., Besharat, S., Abbasi, A., Moradi, A., Kalavi, K., 2006. Crimean-Congo hemorrhagic fever: case series from a medical center in Golestan province, Northeast of Iran (2004). Indian J. Med. Sci. 60, 327-329.

Jameson, L.J., Morgan, P.J., Medlock, J.M., Watola, G., Vaux, A.G., 2012. Importation of Hyalomma marginatum, vector of Crimean-Congo haemorrhagic fever virus, into the United Kingdom by migratory birds. Ticks Tick Borne Dis. 3, 95-99.

Jamil, B., Hasan, R.S., Sarwari, A.R., Burton, J., Hewson, R., Clegg, C., 2005. CrimeanCongo hemorrhagic fever: experience at a tertiary care hospital in Karachi, Pakistan. Trans. R. Soc. Trop. Med. Hyg. 99, 577-584.

Jaureguiberry, S., Tattevin, P., Tarantola, A., Legay, F., Tall, A., Nabeth, P., Zeller, H., Michelet, C., 2005. Imported Crimean-Congo hemorrhagic fever. J. Clin. Microbiol. 43, 4905-4907.

Jones, L.D., Davies, C.R., Green, B.M., Nuttall, P.A., 1987a. Reassortment of Thogoto virus (a tick-borne influenza-like virus) in a vertebrate host. J. Gen. Virol. 68 (Pt 5), 1299-1306.

Jones, L.D., Davies, C.R., Steele, G.M., Nuttall, P.A., 1987b. A novel mode of arbovirus transmission involving a nonviremic host. Science 237, 775-777.

Jones, L.D., Hodgson, E., Williams, T., Higgs, S., Nuttall, P.A., 1992. Saliva activated transmission (SAT) of Thogoto virus: relationship with vector potential of different haematophagous arthropods. Med. Vet. Entomol. 6, 261-265.

Joubert, J.R., King, J.B., Rossouw, D.J., Cooper, R., 1985. A nosocomial outbreak of Crimean-Congo haemorrhagic fever at Tygerberg Hospital. Part III. Clinical pathology and pathogenesis. S. Afr. Med. J. 68, 722-728.

Kalaycioglu, A.T., Durmaz, R., Uyar, Y., Unaldi, O., Aksekili, E., Ozkul, A., Korukluoglu, G., Ertek, M., 2012. Lack of genetic diversity in Crimean-Congo hemorrhagic fever viruses in Turkey: assessment of present and future patterns of disease. J. Med. Virol. 84, 471-478.

Kampen, H., Poltz, W., Hartelt, K., Wolfel, R., Faulde, M., 2007. Detection of a questing Hyalomma marginatum marginatum adult female (Acari, Ixodidae) in southern Germany. Exp. Appl. Acarol. 43, 227-231.

Karlberg, H., Lindegren, G., Mirazimi, A., 2010. Comparison of antiviral activity of recombinant and natural interferons against Crimean-Congo hemorrhagic Fever virus. Open Virol. J. 4, 38-41.

Karlberg, H., Tan, Y.J., Mirazimi, A., 2011. Induction of caspase activation and cleavage of the viral nucleocapsid protein in different cell types during Crimean-Congo hemorrhagic fever virus infection. J. Biol. Chem. 286, $3227-$ 3234.

Karti, S.S., Odabasi, Z., Korten, V., Yilmaz, M., Sonmez, M., Caylan, R., Akdogan, E., Eren, N., Koksal, I., Ovali, E., Erickson, B.R., Vincent, M.J., Nichol, S.T., Comer, J.A. Rollin, P.E., Ksiazek, T.G., 2004. Crimean-Congo hemorrhagic fever in Turkey. Emerg. Infect. Dis. 10, 1379-1384.

Keshtkar-Jahromi, M., Kuhn, J.H., Christova, I., Bradfute, S.B., Jahrling, P.B., Bavari, S., 2011. Crimean-Congo hemorrhagic fever: current and future prospects of vaccines and therapies. Antiviral Res. 90, 85-92.

Khan, A.S., Maupin, G.O., Rollin, P.E., Noor, A.M., Shurie, H.H., Shalabi, A.G., Wasef, S. Haddad, Y.M., Sadek, R., Ijaz, K., Peters, C.J., Ksiazek, T.G., 1997. An outbreak of Crimean-Congo hemorrhagic fever in the United Arab Emirates, 1994-1995. Am. J. Trop. Med. Hyg. 57, 519-525.

Kinsella, E., Martin, S.G., Grolla, A., Czub, M., Feldmann, H., Flick, R., 2004. Sequence determination of the Crimean-Congo hemorrhagic fever virus L segment Virology 321, 23-28.

Kocakova, P., Hajnicka, V., Slovak, M., Nuttall, P.A., Fuchsberger, N., 1999. Promotion of vesicular stomatitis virus nucleocapsid protein production by arthopod saliva. Acta Virol. 43, 251-254.

Koksal, I., Yilmaz, G., Aksoy, F., Aydin, H., Yavuz, I., Iskender, S., Akcay, K., Erensoy, S. Caylan, R., Aydin, K., 2010. The efficacy of ribavirin in the treatment of CrimeanCongo hemorrhagic fever in Eastern Black Sea region in Turkey. J. Clin. Virol. 47 65-68.

Kondratenko, V.F., 1976. Importance of ixodid ticks in the transmission and preservation of the causative agent of Crimean hemorrhagic fever in foci of the infection. Parazitologiia 10, 297-302.

Kubar, A., Haciomeroglu, M., Ozkul, A., Bagriacik, U., Akinci, E., Sener, K., Bodur, H., 2011. Prompt administration of Crimean-Congo hemorrhagic fever (CCHF) virus hyperimmunoglobulin in patients diagnosed with CCHF and viral load monitorization by reverse transcriptase-PCR. Jpn. J. Infect. Dis. 64, 439-443.

Labuda, M., Jiang, W.R., Kaluzova, M., Kozuch, O., Nuttall, P.A., Weismann, P., Eleckova, E., Zuffova, E., Gould, E.A., 1994. Change in phenotype of tick-borne encephalitis virus following passage in Ixodes ricinus ticks and associated amino acid substitution in the envelope protein. Virus Res. 31, 305-315.

Leblebicioglu, H., 2010. Crimean-Congo haemorrhagic fever in Eurasia. Int. J Antimicrob. Agents 36 (Suppl. 1), S43-S46.

Leblebicioglu, H., Bodur, H., Dokuzoguz, B., Elaldi, N., Guner, R., Koksal, I., Kurt, H., Senturk, G.C., 2012. Case management and supportive treatment for patients with Crimean-Congo hemorrhagic fever. Vector Borne Zoonotic Dis. 12, 805 811.

Lee, V.H., Kemp, G.E., 1970. Congo virus: experimental infection of Hyalomma rufipes and transmission to a calf. Bull. Entomologic. Soc. Nigeria 2, 133-135.

Leschinskaya, E.V., 1970. Certain problems in Crimean hemorrhagic fever therapy [Russian; NAMRU3 translation T541]. In: Chumakov, M.P. (Ed.), Crimean haemorrhagic fever: Materials of the 3rd Scientific-Practical Conference in Rostov-on-Don. Moscow, USSR, pp. 111-115.

Lobo, F.P., Mota, B.E., Pena, S.D., Azevedo, V., Macedo, A.M., Tauch, A., Machado, C.R. Franco, G.R., 2009. Virus-host coevolution: common patterns of nucleotide motif usage in Flaviviridae and their hosts. PLoS One 4, e6282.

Logan, T.M., Linthicum, K.J., Bailey, C.L., Watts, D.M., Dohm, D.J., Moulton, J.R., 1990. Replication of Crimean-Congo hemorrhagic fever virus in four species of ixodid ticks (Acari) infected experimentally. J. Med. Entomol. 27, 537-542.

Logan, T.M., Linthicum, K.J., Bailey, C.L., Watts, D.M., Moulton, J.R., 1989 Experimental transmission of Crimean-Congo hemorrhagic fever virus byHyalomma truncatum Koch. Am. J. Trop. Med. Hyg. 40, 207-212.

Lukashev, A.N., 2005. Evidence for recombination in Crimean-Congo hemorrhagic fever virus. J. Gen. Virol. 86, 2333-2338.

Lwande, O.W., Irura, Z., Tigoi, C., Chepkorir, E., Orindi, B., Musila, L., Venter, M. Fischer, A., Sang, R., 2012. Seroprevalence of Crimean Congo hemorrhagic fever virus in Ijara District, Kenya. Vector Borne Zoonotic Dis. 12, 727-732.

Mahanty, S., Bray, M., 2004. Pathogenesis of filoviral haemorrhagic fevers. Lancet Infect. Dis, 4, 487-498.

Majeed, B., Dicker, R., Nawar, A., Badri, S., Noah, A., Muslem, H., 2012. Morbidity and mortality of Crimean-Congo hemorrhagic fever in Iraq: cases reported to the National Surveillance System, 1990-2010. Trans. R. Soc. Trop. Med. Hyg. 106, 480-483.

Maltezou, H.C., Maltezos, E., Papa, A., 2009. Contact tracing and serosurvey among healthcare workers exposed to Crimean-Congo haemorrhagic fever in Greece. Scand. J. Infect. Dis. 41, 877-880.

Maltezou, H.C., Papa, A., 2010. Crimean-Congo hemorrhagic fever: risk for emergence of new endemic foci in Europe? Travel Med. Infect. Dis. 8, 139-143.

Mardani, M., Jahromi, M.K., Naieni, K.H., Zeinali, M., 2003. The efficacy of ora ribavirin in the treatment of Crimean-Congo hemorrhagic fever in Iran. Clin. Infect. Dis. 36, 1613-1618.

Mardani, M., Keshtkar-Jahromi, M., 2007. Crimean-Congo hemorrhagic fever. Arch. Iran Med. 10, 204-214. 
Mardani, M., Rahnavardi, M., Sharifi-Mood, B., 2010. Current treatment of CrimeanCongo hemorrhagic fever in children. Expert Rev. Anti Infect. Ther. 8, 911-918.

Marriott, A.C., Nuttall, P.A., 1996. Large RNA segment of Dugbe nairovirus encodes the putative RNA polymerase. J. Gen. Virol. 77 (Pt 8), 1775-1780.

Mehla, R., Kumar, S.R., et al., 2009. Recent ancestry of Kyasanur Forest disease virus. Emerg. Infect. Dis. 15, 1431-1437.

Meissner, J.D., Seregin, S.S., Seregin, S.V., Vyshemirskii, O.I., Samokhvalov, E.I., Lvov D.K., Netesov, S.V., Petrov, V.S., 2006a. A variable region in the Crimean-Congo hemorrhagic fever virus $\mathrm{L}$ segment distinguishes between strains isolated from different geographic regions. J. Med. Virol. 78, 223-228.

Meissner, J.D., Seregin, S.S., Seregin, S.V., Yakimenko, N.V., Vyshemirskii, O.I. Netesov, S.V., Petrov, V.S., 2006b. Complete L segment coding-region sequences of Crimean Congo hemorrhagic fever virus strains from the Russian Federation and Tajikistan. Arch. Virol. 151, 465-475.

Mertens, M., Schmidt, K., Ozkul, A., Groschup, M.H., 2013. The impact of Crimean-Congo hemorrhagic fever virus on public health. Antiviral Res. 98 248-260.

Midilli, K., Gargili, A., Ergonul, O., Elevli, M., Ergin, S., Turan, N., Sengoz, G., Ozturk, R., Bakar, M., 2009. The first clinical case due to AP92 like strain of Crimean-Congo Hemorrhagic Fever virus and a field survey. BMC Infect. Dis. 9, 90.

Midilli, K., Gargili, A., Ergonul, O., Sengoz, G., Ozturk, R., Bakar, M., Jongejan, F., 2007. Imported Crimean-Congo hemorrhagic fever cases in Istanbul. BMC Infect. Dis. $7,54$.

Mild, M., Simon, M., Albert, J., Mirazimi, A., 2010. Towards an understanding of the migration of Crimean-Congo hemorrhagic fever virus. J. Gen. Virol. 91, 199207.

Mishra, A.C., Mehta, M., Mourya, D.T., Gandhi, S., 2011. Crimean-Congo haemorrhagic fever in India. Lancet 378, 372.

Mofleh, J., Ahmad, Z., 2012. Crimean-Congo haemorrhagic fever outbreak investigation in the Western Region of Afghanistan in 2008. East. Mediterr. Health J. 18, 522-526.

Morikawa, S., Qing, T., Xinqin, Z., Saijo, M., Kurane, I., 2002. Genetic diversity of the M RNA segment among Crimean-Congo hemorrhagic fever virus isolates in China. Virology 296, 159-164.

Morikawa, S., Saijo, M., Kurane, I., 2007. Recent progress in molecular biology of Crimean-Congo hemorrhagic fever. Comp. Immunol. Microbiol. Infect. Dis. 30, 375-389.

Mourya, D.T., Yadav, P.D., Shete, A.M., Gurav, Y.K., Raut, C.G., Jadi, R.S., Pawar, S.D., Nichol, S.T., Mishra, A.C., 2012. Detection, isolation and confirmation of Crimean-Congo hemorrhagic fever virus in human, ticks and animals in Ahmadabad, India, 2010-2011. PLoS Negl. Trop. Dis. 6, e1653.

Mousavi-Jazi, M., Karlberg, H., Papa, A., Christova, I., Mirazimi, A., 2012. Healthy individuals' immune response to the Bulgarian Crimean-Congo hemorrhagic fever virus vaccine. Vaccine 30, 6225-6229.

Mustafa, M.L., Ayazi, E., Mohareb, E., Yingst, S., Zayed, A., Rossi, C.A., Schoepp, R.J., Mofleh, J., Fiekert, K., Akhbarian, Z., Sadat, H., Leslie, T., 2009. Crimean-Congo hemorrhagic fever, Afghanistan, 2009. Emerg. Infect. Dis. 17, 1940-1941.

Nabeth, P., Cheikh, D.O., Lo, B., Faye, O., Vall, I.O., Niang, M., Wague, B., Diop, D., Diallo, M., Diallo, B., Diop, O.M., Simon, F., 2004a. Crimean-Congo hemorrhagic fever, Mauritania. Emerg. Infect. Dis. 10, 2143-2149.

Nabeth, P., Thior, M., Faye, O., Simon, F., 2004b. Human Crimean-Congo hemorrhagic fever, Senegal. Emerg. Infect. Dis. 10, 1881-1882.

Nalca, A.W., Whitehouse, C.A., 2007. Crimean-Congo hemorrhagic fever virus infection among animals. In: Ergonul, O.W., Whitehouse, C.A. (Eds.), CrimeanCongo Hemorrhagic Fever: A Global Perspective, vol. 1. Springer, Dordrecht, The Netherlands, pp. 155-165.

Nuttall, P.A., Jones, L.D., Labuda, M., Kaufman, W.R., 1994. Adaptations of arboviruses to ticks. J. Med. Entomol. 31, 1-9.

Nuttall, P.A., Labuda, M., 2003. Dynamics of infection in tick vectors and at the tickhost interface. Adv. Virus Res. 60, 233-272.

Nuttall, P.A., Labuda, M., 2004. Tick-host interactions: saliva-activated transmission. Parasitology 129 (Suppl.), S177-S189.

Okorie, T.G., 1991. Comparative studies on the vector capacity of the different stages of Amblyomma variegatum Fabricius and Hyalomma rufipes Koch for Congo virus, after intracoelomic inoculation. Vet. Parasitol. 38, 215-223.

Olschlager, S., Gabriel, M., Schmidt-Chanasit, J., Meyer, M., Osborne, E., Conger, N.G., Allan, P.F., Gunther, S., 2011. Complete sequence and phylogenetic characterisation of Crimean-Congo haemorrhagic fever virus from Afghanistan. J. Clin. Virol. 50, 90-92.

Onguru, P., Akgul, E.O., Akinci, E., Yaman, H., Kurt, Y.G., Erbay, A., Bayazit, F.N. Bodur, H., Erbil, K., Acikel, C.H., Cevik, M.A., 2008. High serum levels of neopterin in patients with Crimean-Congo hemorrhagic fever and its relation with mortality. J. Infect. 56, 366-370.

Onguru, P., Dagdas, S., Bodur, H., Yilmaz, M., Akinci, E., Eren, S., Ozet, G., 2010. Coagulopathy parameters in patients with Crimean-Congo hemorrhagic fever and its relation with mortality. J. Clin. Lab. Anal. 24, 163-166.

Onishchenko, G.G., Tumanova, I., Vyshemirskii, O.I., Kuhn, J., Seregin, S.V., Tiunnikov, G.I., Petrova, I.D., Tishkova, F., Ospanov, K.S., Kazakov, S.V. Karimov, S.K., Esmagambetova, A.S., Netesov, S.V., Petrov, V.S., 2005. ELISA and RT-PCR-based research of viruses in the ticks collected in the foci of Crimean-Congo fever in Kazakhstan and Tajikistan in 2001-2002. Vopr. Virusol 50, 23-26.

Ozdarendeli, A., Canakoglu, N., Berber, E., Aydin, K., Tonbak, S., Ertek, M., Buzgan, T., Bolat, Y., Aktas, M., Kalkan, A., 2010. The complete genome analysis of
Crimean-Congo hemorrhagic fever virus isolated in Turkey. Virus Res. 147, 288-293.

Ozkaya, E., Dincer, E., Carhan, A., Uyar, Y., Ertek, M., Whitehouse, C.A., Ozkul, A., 2010. Molecular epidemiology of Crimean-Congo hemorrhagic fever virus in Turkey: occurrence of local topotype. Virus Res. 149, 64-70.

Ozkurt, Z., Kiki, I., Erol, S., Erdem, F., Yilmaz, N., Parlak, M., Gundogdu, M., Tasyaran, M.A., 2006. Crimean-Congo hemorrhagic fever in Eastern Turkey: clinical features, risk factors and efficacy of ribavirin therapy. J. Infect. 52, 207-215.

Ozturk, B., Kuscu, F., Tutuncu, E., Sencan, I., Gurbuz, Y., Tuzun, H., 2010. Evaluation of the association of serum levels of hyaluronic acid, sICAM-1, sVCAM-1, and VEGF-A with mortality and prognosis in patients with Crimean-Congo hemorrhagic fever. J. Clin. Virol. 47, 115-119.

Papa, A., Bino, S., Llagami, A., Brahimaj, B., Papadimitriou, E., Pavlidou, V., Velo, E., Cahani, G., Hajdini, M., Pilaca, A., Harxhi, A., Antoniadis, A., 2002a. CrimeanCongo hemorrhagic fever in Albania, 2001. Eur. J. Clin. Microbiol. Infect. Dis. 21, 603-606.

Papa, A., Bino, S., Velo, E., Harxhi, A., Kota, M., Antoniadis, A., 2006. Cytokine levels in Crimean-Congo hemorrhagic fever. J. Clin. Virol. 36, 272-276.

Papa, A., Bozovi, B., Pavlidou, V., Papadimitriou, E., Pelemis, M., Antoniadis, A. 2002b. Genetic detection and isolation of Crimean-Congo hemorrhagic fever virus, Kosovo, Yugoslavia. Emerg. Infect. Dis. 8, 852-854.

Papa, A., Chaligiannis, I., Xanthopoulou, K., Papaioakim, M., Papanastasiou, S., Sotiraki, S., 2011. Ticks parasitizing humans in Greece. Vector Borne Zoonotic Dis. 11, 539-542.

Papa, A., Christova, I., Papadimitriou, E., Antoniadis, A., 2004. Crimean-Congo hemorrhagic fever in Bulgaria. Emerg. Infect. Dis. 10, 1465-1467.

Papa, A., Dalla, V., Papadimitriou, E., Kartalis, G.N., Antoniadis, A., 2009a. Emergence of Crimean-Congo haemorrhagic fever in Greece. Clin. Microbiol. Infect. 16, 843-847.

Papa, A., Ma, B., Kouidou, S., Tang, Q., Hang, C., Antoniadis, A., 2002c. Genetic characterization of the M RNA segment of Crimean Congo hemorrhagic fever virus strains. China. Emerg. Infect. Dis. 8, 50-53.

Papa, A., Papadimitriou, E., Christova, I., 2010. The Bulgarian vaccine CrimeanCongo haemorrhagic fever virus strain. Scand. J. Infect. Dis. 43, 225-229.

Papa, A., Velo, E., Papadimitriou, E., Cahani, G., Kota, M., Bino, S., 2009b. Ecology of the Crimean-Congo hemorrhagic fever endemic area in Albania. Vector Borne Zoonotic Dis. 9, 713-716.

Papadopoulos, O., Koptopoulos, G., 1978. Isolation of Crimean-Congo hemorrhagic fever (C-CHF) virus from Rhipicephalus bursa ticks in Greece. Acta Hell. Microbiol. 23, 20-28.

Paragas, J., Whitehouse, C.A., Endy, T.P., Bray, M., 2004. A simple assay for determining antiviral activity against Crimean-Congo hemorrhagic fever virus. Antiviral Res. 62, 21-25.

Peyrefitte, C.N., Perret, M., Garcia, S., Rodrigues, R., Bagnaud, A., Lacote, S., Crance, J.M., Vernet, G., Garin, D., Bouloy, M., Paranhos-Baccala, G., 2010. Differential activation profiles of Crimean-Congo hemorrhagic fever virus- and Dugbe virus-infected antigen-presenting cells. J. Gen. Virol. 91, 189-198.

Randolph, S.E., 2011. Transmission of tick-borne pathogens between co-feeding ticks: Milan Labuda's enduring paradigm. Ticks Tick Borne Dis. 2, 179-182.

Rechav, Y., 1986. Seasonal activity and hosts of the vectors of Crimean-Congo haemorrhagic fever in South Africa. S. Afr. Med. J. 69, 364-368.

Saidi, S., Casals, J., Faghih, M.A., 1975. Crimean hemorrhagic fever-Congo (CHF-C) virus antibodies in man, and in domestic and small mammals, in Iran. Am. J. Trop. Med. Hyg. 24, 353-357.

Saluzzo, J.F., Aubry, P., McCormick, J., Digoutte, J.P., 1985. Haemorrhagic fever caused by Crimean Congo haemorrhagic fever virus in Mauritania. Trans. R. Soc. Trop. Med. Hyg. 79, 268.

Saksida, A., Duh, D., Wraber, B., Dedushaj, I., Ahmeti, S., Avsic-Zupanc, T., 2010. Interacting roles of immune mechanisms and viral load in the pathogenesis of Crimean-Congo hemorrhagic fever. Clin. Vaccine Immunol. 17, 1086-1093.

Samudzi, R.R., Leman, P.A., Paweska, J.T., Swanepoel, R., Burt, F.J., 2012. Bacterial expression of Crimean-Congo hemorrhagic fever virus nucleoprotein and its evaluation as a diagnostic reagent in an indirect ELISA. J. Virol. Methods 179, 70-76.

Sanchez, A.J., Vincent, M.J., Erickson, B.R., Nichol, S.T., 2006. Crimean-Congo hemorrhagic fever virus glycoprotein precursor is cleaved by Furin-like and SKI-1 proteases to generate a novel 38-kilodalton glycoprotein. J. Virol. 80, 514525.

Sanchez, A.J., Vincent, M.J., Nichol, S.T., 2002. Characterization of the glycoproteins of Crimean-Congo hemorrhagic fever virus. J. Virol. 76, 7263-7275.

Sang, R., Lutomiah, J., Koka, H., Makio, A., Chepkorir, E., Ochieng, C., Yalwala, S., Mutisya, J., Musila, L., Richardson, J.H., Miller, B.R., Schnabel, D., 2011. CrimeanCongo hemorrhagic fever virus in Hyalommid ticks, northeastern Kenya. Emerg. Infect. Dis. 17, 1502-1505.

Schmaljohn, C.S., Nichol, S.T., 2007. Bunyaviridae. In: Knipe, D.M., Howley, P.M. (Eds.), Fields Virology. Lippincott Williams \& Wilkins, Philadelphia, PA, p. 1741.

Schnittler, H.J., Feldmann, H., 2003. Viral hemorrhagic fever - a vascular disease? Thromb. Haemost. 89, 967-972.

Schwarz, T.F., Nsanze, H., Ameen, A.M., 1997. Clinical features of Crimean-Congo haemorrhagic fever in the United Arab Emirates. Infection 25, 364-367.

Scrimgeour, E.M., 1996. Crimean-Congo haemorrhagic fever in Oman. Lancet 347, 692.

Seregin, S.V., Samokhvalov, E.I., Petrova, I.D., Vyshemirskii, O.I., Samokhvalova, E.G., Lvov, D.K., Gutorov, V.V., Tyunnikov, G.I., Shchelkunov, S.N., Netesov, S.V. 
Petrov, V.S., 2004. Genetic characterisation of the mRNA segment of crimeanCongo hemorrhagic fever virus strains isolated in Russia and Tajikistan. Virus Genes. 28, 187-193.

Shepherd, A.J., Leman, P.A., Swanepoel, R., 1989a. Viremia and antibody response of small African and laboratory animals to Crimean-Congo hemorrhagic fever virus infection. Am. J. Trop. Med. Hyg. 40, 541-547.

Shepherd, A.J., Swanepoel, R., Cornel, A.J., Mathee, O., 1989b. Experimental studies on the replication and transmission of Crimean-Congo hemorrhagic fever virus in some African tick species. Am. J. Trop. Med. Hyg. 40, 326-331.

Shepherd, A.J., Swanepoel, R., Leman, P.A., 1989c. Antibody response in CrimeanCongo hemorrhagic fever. Rev. Infect. Dis. 11 (Suppl. 4), S801-S806.

Shepherd, A.J., Swanepoel, R., Leman, P.A., Shepherd, S.P., 1987a. Field and laboratory investigation of Crimean-Congo haemorrhagic fever virus (Nairovirus, family Bunyaviridae) infection in birds. Trans. R. Soc. Trop. Med. Hyg. 81, 1004-1007.

Shepherd, A.J., Swanepoel, R., Shepherd, S.P., Leman, P.A., Mathee, O., 1991. Viraemic transmission of Crimean-Congo haemorrhagic fever virus to ticks. Epidemiol. Infect. 106, 373-382.

Shepherd, A.J., Swanepoel, R., Shepherd, S.P., McGillivray, G.M., Searle, L.A., 1987b. Antibody to Crimean-Congo hemorrhagic fever virus in wild mammals from southern Africa. Am. J. Trop. Med. Hyg. 36, 133-142.

Shi, X., van Mierlo, J.T., French, A., Elliott, R.M., 2012. Visualizing the replication cycle of bunyamwera orthobunyavirus expressing fluorescent protein-tagged $\mathrm{G}_{\mathrm{C}}$ glycoprotein. J. Virol. 84, 8460-8469.

Sidira, P., Maltezou, H.C., Haidich, A.B., Papa, A., 2011. Seroepidemiological study of Crimean-Congo haemorrhagic fever in Greece, 2009-2010. Clin. Microbiol. Infect. 18, E16-E19.

Simon, M., Falk, K.I., Lundkvist, A., Mirazimi, A., 2006. Exogenous nitric oxide inhibits Crimean Congo hemorrhagic fever virus. Virus Res. 120, 184-190.

Simon, M., Johansson, C., Lundkvist, A., Mirazimi, A., 2009a. Microtubule-dependent and microtubule-independent steps in Crimean-Congo hemorrhagic fever virus replication cycle. Virology 385, 313-322.

Simon, M., Johansson, C., Mirazimi, A., 2009b. Crimean-Congo hemorrhagic fever virus entry and replication is clathrin-, $\mathrm{pH}$ - and cholesterol-dependent. J. Gen. Virol. 90, 210-215.

Simpson, D.I., Knight, E.M., Courtois, G., Williams, M.C., Weinbren, M.P., Kibukamusoke, J.W., 1967. Congo virus: a hitherto undescribed virus occurring in Africa. I. Human isolations-clinical notes. East Afr. Med. J. 44, 86-92.

Smego Jr., R.A., Sarwari, A.R., Siddiqui, A.R., 2004. Crimean-Congo hemorrhagic fever: prevention and control limitations in a resource-poor country. Clin. Infect. Dis. 38, 1731-1735.

Smirnova, S.E., 1979. A comparative study of the Crimean hemorrhagic fever-Congo group of viruses. Arch. Virol. 62, 137-143.

Soares-Weiser, K., Thomas, S., Thomson, G., Garner, P., 2010. Ribavirin for CrimeanCongo hemorrhagic fever: systematic review and meta-analysis. BMC Infect. Dis. 10, 207.

Spik, K., Shurtleff, A., McElroy, A.K., Guttieri, M.C., Hooper, J.W., SchmalJohn, C., 2006. Immunogenicity of combination DNA vaccines for Rift Valley fever virus, tick-borne encephalitis virus, Hantaan virus, and Crimean Congo hemorrhagic fever virus. Vaccine 24, 4657-4666.

Suleiman, M.N., Muscat-Baron, J.M., Harries, J.R., Satti, A.G., Platt, G.S., Bowen, E.T., Simpson, D.I., 1980. Congo/Crimean haemorrhagic fever in Dubai. An outbreak at the Rashid Hospital. Lancet 2, 939-941.

Sureau, P., Klein, J.M., 1980. Arboviruses in Iran (author's transl). Med. Trop. (Mars) 40, 549-554.

Swanepoel, R., Gill, D.E., Shepherd, A.J., Leman, P.A., Mynhardt, J.H., Harvey, S., 1989. The clinical pathology of Crimean-Congo hemorrhagic fever. Rev. Infect. Dis. 11 (Suppl. 4), S794-S800.

Swanepoel, R., Leman, P.A., Burt, F.J., Jardine, J., Verwoerd, D.J., Capua, I., Bruckner, G.K., Burger, W.P., 1998. Experimental infection of ostriches with CrimeanCongo haemorrhagic fever virus. Epidemiol. Infect. 121, 427-432.

Swanepoel, R., Shepherd, A.J., Leman, P.A., Shepherd, S.P., McGillivray, G.M., Erasmus, M.J., Searle, L.A., Gill, D.E., 1987. Epidemiologic and clinical features of Crimean-Congo hemorrhagic fever in southern Africa. Am. J. Trop. Med. Hyg. 36, 120-132.

Swanepoel, R., Shepherd, A.J., Leman, P.A., Shepherd, S.P., Miller, G.B., 1985. A common-source outbreak of Crimean-Congo haemorrhagic fever on a dairy farm. S. Afr. Med. J. 68, 635-637.

Tantawi, H.H., Al-Moslih, M.I., Al-Janabi, N.Y., et al., 1980. Crimean-Congo haemorrhagic fever virus in Iraq: isolation, identification and electron microscopy. Acta Virol. 24, 464-467.

Tasdelen Fisgin, N., Doganci, L., Tanyel, E., Tulek, N., 2010. Initial high rate of misdiagnosis in Crimean Congo haemorrhagic fever patients in an endemic region of Turkey. Epidemiol. Infect. 138, 139-144.

Tasdelen Fisgin, N., Ergonul, O., Doganci, L., Tulek, N., 2009. The role of ribavirin in the therapy of Crimean-Congo hemorrhagic fever: early use is promising. Eur. J. Clin. Microbiol. Infect. Dis. 28, 929-933.

Tasdelen Fisgin, N., Fisgin, T., Tanyel, E., Doganci, L., Tulek, N., Guler, N., Duru, F. 2008. Crimean-Congo hemorrhagic fever: five patients with hemophagocytic syndrome. Am. J. Hematol. 83, 73-76.

Tignor, G.H., Hanham, C.A., 1993. Ribavirin efficacy in an in vivo model of Crimean-Congo hemorrhagic fever virus (CCHF) infection. Antiviral Res. 22, 309-325.
Tkachenko, E.A., Butenko, A.M., Badalov, M.Y., Zaradova, T.I., Chumakov, M.P., 1971 Investigation of immunogenic activity of killed brain vaccine against Crimean hemorrhagic fevers. In: M.P., Chumakov (Ed.), Viral hemorrhagic fevers, Trudi Instituta Poliomielita i Virusnykh Entsefalitov, vol. XIX. USSR Academy of Medical Sciences, Moscow, USSR, pp. 119-129.

Tkachenko, E.A., Butenko, A.M., Butenko, S.A., Zaradova, T.I., Chumakov, M.P., 1970. Prophylactic characteristifs of a protective Crimean hemorrhagic fever vaccine. In: Chumakov, M.P. (Ed.), Crimean Hemorrhagic Fever - Materials of the 3rd Scientific-Practical Conference in Rostov-na-Donu Region. USSR, Moscow, pp. $136-138$.

Todorov, S.K., Kovacheva, T., Velcheva, D., Katzarov, G., 2001. Congo-Crimean hemorrhagic fever-prophylaxis and treatment. Contemp. Med. 42, 54-60.

Turell, M.J., 2007. Role of ticks in the transmission of Crimean-Congo hemorrhagic fever virus. In: Ergonul, O.W., Whitehouse, C.A. (Eds.), Crimean-Congo Hemorrhagic Fever: A Global Perspective, vol. 1. Springer, Dordrecht, The Netherlands, pp. 144-154.

van de Wal, B.W., Joubert, J.R., van Eeden, P.J., King, J.B., 1985. A nosocomia outbreak of Crimean-Congo haemorrhagic fever at Tygerberg Hospital. Part IV Preventive and prophylactic measures. S. Afr. Med. J. 68, 729-732.

van Eeden, P.J., Joubert, J.R., van de Wal, B.W., King, J.B., de Kock, A., Groenewald, J.H., 1985a. A nosocomial outbreak of Crimean-Congo haemorrhagic fever at Tygerberg Hospital. Part I. Clinical features. S. Afr. Med. J. 68, 711-717.

van Eeden, P.J., van Eeden, S.F., Joubert, J.R., King, J.B., van de Wal, B.W., Michell, W.L., 1985b. A nosocomial outbreak of Crimean-Congo haemorrhagic fever at Tygerberg Hospital. Part II. Management of patients. S. Afr. Med. J. 68, 718-721.

Vanhomwegen, J., Alves, MJ. Zupanc, T.A, Bino, S., Chinikar, S, Karlberg, $\mathrm{H}_{\text {, }}$ Korukluoglu, G., Korva, M., Mardani, M., Mirazimi, A., Mousavi, M., Papa, A., Saksida, A., Sharifi-Mood, B., Sidira, P., Tsergouli, K., Wolfel, R., Zeller, H., Dubois, P., 2012. Diagnostic assays for Crimean-Congo hemorrhagic fever. Emerg. Infect. Dis. 18, 1958-1965.

Vassilenko, S.M., Vassilev, T.L., Bozadjiev, L.G., Bineva, I.L., Kazarov, G.Z., 1990 Specific intravenous immunoglobulin for Crimean-Congo haemorrhagic fever Lancet 335, 791-792.

Vassilev, T., Valchev, V., Kazarov, G., Razsukanova, L., Vitanov, T., 1991. A reference preparation for human immunoglobulin against Crimean/Congo hemorrhagic fever. Biologicals 19, 57.

Vincent, M.J., Sanchez, A.J., Erickson, B.R., Basak, A., Chretien, M., Seidah, N.G. Nichol, S.T., 2003. Crimean-Congo hemorrhagic fever virus glycoprotein proteolytic processing by subtilase SKI-1. J. Virol. 77, 8640-8649.

Wang, Y., Dutta, S., Karlberg, H., Devignot, S., Weber, F., Hao, Q., Tan, Y.J., Mirazimi, A., Kotaka, M., 2012. Structure of Crimean-Congo hemorrhagic Fever virus nucleoprotein: superhelical homo-oligomers and the role of caspase-3 cleavage. J. Virol. 86, 12294-12303.

Watts, D.M., Ussery, M.A., Nash, D., Peters, C.J., 1989. Inhibition of Crimean-Congo hemorrhagic fever viral infectivity yields in vitro by ribavirin. Am. J. Trop. Med. Hyg. 41, 581-585.

Weaver, S.C., 2006. Evolutionary influences in arboviral disease. Curr. Top. Microbiol. Immunol. 299, 285-314.

WHO SEARO, 2011. Crimean-Congo Hemorrhagic Fever (WHO SEARO Fact Sheet) WHO SEARO, New Delhi, India. Available from: <http://www.searo.who.int/ entity/emerging diseases/links/CCHF_Fact_Sheet_SEARO.pdf $\rangle$.

Willadsen, P., 2004. Anti-tick vaccines. Parasitology 129 (Suppl.), S367-S387.

Williams, R.J., Al-Busaidy, S., Mehta, F.R., Maupin, G.O., Wagoner, K.D., Al-Awaidy, S., Suleiman, A.J., Khan, A.S., Peters, C.J., Ksiazek, T.G., 2000. Crimean-Congo haemorrhagic fever: a seroepidemiological and tick survey in the Sultanate of Oman. Trop Med Int Health 5, 99-106.

Wilson, M.L., Gonzalez, J.P., Cornet, J.P., Camicas, J.L., 1991. Transmission of Crimean-Congo haemorrhagic fever virus from experimentally infected sheep toHyalomma truncatum ticks. Res. Virol. 142, 395-404.

Wolfel, R., Paweska, J.T., Petersen, N., Grobbelaar, A.A., Leman, P.A., Hewson, R. Georges-Courbot, M.C., Papa, A., Gunther, S., Drosten, C., 2007. Virus detection and monitoring of viral load in Crimean-Congo hemorrhagic fever virus patients. Emerg. Infect. Dis. 13, 1097-1100.

Woodall, J.P., Williams, M.C., Simpson, D.I., 1967. Congo virus: a hitherto undescribed virus occurring in Africa. II. Identification studies. East Afr. Med. J. 44, 93-98.

Xiao, X., Feng, Y., Zhu, Z., Dimitrov, D.S., 2011. Identification of a putative CrimeanCongo hemorrhagic fever virus entry factor. Biochem. Biophys. Res. Commun. 411, 253-258.

Yadav, P.D., Cherian, S.S., Zawar, D., Kokate, P., Gunjikar, R., Jadhav, S., Mishra, A.C., Mourya, D.T., 2013. Genetic characterisation and molecular clock analyses of the Crimean-Congo haemorrhagic fever virus from human and ticks in India, 2010-2011. Infect. Gen. Evol. 14, 223-231.

Yashina, L., Petrova, I., Seregin, S., Vyshemirskii, O., Lvov, D., Aristova, V., Kuhn, J. Morzunov, S., Gutorov, V., Kuzina, I., Tyunnikov, G., Netesov, S., Petrov, V., 2003a. Genetic variability of Crimean-Congo haemorrhagic fever virus in Russia and Central Asia. J. Gen. Virol. 84, 1199-1206.

Yashina, L., Vyshemirskii, O., Seregin, S., Petrova, I., Samokhvalov, E., Lvov, D. Gutorov, V., Kuzina, I., Tyunnikov, G., Tang Y.W. Netesov, S., Petrov, V., 2003b. Genetic analysis of Crimean-Congo hemorrhagic fever virus in Russia. J. Clin. Microbiol. 41, 860-862.

Yen, Y.C, Kong L.X, Lee, L, Zhang Y. Li, F, Cai, B.J., Gao, S.Y 1985, Characteristics of Crimean-Congo hemorrhagic fever virus (Xinjiang strain) in China. Am. J. Trop. Med. Hyg. 34, 1179-1182. 
Yesilbag, K., Aydin, L., Dincer, E., Alpay, G., Girisgin, A.O., Tuncer, P., Ozkul, A., 2013. Tick survey and detection of Crimean-Congo hemorrhagic fever virus in tick species from a non-endemic area, Turkey. Exp. Appl. Acarol. 60, 253-261.

Yilmaz, M., Aydin, K., Akdogan, E., Sucu, N., Sonmez, M., Omay, S.B., Koksal, I., 2008.

Peripheral blood natural killer cells in Crimean-Congo hemorrhagic fever. J.

Clin. Virol. 42, 415-417.
Zeller, H.G., Cornet, J.P., Camicas, J.L., 1994. Experimental transmission of CrimeanCongo hemorrhagic fever virus by west African wild ground-feeding birds to Hyalomma marginatum rufipes ticks. Am. J. Trop. Med. Hyg. 50, 676-681. 